\title{
Analysis of Hydraulic Responses from the ER-6-1 Multiple-Well Aquifer Test, Yucca Flat FY 2004 Testing Program, Nevada Test Site, Nye County, Nevada
}

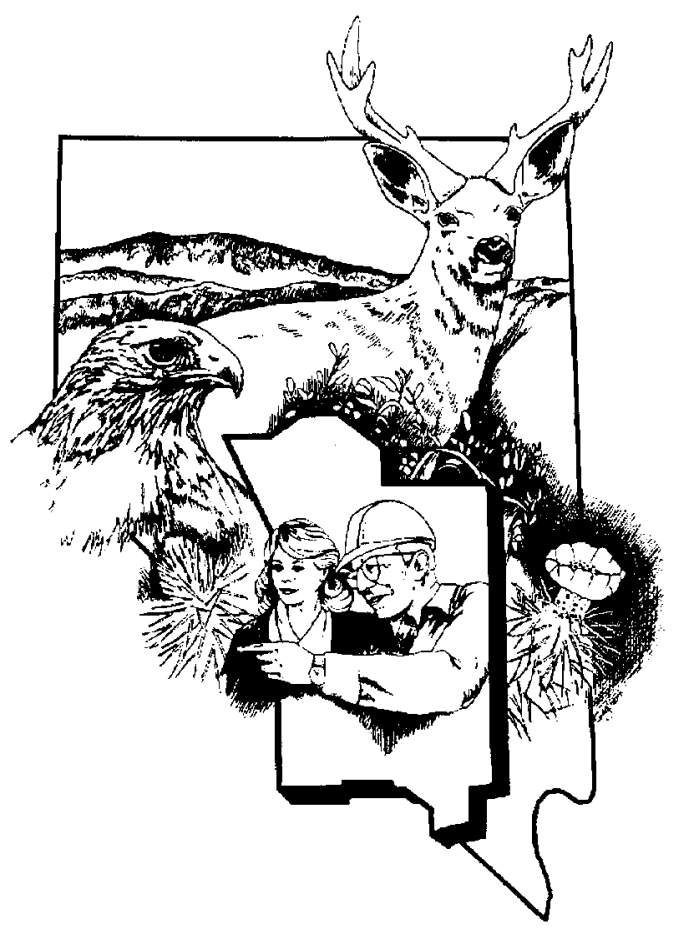

Revision No.: 0

Prepared for U.S. Department of Energy under Contract No. DE-AC52-03NA99205 Approved for public release; further dissemination unlimited. 
Available for sale to the public from:

U.S. Department of Commerce

National Technical Information Service

5285 Port Royal Road

Springfield, VA 22161

Phone: 800.553 .6847

Fax: 703.605.6900

Email: orders@ntis.gov

Online ordering: http://www.ntis.gov/ordering.htm

Available electronically at $h t t p: / / w w w . o s t i . g o v / b r i d g e$

Available for a processing fee to U.S. Department of Energy and its contractors, in paper, from:

U.S. Department of Energy

Office of Scientific and Technical Information

P.O. Box 62

Oak Ridge, TN 37831-0062

Phone: 865.576 .8401

Fax: 865.576.5728

Email: reports@adonis.osti.gov

Reference herein to any specific commercial product, process, or service by trade name, trademark, manufacturer, or otherwise, does not necessarily constitute or imply its endorsement, recommendation, or favoring by the United States Government or any agency thereof or its contractors or subcontractors. 


\section{ANALYSIS OF HYDRAULIC RESPONSES FROM THE ER-6-1 MULTIPLE-WELL AQUIFER TEST, YUCCA FLAT FY 2004 TESTING PROGRAM, NEVADA TEST SITE, NYE COUNTY, NEVADA}

Revision No.: 0

June 2005

E. Bhark, G. Ruskauff, V. Kelley

Stoller-Navarro Joint Venture

7710 W. Cheyenne, Building 3

Las Vegas, NV 89129 


\section{ANALYSIS OF HYDRAULIC RESPONSES FROM THE ER-6-1 MULTIPLE-WELL AQUIFER TEST, YUCCA FLAT FY 2004 TESTING PROGRAM, NEVADA TEST SITE, NYE COUNTY, NEVADA}

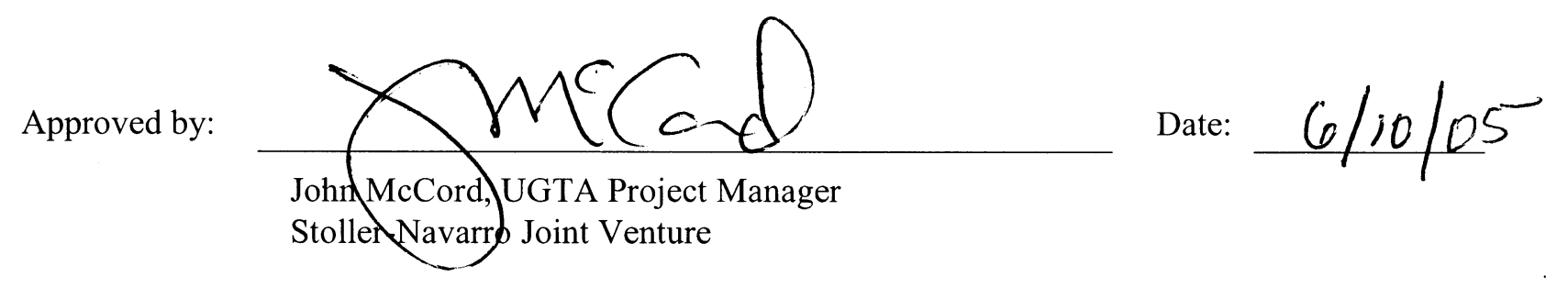




\section{Table of Contents}

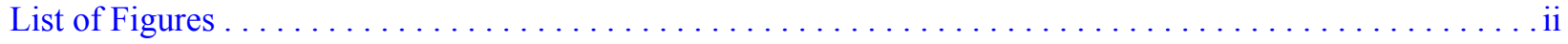

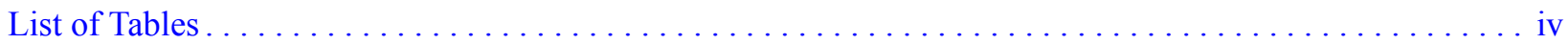

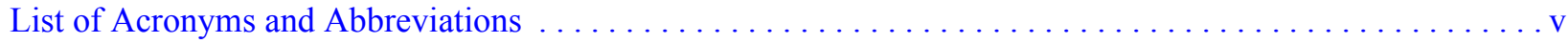

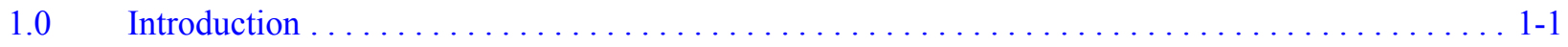

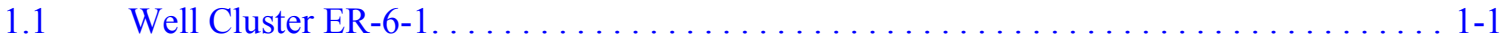

1.2 Distal Observation Wells . . . . . . . . . . . . . . . . . . . . . . . . . . 1-7

1.3 Well Configuration and Yucca Flat Hydrogeology . . . . . . . . . . . . . . . 1-10

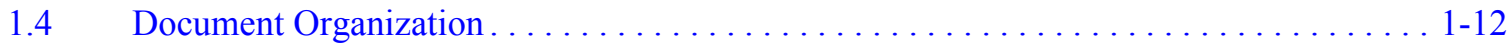

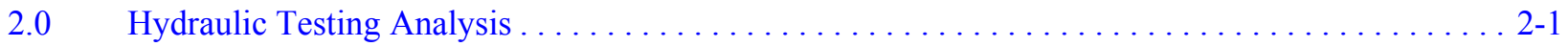

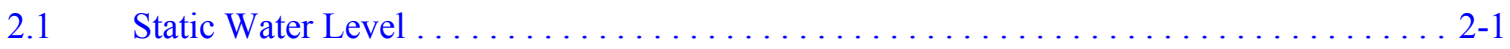

2.2 Multiple-Well Aquifer Test-Tracer Test (MWAT-TT) . . . . . . . . . . . . . . . 2-5

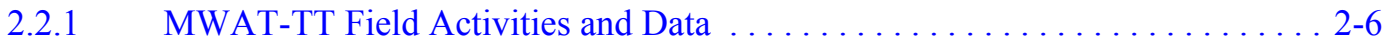

2.2.2 Method of Analysis. . . . . . . . . . . . . . . . . . . . . . 2-6

2.2.3 Conceptual Model. .............................. 2-9

2.2.3.1 ER-6-1 Well Cluster . . . . . . . . . . . . . . . . . . 2-9

2.2.3.2 Distal Wells . . . . . . . . . . . . . . . . . . . 2-16

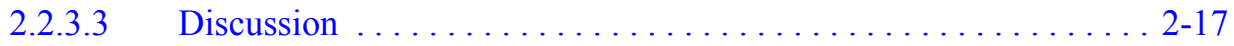

2.2.4 Hydraulic Response Analysis . . . . . . . . . . . . . . . . . . . . . 2-18

$2.3 \quad$ Borehole Flow Logging . . . . . . . . . . . . . . 22

2.3.1 Transmissivity as Calculated from Fluid Logging Flow Rates . . . . . . . . . 2-25

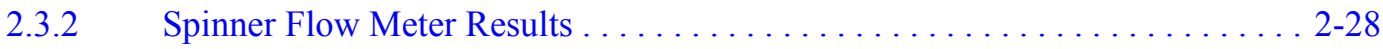

2.3.2.1 Borehole ER-6-1 . . . . . . . . . . . . . . . . . . . . 2-28

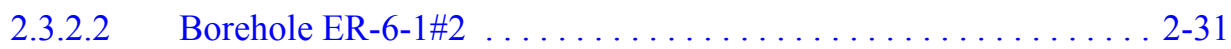

2.3.3 Thermal Flow Meter Results $\ldots \ldots \ldots \ldots \ldots \ldots \ldots \ldots \ldots \ldots \ldots \ldots \ldots . \ldots \ldots \ldots$

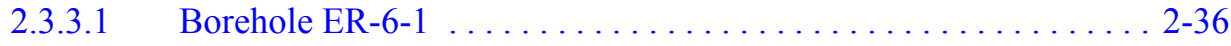

2.3.3.2 Borehole ER-6-1\#2 . . . . . . . . . . . . . . . . . . . 2-39

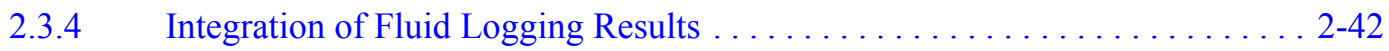

$3.0 \quad$ Summary of Hydraulic Test Interpretation and Results $\ldots \ldots \ldots \ldots \ldots \ldots \ldots \ldots \ldots \ldots \ldots \ldots \ldots$

3.1 Interpretive Model and Formation Hydraulic Properties. . . . . . . . . . . . . . 3-1

3.2 Comparison to Previous Analyses for the LCA . . . . . . . . . . . . . . . . . 3

$4.0 \quad$ References . . . . . . . . . . . . . . . . . . . . . . . . . . . . . . . 


\section{List of Figures}

Number

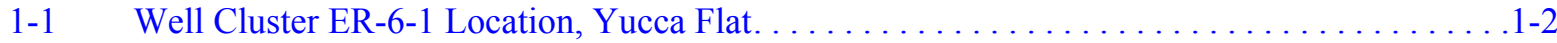

1-2 Well Cluster ER-6-1 Site Layout $\ldots \ldots \ldots \ldots \ldots \ldots \ldots \ldots \ldots \ldots \ldots \ldots \ldots \ldots \ldots \ldots \ldots \ldots \ldots \ldots \ldots \ldots$

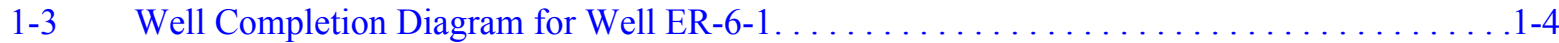

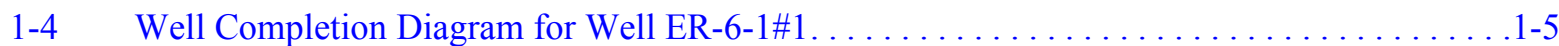

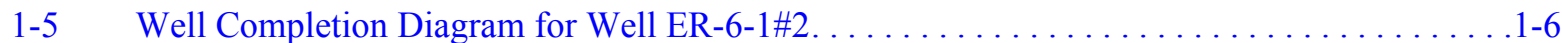

1-6 Projection of On-site Wells onto a West-East Cross-Section with

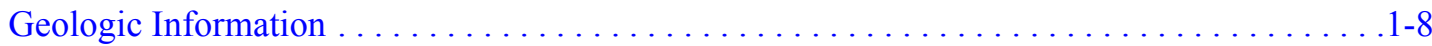

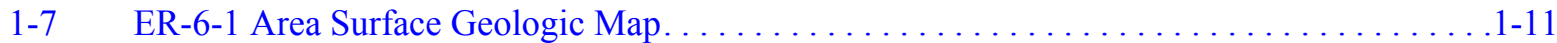

1-8 Fault Trace Map at the LCA Surface Over the Areal Extent of the

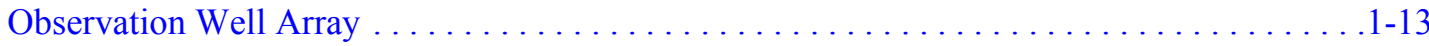

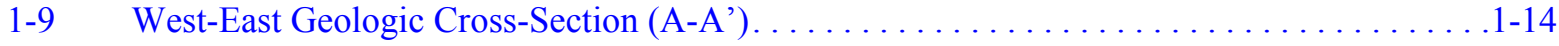

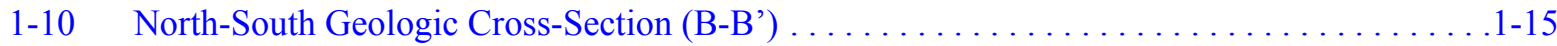

2-1 Yucca Flat LCA Predevelopment Groundwater Contours . . . . . . . . . . . . . . . .2-3

2-2 Yucca Flat Time-Averaged Groundwater Contours Across the MWAT-TT

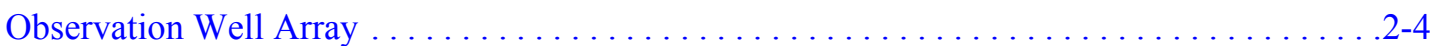

2-3 Cluster (a) and Distal (b) Cartesian Well Response Sequences and

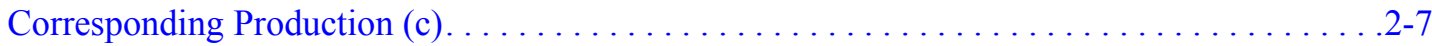

2-4 Observation Well ER-6-1 Upper Completion Log-Log Diagnostics . . . . . . . . . . . . . . . . 2-10

2-5 Observation Well ER-6-1 Lower Completion Log-Log Diagnostics . . . . . . . . . . . . . . . . . .2-11

2-6 Observation Well ER-6-1\#1 Log-Log Diagnostics $\ldots \ldots \ldots \ldots \ldots \ldots \ldots \ldots \ldots \ldots \ldots \ldots \ldots$ 


\section{List of Figures (Continued)}

Number

Title

Page

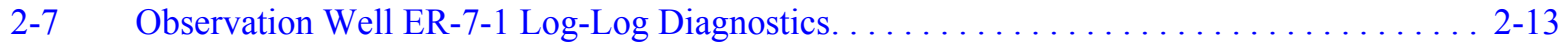

2-8 (a) Pumping Well ER-6-1\#2 and ER-3-1, and (b) UE-7nS and U3cn5

Cartesian Response Sequences ................................ 2-14

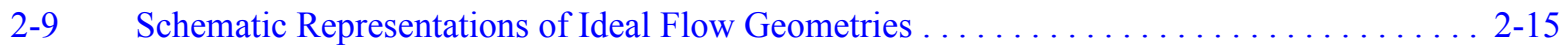

2-10 ER-6-1\#2 Cooper-Jacob Analysis. . . . . . . . . . . . . . . . . . . . . . 2-23

2-11 Normalized Spinner Flow Meter Log for ER-6-1 (SFM-1) . . . . . . . . . . . . . . . 2-29

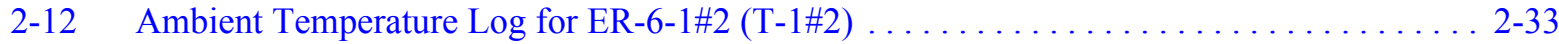

2-13 Normalized Spinner Flow Meter Log for ER-6-1\#2 (SFM-1\#2) . . . . . . . . . . . . 2-34

2-14 TFM Borehole Flow Rates for ER-6-1 (TFM-2 \& TFM-1) . . . . . . . . . . . . . . . . . . . 2-37

2-15 TFM Interval Flow Rates for ER-6-1 (TFM-2 \& TFM-1) . . . . . . . . . . . . . 2-38

2-16 TFM Borehole Flow Rates for ER-6-1\#2 (TFM-1\#2 \& TFM-2\#2) . . . . . . . . . . . . 2-40

2-17 TFM Interval Flow Rates for ER-6-1\#2 (TFM-1\#2 \& TFM-2\#2) $\ldots \ldots \ldots \ldots \ldots \ldots \ldots . . \ldots 2-4$

2-18 Composite SFM Logs for Boreholes ER-6-1 and ER-6-1\#2 $\ldots \ldots \ldots \ldots \ldots \ldots \ldots \ldots$ 2-43

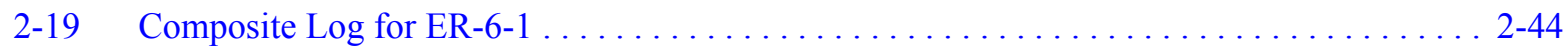

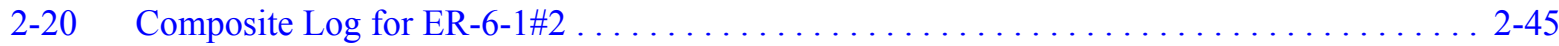




\section{List of Tables}

Number

Title

Page

1-1 Production Well and Observation Well Locations, Elevations, Distances,

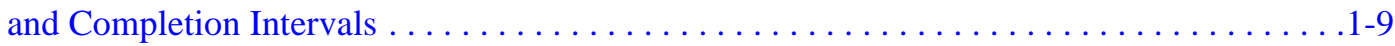

2-1 Well Cluster ER-6-1 LCA Static Formation Head During the MWAT-TT . . . . . . . . 2-5

2-2 Best-fit Parameter Estimates Derived from Individual Observation Well

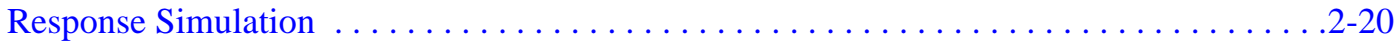

2-3 DRI Logging Campaigns for the ER-6-1 Well Cluster $\ldots \ldots \ldots \ldots \ldots \ldots \ldots \ldots \ldots \ldots \ldots \ldots$

2-4 ER-6-1 SFM-1 Normalized Flow and Transmissivity (SFM-1) $\ldots \ldots \ldots \ldots \ldots \ldots \ldots . \ldots \ldots$

2-5 ER-6-1\#2 Normalized Flow and Transmissivity (SFM-1\#2) $\ldots \ldots \ldots \ldots \ldots \ldots \ldots \ldots \ldots \ldots$

3-1 Summary Table for Derived LCA Hydraulic Properties $\ldots \ldots \ldots \ldots \ldots \ldots \ldots \ldots \ldots . \ldots \ldots$

3-2 Summary Table for Selected Historical NTS and Yucca Flat LCA

Hydraulic Testing Results. ................................ $3-4$ 


\section{List of Acronyms and Abbreviations}

\begin{tabular}{|c|c|}
\hline amsl & Above mean sea level \\
\hline $\mathrm{BE}$ & Barometric efficiency \\
\hline bgs & Below ground surface \\
\hline $\mathrm{BN}$ & Bechtel Nevada \\
\hline CAU & Corrective Action Unit \\
\hline $\mathrm{cm}$ & Centimeter \\
\hline CS & Carbon-steel \\
\hline DOE & U.S. Department of Energy \\
\hline DRI & Desert Research Institute \\
\hline $\mathrm{ft}$ & Foot \\
\hline $\mathrm{ft} / \mathrm{d}$ & Feet per day \\
\hline $\mathrm{ft}^{2} / \mathrm{d}$ & Square feet per day \\
\hline FY & Fiscal year \\
\hline gpm & Gallon per minute \\
\hline GTFM & Graph Theoretic Field Model \\
\hline HSU & Hydrostratigraphic Unit \\
\hline IARF & Infinite-acting radial flow \\
\hline id & Inside diameter \\
\hline in. & Inch \\
\hline JD & Julian Day \\
\hline $\mathrm{km}$ & Kilometer \\
\hline $\mathrm{km}^{2}$ & Square kilometer \\
\hline LCA & Lower Carbonate Aquifer \\
\hline LTCU & Lower Tuff Confining Unit \\
\hline $\mathrm{m}$ & Meter \\
\hline $\mathrm{m} / \mathrm{d}$ & Meters per day \\
\hline $\mathrm{m} / \mathrm{s}$ & Meters per second \\
\hline MWAT-TT & Multiple-Well Aquifer Test-Tracer Test \\
\hline NAD 27 & North American Datum 1927 \\
\hline NNSA/NSO & U.S. Department of Energy, National Nuclear Security Administration Nevada Site Office \\
\hline NRC & National Research Council \\
\hline NTS & Nevada Test Site \\
\hline nSIGHTS & n-Dimensional Statistical Inverse Graphical Hydraulic Test Simulator \\
\hline
\end{tabular}


od Outside diameter

OSBCU Oak Spring Butte Confining Unit

PXD Pressure transducer

SFM Spinner flow meter

SNJV Stoller-Navarro Joint Venture

TCU Tuff Confining Unit

TFM Thermal flow meter

TSA Topopah Springs Aquifer

UGTA Underground Test Area

USGS U.S. Geological Survey

UTM Universal Transverse Mercator

WIPP Waste Isolation Pilot Plant

${ }^{\circ} \mathrm{C} \quad$ Degrees Celsius

${ }^{\circ} \mathrm{F} \quad$ Degrees Fahrenheit 


\subsection{Introduction}

This report documents the interpretation and analysis of the hydraulic data collected for the Fiscal Year (FY) 2004 Multiple-Well Aquifer Test-Tracer Test (MWAT-TT) conducted at the ER-6-1 Well Cluster in Yucca Flat Corrective Action Unit (CAU) 97, on the Nevada Test Site (NTS). The MWAT-TT was performed to investigate CAU-scale groundwater flow and transport processes related to the transport of radionuclides from sources on the NTS through the Lower Carbonate Aquifer (LCA) Hydrostratigraphic Unit (HSU).

The ER-6-1 MWAT-TT was planned and executed by contractor participants for the Underground Test Area (UGTA) Project of the Environmental Restoration (ER) program of the U.S. Department of Energy (DOE), National Nuclear Security Administration Nevada Site Office (NNSA/NSO). Participants included Stoller-Navarro Joint Venture (SNJV), the Environmental Engineering Services Contractor; Bechtel Nevada (BN); the Desert Research Institute (DRI); Los Alamos National Laboratory; and the University of Nevada, Las Vegas-Harry Reid Center. The SNJV team consists of the S.M. Stoller Corporation, Navarro Research and Engineering, Battelle Memorial Institute, INTERA Inc., and Weston Solutions, Inc.

The MWAT-TT was implemented according to the Underground Test Area Project, ER-6-1 Multi-Well Aquifer Test - Tracer Test Plan (SNJV, 2004a) issued in April 2004. The objective of the aquifer test was to determine flow processes and local hydraulic properties for the LCA through long-term constant-rate pumping at the well cluster. This objective was to be achieved in conjunction with detailed sampling of the composite tracer breakthrough at the pumping well, as well as with depth-specific sampling and logging at multiple wells, to provide information for the depth-discrete analysis of formation hydraulic properties, particularly with regard to fracture properties.

\subsection{Well Cluster ER-6-1}

Well Cluster ER-6-1 is located in the northeastern corner of NTS Area 6 in southeastern Yucca Flat, shown in Figure 1-1. The cluster consists of three wells that were utilized for the MWAT-TT: ER-6-1, ER-6-1\#1, and ER-6-1\#2.

Figure 1-2 shows the cluster layout, the relative locations of the three wells, and the earthen fluid storage sumps. ER-6-1\#2 was utilized as the production well, and both ER-6-1 and ER-6-1\#1 were utilized as both observation wells and tracer-injection wells for the MWAT-TT. Well construction diagrams for ER-6-1, ER-6-1\#1, and ER-6-1\#2 are presented in Figure 1-3, Figure 1-4, and Figure 1-5, respectively. 


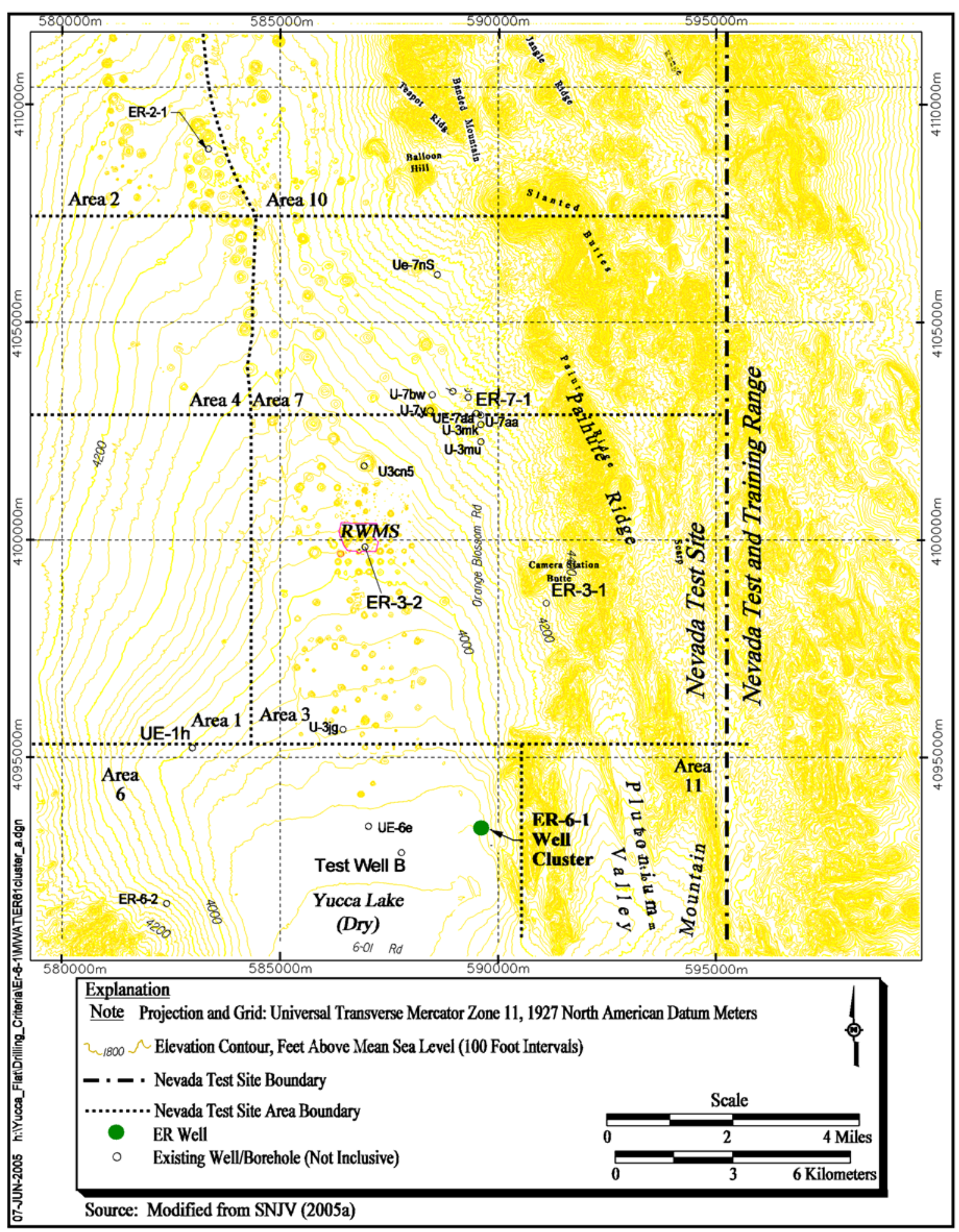

Figure 1-1

Well Cluster ER-6-1 Location, Yucca Flat 


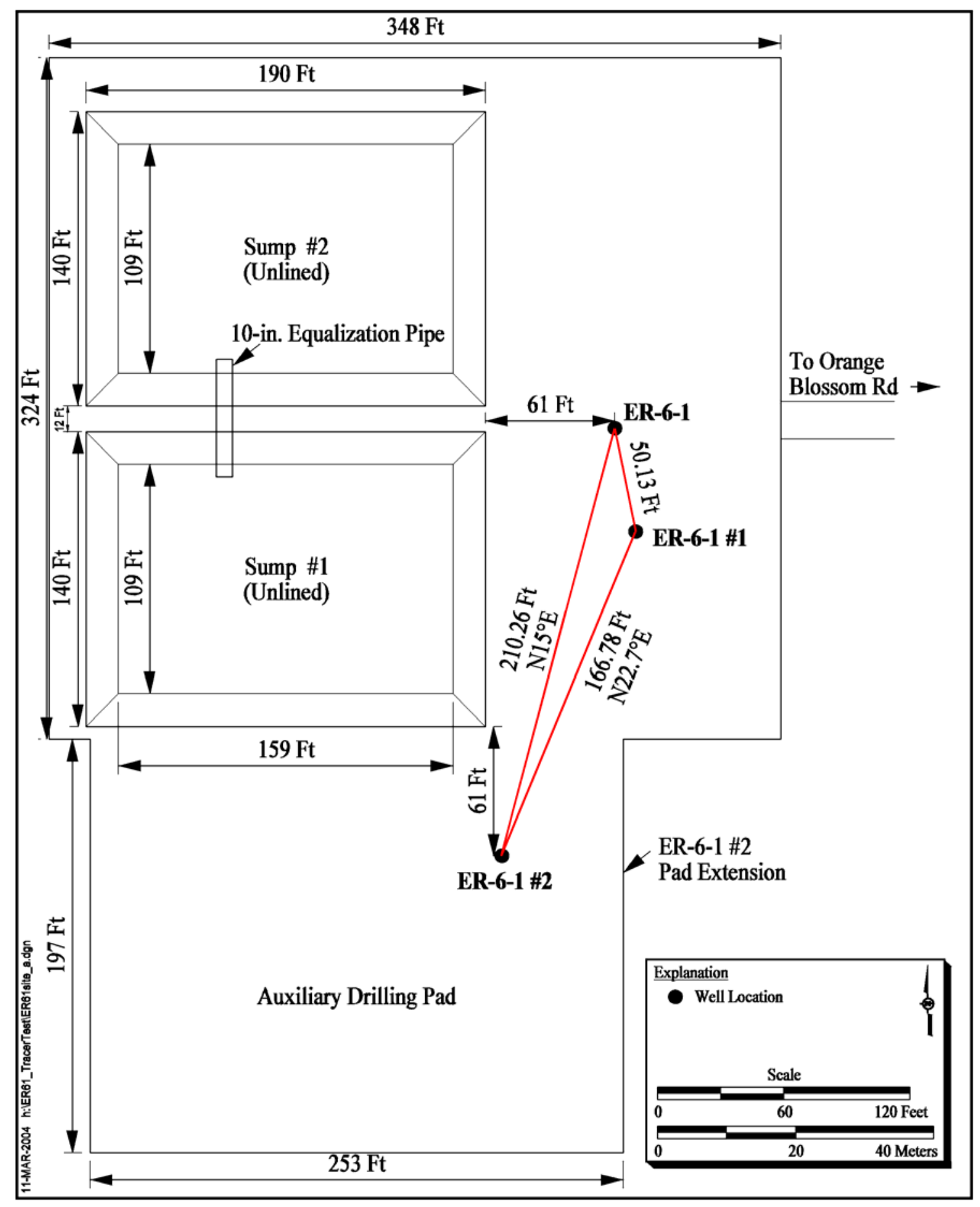

Figure 1-2

Well Cluster ER-6-1 Site Layout 


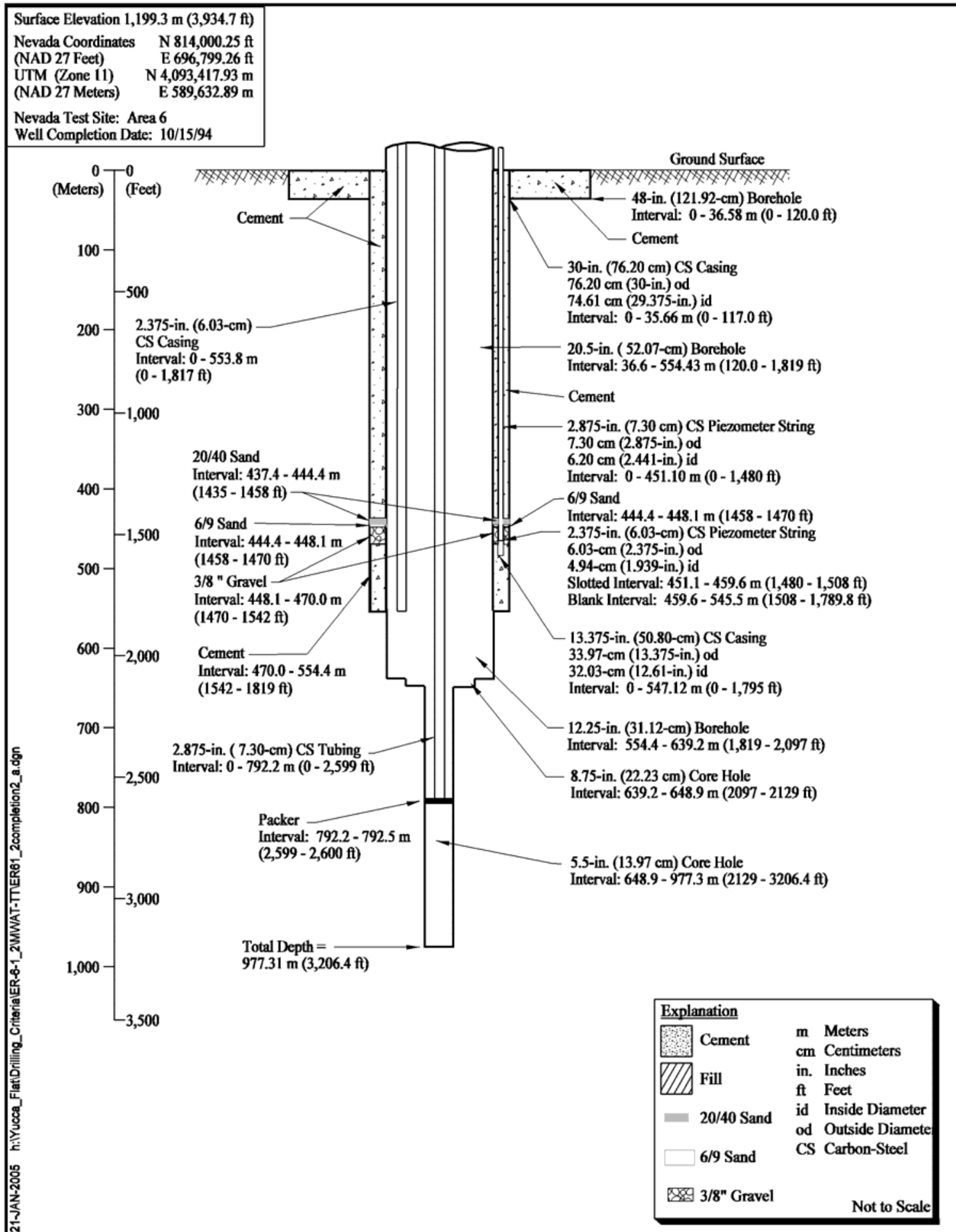

Figure 1-3

Well Completion Diagram for Well ER-6-1 


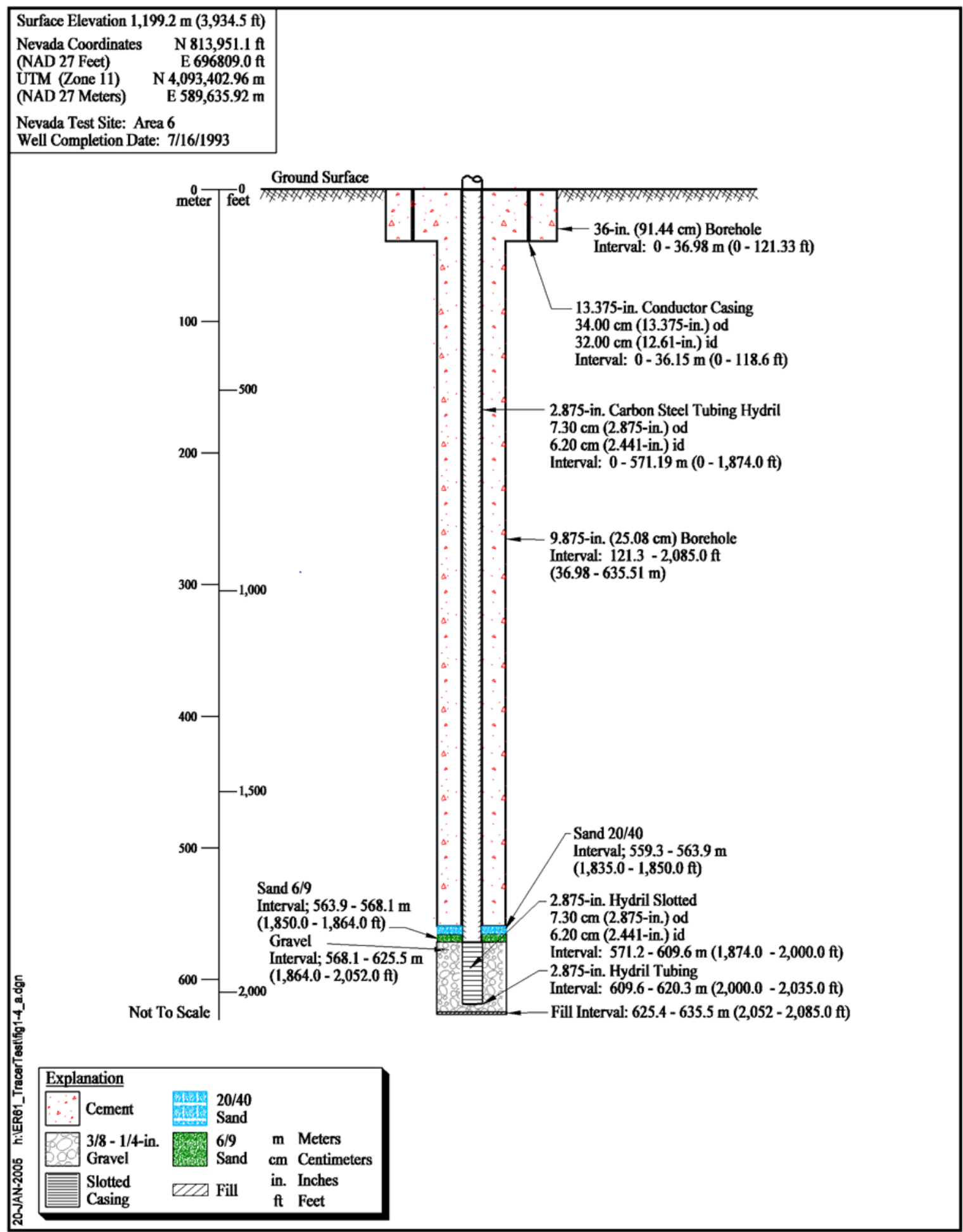

Figure 1-4

Well Completion Diagram for Well ER-6-1\#1 


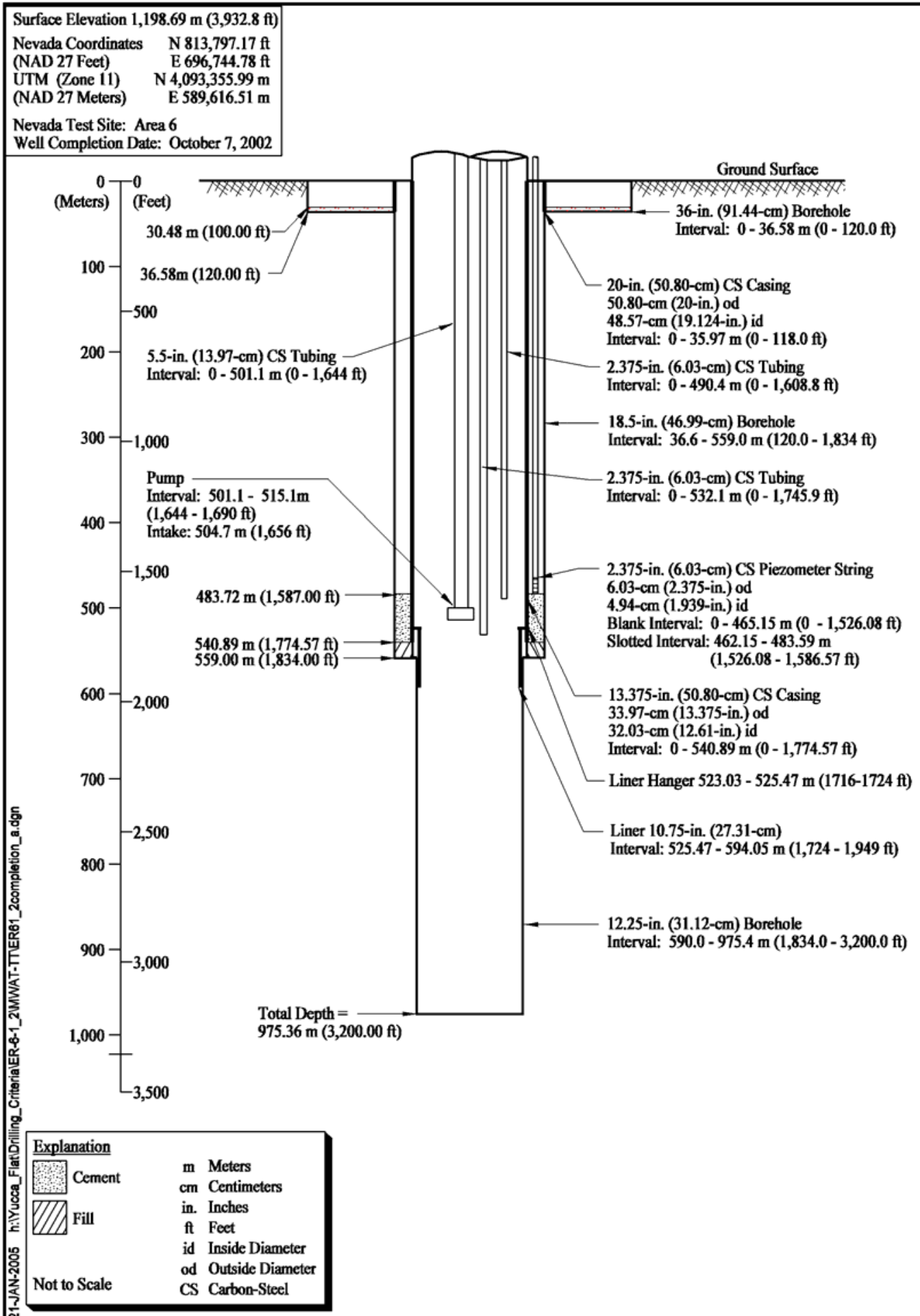

Figure 1-5

Well Completion Diagram for Well ER-6-1\#2 
Both ER-6-1 and ER-6-1\#2 penetrate nearly the full thickness of the LCA (excluding segments of the LCA top), approximately 1,300 feet (ft). Figure 1-6 presents the wells in cross-section for a visual comparison of the completion intervals. For the MWAT-TT, ER-6-1 was divided into two test intervals to provide information related to differences in fracturing with depth. The test interval for ER-6-1\#1 partially penetrates the LCA; the completion intersects a 300 -ft interval near the LCA top. Table 1-1 provides the geographic coordinates, well-to-well distances, and completion interval information for wells within the cluster.

During execution of the MWAT-TT, tracers were injected into ER-6-1 separately into the upper and lower intervals, and into ER-6-1\#1. The tracers were recovered from ER-6-1\#2 through continuous pumping. The three wells are positioned in rough alignment with the dominant local fracture orientation so that flow and transport occurred parallel to, rather than orthogonally to, the direction of maximum fracture continuity. The "forced-gradient" imposed by pumping created a flow field that overcame the natural gradient in the formation and directed the path of tracer transport to the pumping (recovery) well.

Complimentary to the MWAT-TT, hydraulic testing data was additionally gathered prior to the MWAT-TT from thermal-pulse and spinner-tool flow logging conducted in ER-6-1 and ER-6-1\#2. The logging campaigns measured depth-discrete in/outflow from the formation, under both ambient and variable-rate pumping conditions, from which interval hydraulic conductivities are determined at the scale of the measurement.

Additional information regarding drilling and completion activities, including previous well development and hydraulic testing data, is available in Preliminary Geology and Drill Hole Data Report for Groundwater Characterization Well ER-6-1, Nevada Test Site, Nye County, Nevada (Drellack et al., 1992); ER-6-1 Hydrologic Testing and Geochemical Sampling Results - Data Report (DRI, 1993); Yucca Flat Well ER-6-1\#2 Well Data Report, Preliminary, Rev. 0 (IT, 2003); Yucca Flat Well ER-6-1\#2 Data Report for Development and Hydraulic Testing, Preliminary, Rev. 0, (SNJV, 2003); Completion Report for Wells ER-6-1 and ER-6-1 Satellite Hole \#1 (IT, 1997); and ER-6-1 Well Cluster Multiple-Well Aquifer Test - Tracer Test Data Report, Volumes I, II, and III (SNJV, 2005a). Information on fracturing from core analysis and geophysical logging is contained in IT (1996) and SNJV (2005b) documents.

\subsection{Distal Observation Wells}

During the MWAT-TT, continuous water-level monitoring was conducted in five wells distal to the ER-6-1 well cluster (see Figure 1-1). This is in addition to the ER-6-1 and ER-6-1\#2 piezometers completed in the volcanic formation overlying the LCA. Stoller-Navarro Joint Venture monitored three wells (UE-1h, ER-7-1, ER-3-1) completed in the LCA at respective distances of 22,609, 32,556, and 21,080 ft from ER-6-1\#2; two wells (ER-6-1 and ER-6-1\#2 piezometers) completed in the overlying volcanic formation (Tuff Confining Unit [TCU]); and one well (UE-6e) completed in a second overlying volcanic confining unit (Lower Tuff Confining Unit [LTCU]) at 8,545 ft from the cluster. In addition, 


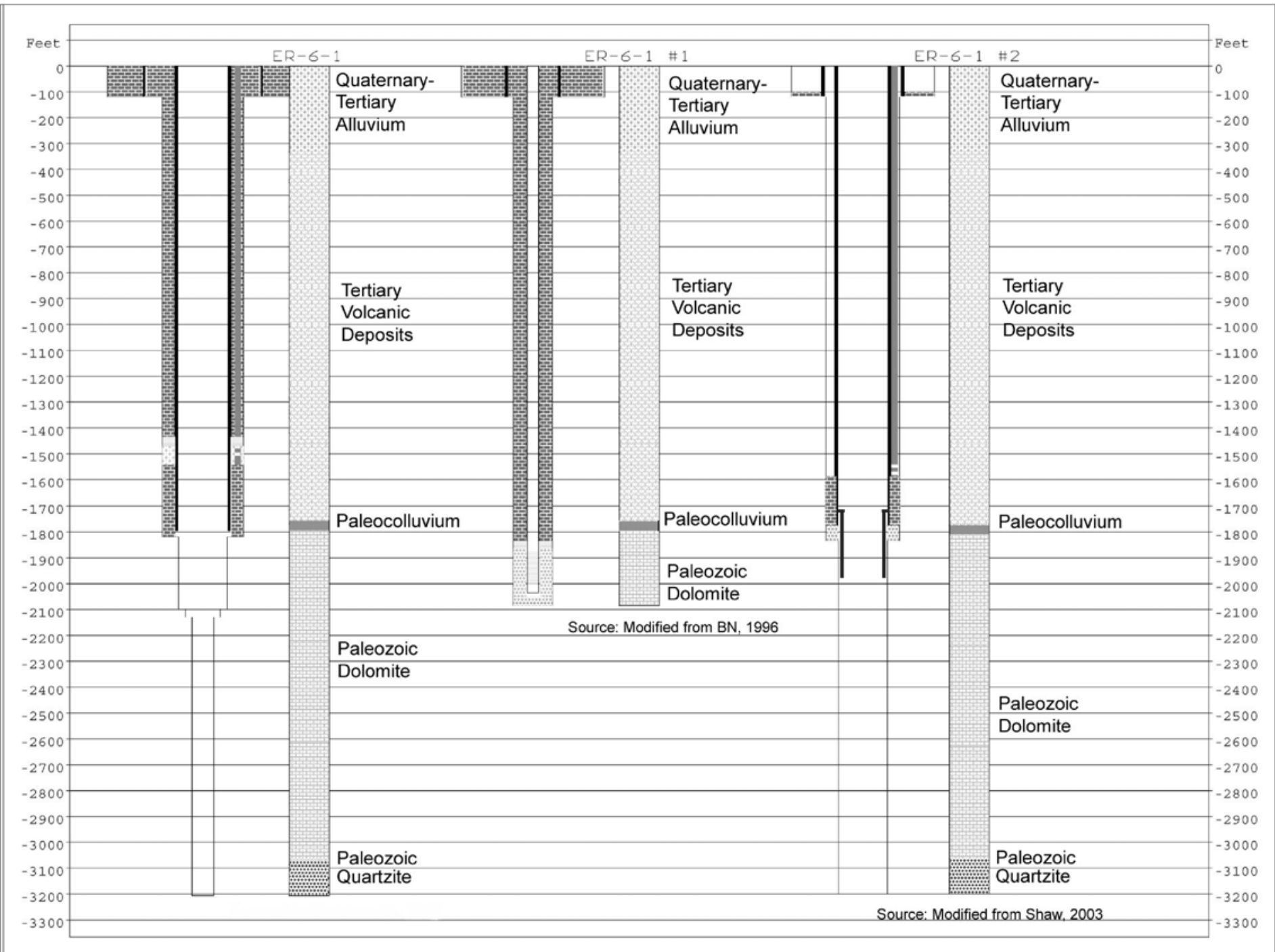


Table 1-1

Production Well and Observation Well Locations, Elevations, Distances, and Completion Intervals

\begin{tabular}{|c|c|c|c|c|c|c|c|c|c|}
\hline \multirow{2}{*}{ Well } & \multicolumn{2}{|c|}{$\begin{array}{l}\text { Nevada State Plane } \\
\text { NAD } 27 \text { (ft) }\end{array}$} & \multirow{2}{*}{$\begin{array}{l}\text { Information } \\
\text { Source }\end{array}$} & \multicolumn{2}{|c|}{$\begin{array}{l}\text { UTM Zone } 11 \\
\text { NAD } 27(m)\end{array}$} & \multirow{2}{*}{$\begin{array}{l}\text { Ground } \\
\text { Surface } \\
\text { Elevation } \\
\text { (ft amsl) }\end{array}$} & \multirow{2}{*}{$\begin{array}{c}\text { Distance from } \\
\text { ER-6-1\#2 / ER-6-1 } \\
(\mathrm{ft})\end{array}$} & \multirow{2}{*}{$\begin{array}{c}\text { Primary } \\
\text { Completion } \\
\text { HSU }\end{array}$} & \multirow{2}{*}{$\begin{array}{l}\text { Open Interval } \\
\text { top - bottom depth } \\
\text { (ft) }\end{array}$} \\
\hline & Northing & Easting & & Northing & Easting & & & & \\
\hline \multicolumn{10}{|c|}{ MWAT-TT Production Well } \\
\hline ER-6-1\#2* & $813,797.17$ & $696,744.78$ & BN, 2003 & $4,093,355.99$ & $589,616.51$ & $3,932.78$ & $0 / 210.20$ & LCA & $1,939-3,200$ \\
\hline \multicolumn{10}{|c|}{ Tracer Test Injection Wells, Aquifer Test Observation Wells } \\
\hline ER-6-1\#1* & $813,951.08$ & $696,809.02$ & BN, 2003 & $4,093,402.96$ & $589,635.92$ & $3,934.51$ & $166.69 / 50.13$ & LCA & $1,874-2,000$ \\
\hline $\begin{array}{l}\text { ER-6-1 Upper } \\
\text { Zone }\end{array}$ & $814,000.25$ & $696,799.26$ & BN, 2003 & $4,093,417.93$ & $589,632.89$ & $3,934.65$ & 210.20 & LCA & $1,819-2,599$ \\
\hline $\begin{array}{l}\text { ER-6-1 Lower } \\
\text { Zone }\end{array}$ & $814,000.25$ & $696,799.26$ & BN, 2003 & $4,093,417.93$ & $589,632.89$ & $3,934.65$ & 210.20 & LCA & $2,600-3,206.4$ \\
\hline \multicolumn{10}{|c|}{ Aquifer Test Observation Wells } \\
\hline $\begin{array}{l}\text { ER-6-1\#2 } \\
\text { piezometer }\end{array}$ & $813,797.17$ & $696,744.78$ & BN, 2003 & $4,093,355.99$ & $589,616.51$ & $3,932.78$ & 0 & OSBCU & $1,526.08-1,586.57$ \\
\hline $\begin{array}{c}\text { ER-6-1 } \\
\text { piezometer }\end{array}$ & $814,000.25$ & $696,799.26$ & BN, 2003 & $4,093,417.93$ & $589,632.89$ & $3,934.65$ & 210.26 & OSBCU & $1,480-1,508$ \\
\hline UE-6e & $814,000.29$ & $688,199.94$ & UGTA & $4,093,408.77$ & $587,012.48$ & $3,938.14$ & $8,545.15$ & TSA/LTCU & $2,090-2,289$ \\
\hline ER-3-1(\#2) & $826,809.88$ & $713,335.70$ & UGTA & $4,097,338.98$ & $594,658.28$ & $4,406.74$ & $21,080.18$ & LCA & $2,260-2,290$ \\
\hline UE-1h & $820,001.92$ & $674,997.94$ & UGTA & $4,095,223.52$ & $582,983.12$ & $3,994.92$ & $22,609.13$ & LCA & $2,134-3,358$ \\
\hline ER-7-1 & $846,349.74$ & $695,869.20$ & BN, 2003 & $4,103,274.60$ & $589,314.94$ & $4,246.7$ & $32,556.41$ & LCA & $2,181.49-2,479.32$ \\
\hline UE-7nS & 855,600 & 693,700 & USGS & $4,106,091.06$ & $588,644.04$ & $4,366.71$ & 41,914 & LCA & $1,707-2,205$ \\
\hline U $3 \mathrm{cn} 5$ & 841,255 & 687,998 & USGS & $4,101,713.70$ & $586,921.84$ & $4,009.22$ & 28,817 & LCA & $2,832-3,030$ \\
\hline
\end{tabular}

* These wells used for observation during development and testing of ER-6-1.

BN - Bechtel Nevada

$\mathrm{m}$ - Meter

$\mathrm{ft}$ - Foot

$\mathrm{ft}$ amsl - Feet above mean sea level

HSU - Hydrostratigraphic unit

LCA - Lower Carbonate Aquifer

NAD 27 - North American Datum 1927

OSBCU - Oak Spring Butte Confining Unit

TSA - Topopah Spring Aquifer

UGTA - Underground Test Area

LTCU - Lower Tuff Confining Unit

USGS - U.S. Geological Survey

UTM - Universal Transverse Mercator 
the U.S. Geological Survey (USGS), as part of its periodic Yucca Flat monitoring, obtained water levels from wells UE-7nS and U3cn5, respectively 41,914 and $28,817 \mathrm{ft}$ north of the ER-6-1 cluster. All distal observation well coordinates, distances from the ER-6-1 cluster, and completion intervals are listed in Table 1-1. Figure 1-1 shows their geographic locations in Yucca Flat relative to the ER-6-1 cluster.

For the MWAT-TT, ER-6-1 was divided into an upper and a lower interval with a packer set from 2,599 to 2,600 ft below ground surface (bgs) (Figure 1-3), and the intervals were monitored separately. Water levels in the pumping well and all SNJV-monitored observation wells were measured using pressure transducers (PXDs) and data loggers in order to capture a continuous response. Water levels at the USGS-monitored wells were obtained by periodic depth-to-water measurements.

\subsection{Well Configuration and Yucca Flat Hydrogeology}

The hydraulic response measured at an observation well is strongly impacted by aquifer heterogeneity that exists within the volume of the formation tested. The Yucca Flat LCA is highly heterogeneous, both laterally and vertically across the well cluster, and also across the larger general kilometer $(\mathrm{km})$-scale section of the LCA that spans the observation-well array. Flow through the LCA is primarily controlled by fracture permeability that has resulted from brittle deformation of the carbonates. Laczniack et al. (1996), Gonzales et al. (1998), and Gonzales and Drellack (1999), who developed a hydrogeologic framework for Yucca Flat, report that the LCA hydraulic conductivity is highly spatially variable and reflects the observed differences in fracturing and fault density.

Yucca Flat is a topographically closed basin bounded on all sides by low ranges consisting of volcanic and sedimentary rocks that have, through erosion, deposited thick sheets of alluvium on the underlying sedimentary and volcanic units. The general stratigraphy, from oldest to youngest, is comprised of thick Paleozoic and older carbonate and silicic units representative of sedimentation near the continental margin, overlain by Tertiary age volcanic rocks deposited from multiple eruptive events of the southwestern Nevada volcanic field (Gonzales et al., 1998). The overlying sedimentary units are Quaternary and Tertiary in age, with minor components of Tertiary volcanics, and primarily include alluvium and playa deposits. Figure 1-7 shows the surface geologic map over the areal extent of the ER-6-1 MWAT-TT observation-well array.

The LCA HSU is the primary component of the pre-Tertiary sedimentary units within Yucca Flat. It is the principal aquifer for much of southern Nevada. The LCA is confined above and below, respectively, by zeolitized tuffs within the LTCU HSU and by the LCCU HSU, projected to be deep and below the depth of interest. The top of the LCA is an erosional surface, highly fractured, and the uppermost part potentially karstified (SNJV, 2004a). A thin (tens-of-feet thick) layer of paleocolluvium is found at the contact of the LCA and the overlying volcanics. Fine sediments and muds from this unit penetrate the fractured surface of the LCA. In general, the LCA is composed of multiple formations that include some aquitard units including shale, quartzite, or siltstone that may create 


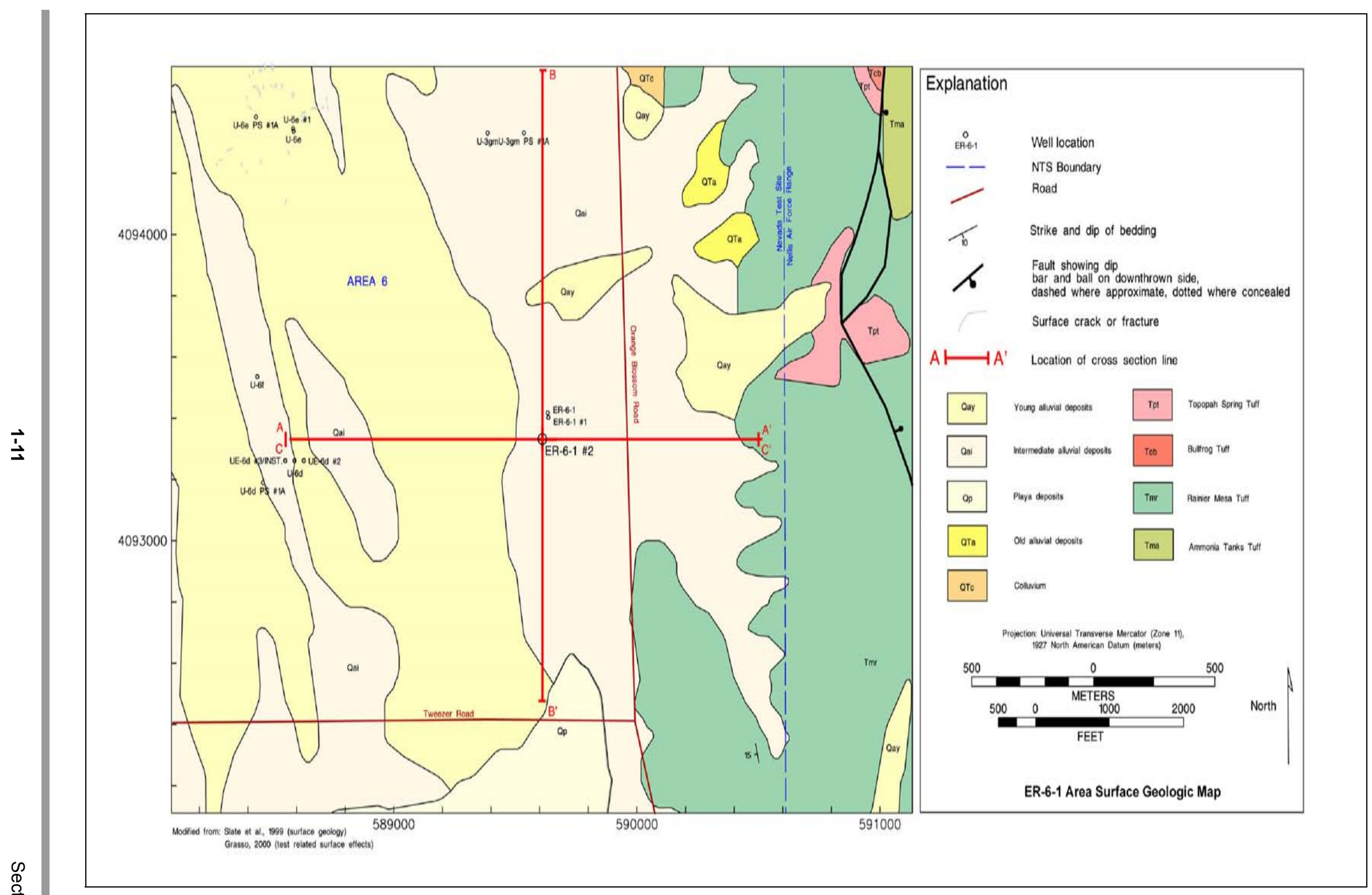

Figure 1-7

ER-6-1 Area Surface Geologic Map 
semi-independent flow systems within the LCA in the horizontal plane (Laczniack et al., 1996); however, aquitard units were not encountered within the LCA at the cluster wells. The lowest unit penetrated in the ER-6-1 wells is the Eureka Quartzite, which serves as a lower confining unit for the section of LCA penetrated at the cluster.

The lateral extent of the LCA is uncertain, although the northern and western limits of the aquifer are likely truncated, respectively, by depositional contacts and fault contacts with confining units. A steep hydraulic gradient across confining units that bound the basin to the north, northeast, and west provide evidence of the hydraulic isolation of the LCA from adjacent units (Laczniack et al., 1996).

Relative to the observation well array, the LCA is laterally continuous, or hydraulically connected, with the possible exception of the Carpetbag and Tippinip fault systems in western Yucca Flat where the LCA juxtaposes confining units as a result of normal faulting (Laczniack et al., 1996). The large permeability contrast between the units may create a barrier to lateral flow. A fault trace map at the projected LCA surface, presented in Figure 1-8, shows the ubiquitous north-south-trending faults beneath Yucca Flat, including those mentioned above. These faults are predominantly high-angle normal faults related to Basin and Range extension (Byers et al., 1976). The majority of the observation wells, relative to pumping well ER-6-1\#2, are oriented along the direction of fault continuity with the exception of UE-1h and ER-3-1. UE-1h is located west of the pumping well, across the Topgallant and Yucca Faults, which may act as flow barriers. ER-3-1 is located northeast of the pumping well across at least three major faults.

The ER-6-1 well site is located on a minor structural block bounded by two north-south trending faults. Both faults dip steeply to the west and have stratigraphic displacement down to the west, with less stratigraphic throw than the valley-forming faults. The western-most fault is inferred from gravity and seismic data (see Figures 23 and 24 in Drellack et al., 1992), while the east-bounding fault was penetrated in the TCU by well ER-6-1 and well ER-6-1\#1 at a depth of approximately 1,714 ft during drilling operations (IT, 2002). East-to-west and north-to-south trending cross sections that intersect the well site are presented in Figure 1-9 and Figure 1-10, respectively, and show the hydrostratigraphy of the minor fault block. The cross-section traces are presented in Figure 1-7. The cross sections also show the approximate water table depth located in the volcanics above the LCA. The influence of the observed structural features on the observation well responses measured during the MWAT-TT is discussed in Section 2.2.

\subsection{Document Organization}

The document is organized into three main sections. Section 1.0 presents an introduction to the ER-6-1 MWAT-TT, including the general test implementation guidelines and data sources, a description of wells within the cluster and remote observation wells, and a hydrogeologic and structural introduction to the Yucca

Flat LCA. Section 2.0 presents the analysis of the hydraulic testing data relevant 


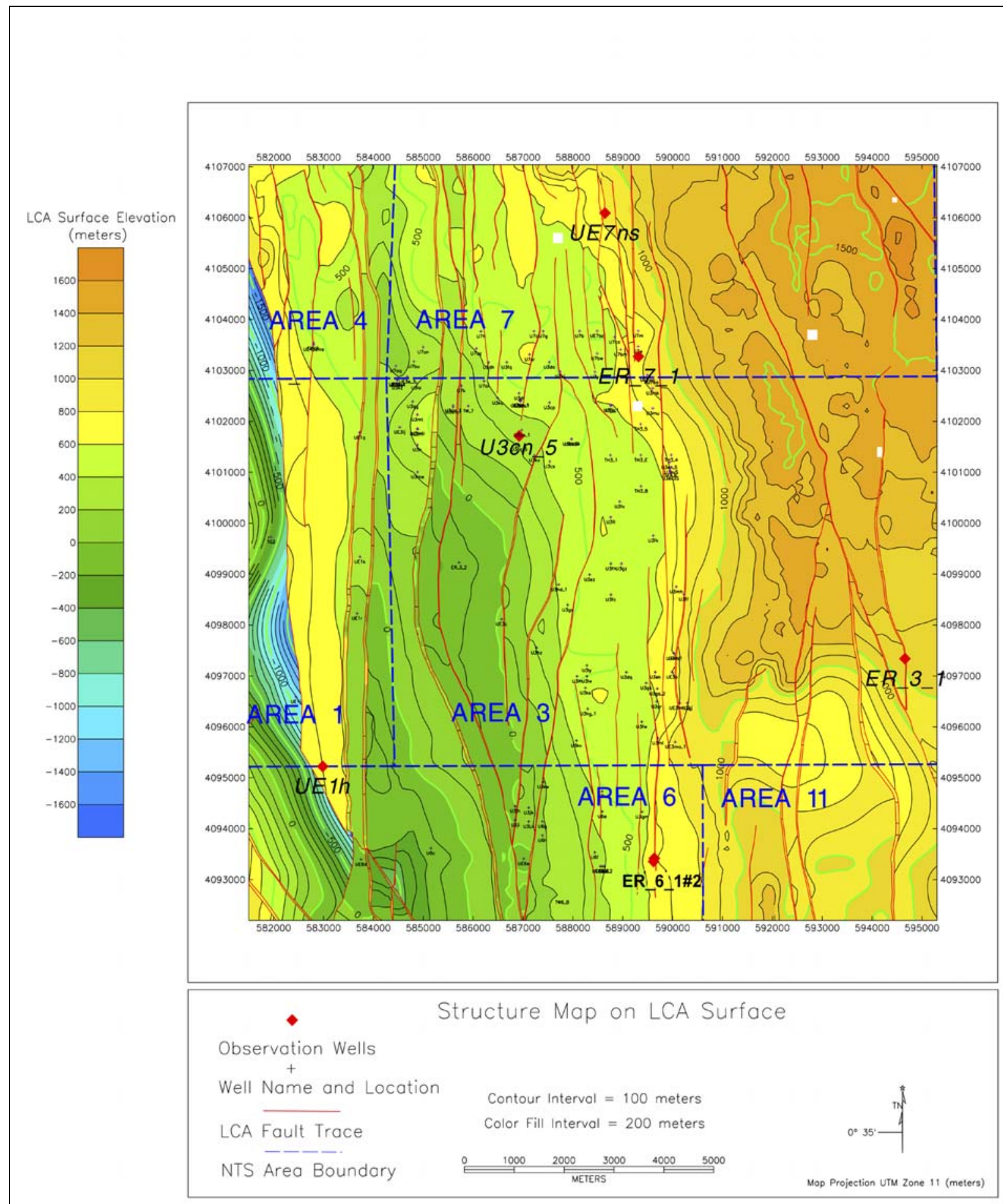

Figure 1-8

Fault Trace Map at the LCA Surface Over the Areal Extent of the Observation Well Array 


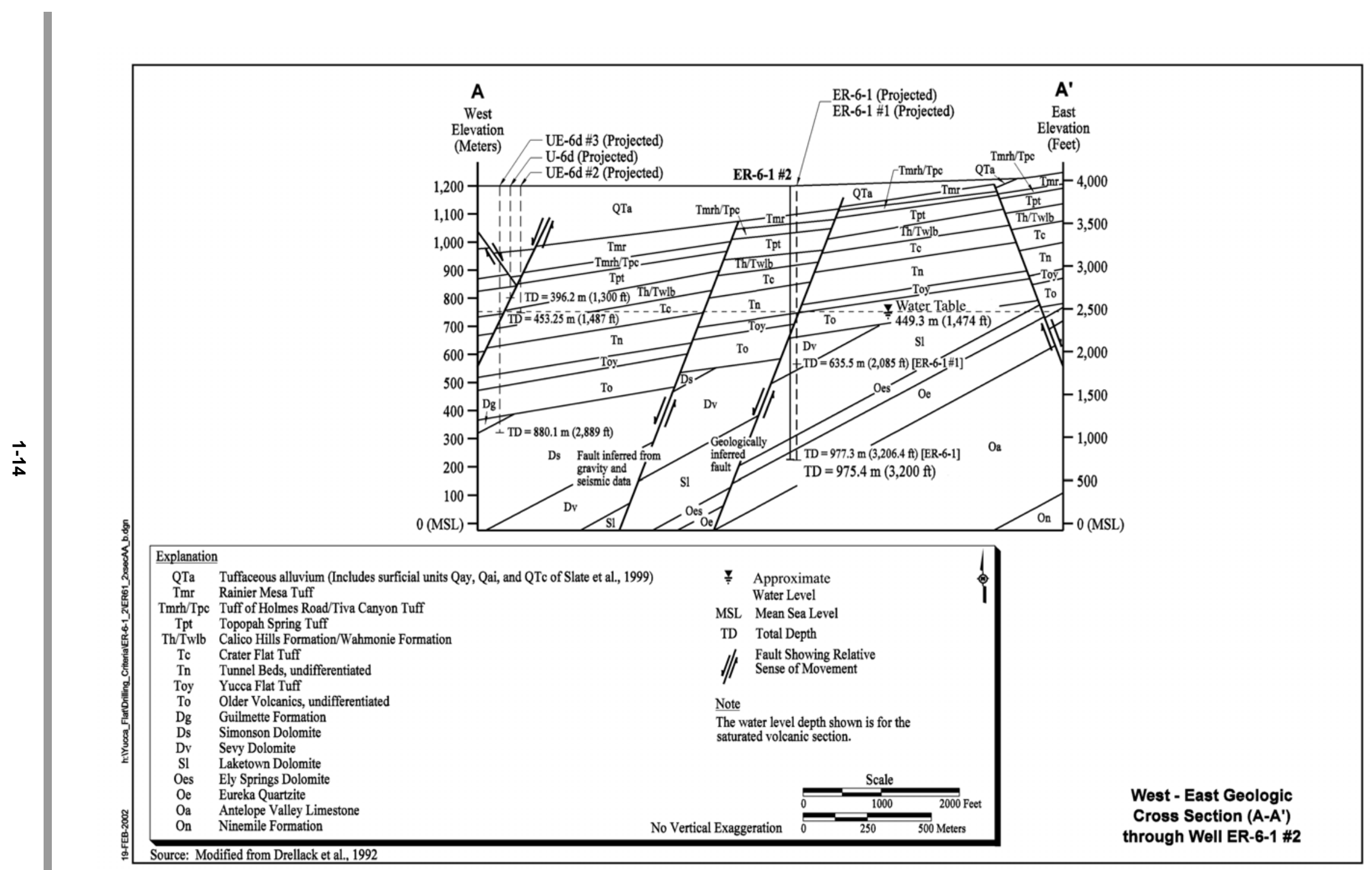

Figure 1-9

West-East Geologic Cross-Section (A-A') 

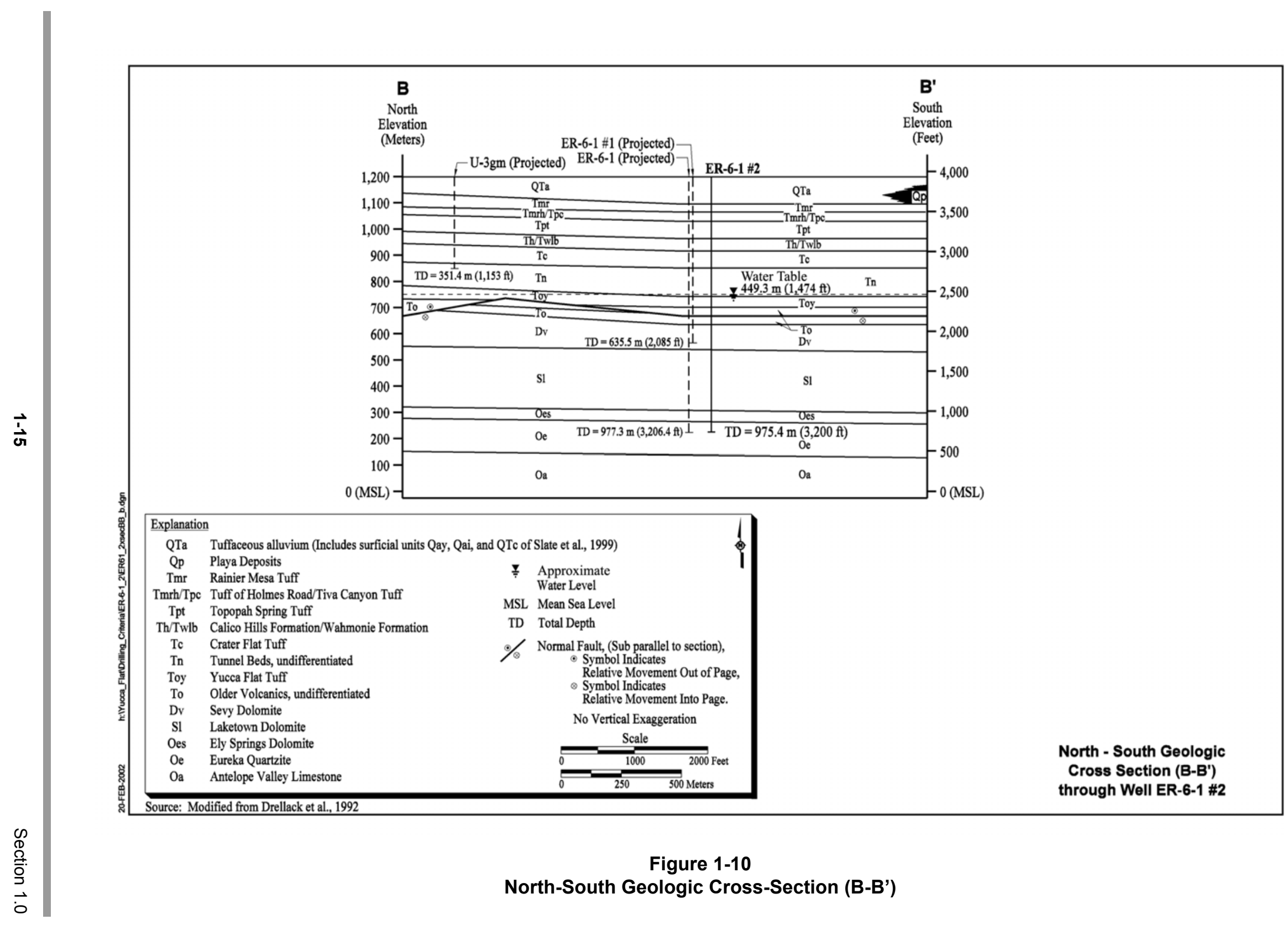

Figure 1-10

North-South Geologic Cross-Section (B-B') 
to the determination of formation hydraulic properties. These include analysis of both the observation well responses under nonpumping, natural-gradient conditions and under transient conditions in response to pumping. The latter analysis includes analysis of the MWAT-TT proper (constant-rate pumping of ER-6-1\#2) and of flow logging conducted at ER-6-1 and ER-6-1\#2 under variable-rate pumping conditions. Section 3.0 presents the compilation of derived LCA hydraulic properties and their incorporation into the conceptual model. A comparison of results with those derived from historical hydraulic testing of the LCA is also presented. 


\subsection{Hydraulic Testing Analysis}

The hydraulic response of wells to pumping is analyzed to provide both the composite and discrete-interval hydraulic conductivity of hydrostratigraphic sections of the LCA. The analyses are based on interpretation of a 90-day, effectively constant-rate pumping test and on thermal-pulse and spinner-tool flow logging that was conducted under ambient and variable-rate pumping conditions.

\subsection{Static Water Level}

Static formation head is equivalent to the composite equilibrium head of the formation(s) that are exposed in the borehole. The well is effectively connecting an interval that includes a mixture of confined zones that provide an approximation to the composite formation static head. Following well production, the static formation head represents that which the recovering formation head approaches through time. It is a critical datum for the interpretation of the formation pressure transient in well-test analysis. In theory, measurement of the static formation head is straightforward, typically utilizing either depth-to-water/head measurements and/or in situ pressure transducer measurements. In practice, this measurement can be difficult. Depth-to-water measurements made during static conditions may reflect both earth tide and barometric fluctuations, and also variations in the density of the water column with depth, that result in uncertain estimation of the static water level/formation head. Similarly, measurement of static formation head using a pressure transducer produces uncertainty in the estimate if the transducer is not located at the well bottom, or at a depth below which water density is constant. The depth of transducer insertion is also an uncertain measurement in the field. For example, transducer set depths measured during insertion and retrieval may differ by greater than $1.0 \mathrm{ft}$ (Volume 1, Appendix D of SNJV, 2005a). Therefore, depth-to-water measurements are used to provide the most accurate measurement of static formation head at each observation well. Transducer measurements are used to confirm that static conditions were achieved. The following summarizes the static head in the LCA at both the CAU and well-cluster scale.

Stoller-Navarro Joint Venture (2005a) provides a comprehensive presentation of the LCA static formation head addressed through the analysis of depth-to-water measurements, predevelopment completion pressure monitoring, and barometric efficiency (BE). The thermal effect on water levels is incorporated through fluid density. From continuous pressure measurements, which include earth-tide- and barometric-induced responses, it was shown that static conditions were achieved in all observation wells prior to the start of the MWAT-TT. The formation head fully recovered from development activities across the well cluster. This also 
indicates that the local formation head is not impacted from pumping of the LCA at other NTS locations. For example, Water Well C at the southern tip of Yucca Flat produced between 0.5 and 2.0 million gallons per month in 2004 prior to and throughout the MWAT-TT.

Hydraulic head in the LCA is confined above by the TCU and below by the LCCU (considered to be the hydrologic basement for the region), and is substantially lower than the water table located in the overlying volcanics. During preliminary hydraulic testing conducted at the ER-6-1 well cluster in January of 2003, water levels measured in the TCU at the well site (ER-6-1 piezometer and ER-6-1\#2 piezometer) were between 72 and $73 \mathrm{ft}$ higher than those measured within the LCA below (SNJV, 2004a). Within the TCU, the tuffs are zeolitized below the water table, a characteristic that is fairly consistent across the NTS, and have a sufficiently low permeability that an effective confining barrier is formed at the LCA contact.

At the CAU scale, Figure 2-1 shows general predevelopment hydraulic head at wells completed in the LCA across Yucca Flat, using regional head contours reproduced from Laczniak et al. (1996). The use of CAU-scale, predevelopment information to determine the general groundwater flow pattern avoids local inconsistencies that may be derived from unsteady head measurements made at the well-cluster that result from developmental pumping. The data in Figure 2-1 suggest that north-south trending faults and subsequent juxtapositioning of HSUs primarily control CAU-scale head gradients and that, from a regional perspective, the LCA head gradient in the area of the ER-6-1 cluster is generally west-southwest. However, LCA head contours across the MWAT-TT observation well array, presented in Figure 2-2, indicate that the gradient direction is locally variable. Although these are time-averaged head data over about four decades, and although the lateral interpolation of head from measured data does not incorporate the influence of faults, the point is made that at the cluster scale there is not a clear head gradient direction.

Static head measurements recorded across the observation well array, listed in Table 2-1, generally confirm the data presented in Figure 2-1 and Figure 2-2. As evidenced in Figure 2-1, water levels at wells on the other side of major faults, relative to the ER-6-1 cluster (e.g., UE-1h, UE-7nS), are higher by tens of feet and indicate the confining effects of the faults, e.g., a loss of transmissivity across a fault. Water levels at wells within the central portion of Yucca Flat, unseparated by any major fault systems, differ by only a few feet. At the ER-6-1 well site, several sets of (nearly) simultaneous water-level measurements were collected in the three ER-6-1 wells; however, the measured head differences were small, less than the uncertainty in the individual depth-to-water measurements

(SNJV, 2005a). Further, the well completions have varying interval depths within the LCA, which itself is a fractured system through which discrete-interval heads are variable along boreholes (see presentation of borehole flow logging data in Section 2.3.1). Consequently, the interpretation of lateral and vertical head gradients from these data at the ER-6-1 pad scale is uncertain. Similarly, neither a horizontal nor vertical gradient within the LCA could be established with any certainty from static water-level measurements collected during hydraulic testing at the site in 2003 (SNJV, 2003). This result is expected as head within the LCA, 


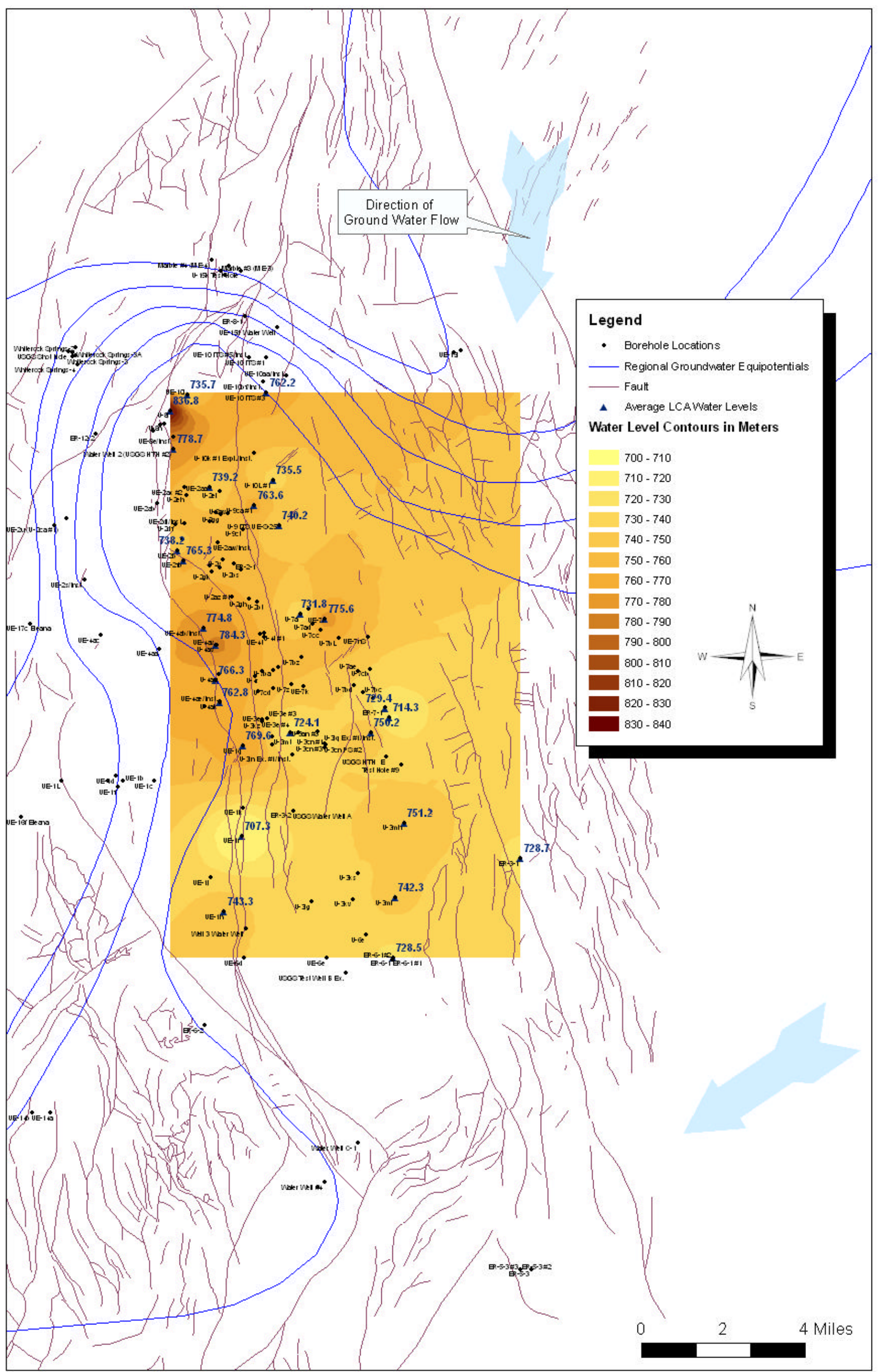

Figure 2-1

Yucca Flat LCA Predevelopment Groundwater Contours 


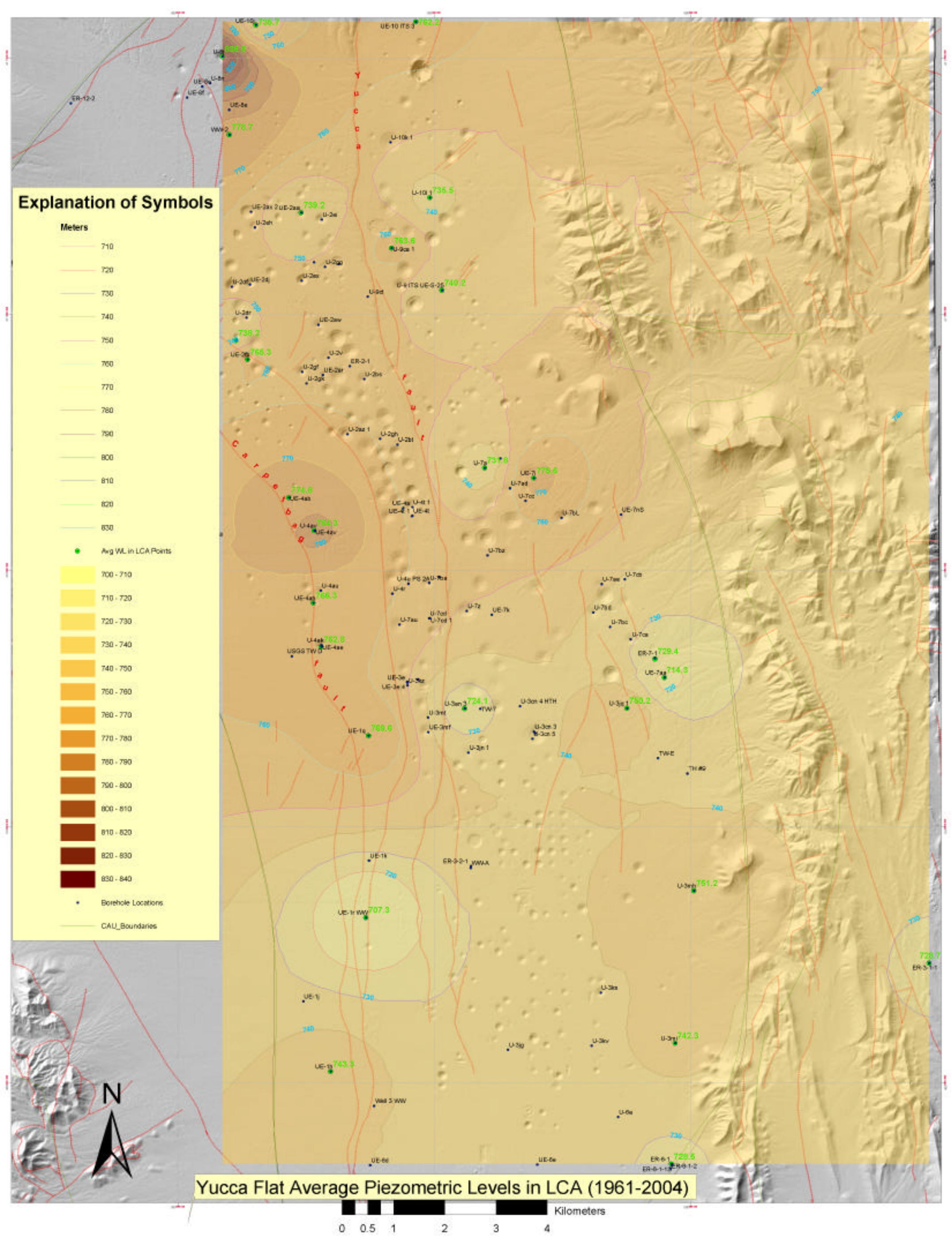

Figure 2-2 
Table 2-1

Well Cluster ER-6-1 LCA Static Formation Head During the MWAT-TT

\begin{tabular}{|c|c|c|c|c|c|c|c|c|}
\hline Date & Time & $\begin{array}{l}\text { ER-6-1 Upper } \\
\text { (ft amsl) }\end{array}$ & $\begin{array}{l}\text { ER-6-1 Lower } \\
\text { (ft amsl) }\end{array}$ & $\begin{array}{l}\text { ER-6-1\#1 } \\
\text { (ft amsl) }\end{array}$ & $\begin{array}{r}\text { ER-6-1\#2 } \\
\text { (ft amsl) }\end{array}$ & ER-7-1 & ER-3-1 & UE-1h \\
\hline \multicolumn{9}{|c|}{ Well Cluster Development - Prior to Removal of Well ER-6-1 Bridge Plugs } \\
\hline $10 / 16 / 2003$ & 9:18 & \multicolumn{2}{|c|}{$2,387.07$} & - & - & & & \\
\hline $10 / 16 / 2003$ & 10:30 & \multicolumn{2}{|c|}{-} & $2,387.14$ & - & & & \\
\hline 10/16/2003 & $12: 15$ & \multicolumn{2}{|c|}{-} & - & $2,387.26$ & & & \\
\hline \multicolumn{9}{|c|}{ Well Cluster Development - Following ER-6-1 Packer Installation } \\
\hline $4 / 9 / 2004$ & 14:56 & $2,386.84$ & - & - & - & & & \\
\hline $4 / 9 / 2004$ & $15: 12$ & - & $2,386.77$ & - & - & & & \\
\hline \multicolumn{9}{|c|}{ Following Well Development and Prior to the MWAT-TT } \\
\hline $4 / 13 / 2004$ & 14:25 & - & - & - & - & - & - & - \\
\hline $4 / 13 / 2004$ & 16:55 & - & - & - & - & - & - & $2,439.65$ \\
\hline $4 / 16 / 2004$ & $8: 43$ & - & - & - & $2,387.15$ & - & - & - \\
\hline $4 / 14 / 2004$ & 14:00 & - & - & $2,387.19$ & - & - & - & - \\
\hline $4 / 14 / 2004$ & 9:43 & NA & $2,386.68$ & - & - & - & - & - \\
\hline $4 / 14 / 2004$ & 9:12 & $2,387.28$ & - & - & - & - & - & - \\
\hline \multicolumn{9}{|c|}{ At the End of and Post Monitoring Following the MWAT-TT } \\
\hline $8 / 27 / 2004$ & 10:30 & - & - & - & $2,387.03$ & - & - & - \\
\hline $8 / 27 / 2004$ & 12:50 & - & - & $2,387.03$ & - & - & - & - \\
\hline $8 / 27 / 2004$ & 16:03 & - & $2,387.38$ & - & - & - & - & - \\
\hline $8 / 27 / 2004$ & $15: 40$ & $2,387.28$ & - & - & - & - & - & - \\
\hline $11 / 2 / 2004$ & $17: 00$ & - & - & - & - & $2,393.00$ & - & - \\
\hline $11 / 3 / 2004$ & $13: 50$ & - & - & - & - & - & $2,392.81$ & - \\
\hline
\end{tabular}

$\mathrm{ft}$ amsl - Feet above mean sea level

when unobstructed by regional faulting, is shown to be laterally consistent, indicative of a hydraulically continuous, fracture-flow dominated permeability field. For example, the lateral hydraulic gradient in the LCA between northeastern Yucca Flat and Frenchman Flat, connected beneath Frenchman Peak, is less than $1 \mathrm{ft}$ per mile (Laczniak et al., 1996).

\subsection{Multiple-Well Aquifer Test-Tracer Test (MWAT-TT)}

The following sections describe the data (Section 2.2.1), approach (Section 2.2.2), conceptual model (Section 2.2.3), and analysis (Section 2.2.4) for MWAT-TT drawdown and recovery data collected at the observation wells. 


\subsubsection{MWAT-TT Field Activities and Data}

Stoller-Navarro Joint Venture (2005a) provides an in-depth description of field activities and data collected during the MWAT-TT. A brief recounting of only the events immediately preceding, during, and following the MWAT-TT are presented here.

Following well development and testing activities at the ER-6-1 well site, the completed formation head was permitted to recover from February 21 (Julian Day [JD] 52) to April 24 (JD 115), 2004. All observation well heads achieved approximate static conditions during this period. The 90 -day production period of the MWAT-TT was initiated at ER-6-1\#2 on April 24, 2004, at a rate of 300 gallons per minute (gpm) (Figure 2-3). The rate was increased over the next three hours until a steady rate averaging $522 \mathrm{gpm}$ was achieved. The average pumping rate over the entire course of the MWAT-TT was $523.8 \mathrm{gpm}$. Several power surges and related technical difficulties halted production at intermittent periods throughout pumping and are evident in the observation well response records. A four-day pumping interruption was scheduled 15 days prior to the end of the pump test, between July 8 (JD 190) and July 12 (JD 194), 2004, for a design objective related to the tracer test. Pumping at ER-6-1\#2 ceased on July 23 (JD 205), 2004. The remainder of the MWAT-TT consisted of a recovery period ending on August 27 (JD 240), 2004.

Stoller-Navarro Joint Venture monitored hydraulic responses to MWAT-TT pumping at the following cluster wells: ER-6-1\#2, ER-6-1\#2 piezometer, ER-6-1\#1, ER-6-1 upper completion, and ER-6-1 lower completion. Those cluster well responses utilized for the interpretation are shown in Figure 2-3. The data are corrected for barometric effects (SNJV, 2005a). All cluster wells, with the exception of the ER-6-1\#2 piezometer, are completed in the LCA. The ER-6-1\#2 piezometer, completed in the overlying TCU, did not respond to production of the LCA and confirms the hydraulic isolation of the pre-Tertiary carbonates from the Tertiary volcanics (see Section 1.3). Three distal wells, each completed in the LCA, were monitored by SNJV: ER-7-1, ER-3-1, and UE-1h (Figure 2-3). The distal wells ER-3-1 and ER-7-1 showed a hydraulic response to pumping and were utilized for interpretation, while UE-1h did not. Their responses are presented in Figure 2-3. The USGS measured periodic water levels at Yucca Flat wells UE-7nS and U3cn5, both completed in the LCA. These well also indicated a hydraulic response to pumping, although the data measured are sparse. All hydraulic response data capture the LCA head under static conditions prior to the MWAT-TT, drawdown from the pump test, and partial recovery (through JD 240 for the cluster wells and about JD 300 for the distal wells).

\subsubsection{Method of Analysis}

The analysis of pressure/head transient data begins by reviewing the data with the log-log pressure and pressure derivative diagnostic plot in order to identify responses that are characteristic of certain types of flow regimes, and also to identify how changes over time further refine conceptual understanding (Horne, 1995). For instance, in the pumping well the wellbore storage period 
(a)

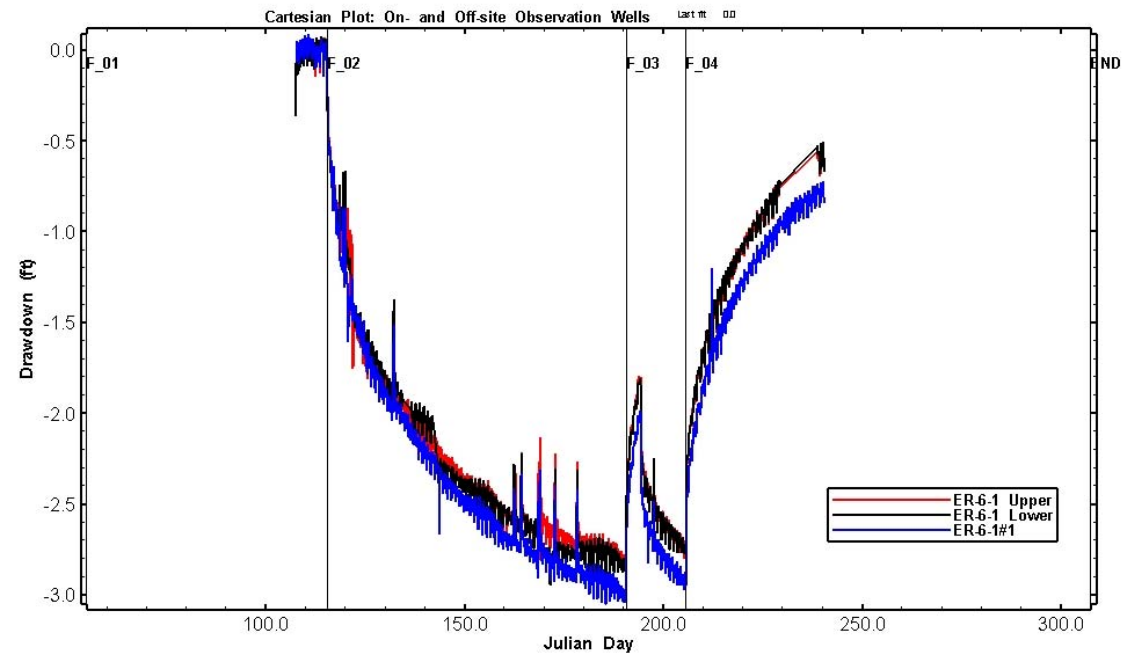

(b)

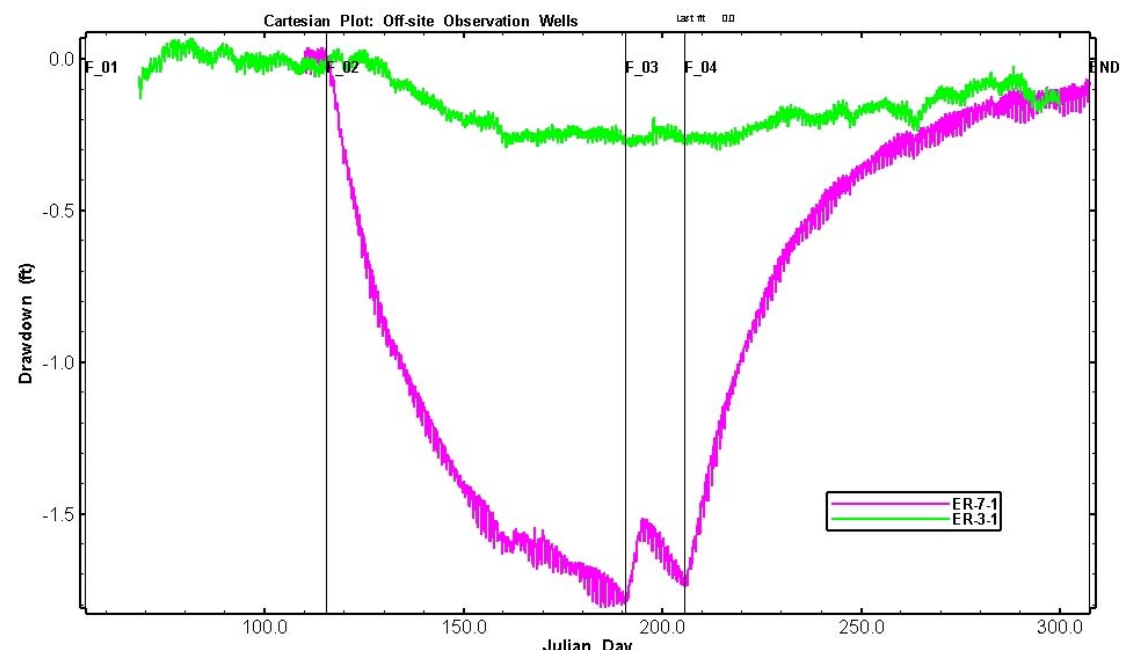

(c)

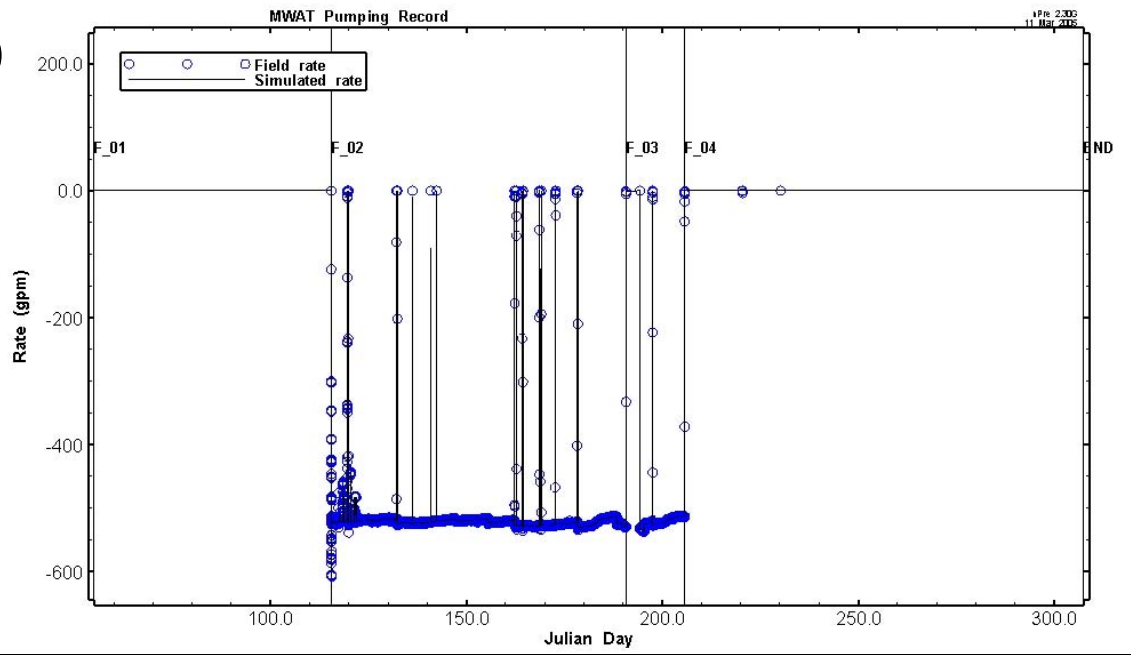

Figure 2-3

Cluster (a) and Distal (b) Cartesian Well Response Sequences and Corresponding Production (c) 
has a unit slope, and having identified the end of the wellbore storage period, infinite-acting radial flow (IARF) could be expected within 1.5 log cycles (Horne, 1995). If a constant rate of drawdown (e.g., Theis-like conditions) does not occur, then some other interpretive model must be considered.

After diagnosing the interpretive model from a log-log analysis, the formation properties associated with the interpretive model (e.g., transmissivity and storativity for a homogeneous infinite system) are adjusted to fit the log-log plot. Inferring the proper interpretive model and formation hydraulic parameters from measured formation response and well production data is an inverse problem. Inherent to any inverse problem is some degree of uncertainty, in both the interpretive model and its associated parameters, that results from the combined affect of non-ideality inherent in real geologic systems and parameter correlation (nonuniqueness). Considering uncertainty derived from the interpretive model, any response indicative of a heterogeneous formation needs to be qualitatively interpreted in the context of the geologic model in order to have some confidence in the parameters estimated. Additional confidence is gained in the estimated properties if the entire test sequence (i.e., drawdown and recovery to static) is also fit by consistent estimated parameters.

The well-test interpretation program nSIGHTS was used to estimate the formation properties. nSIGHTS was developed by INTERA for Sandia National Laboratories, based on the well-test analysis code GTFM (Graph Theoretic Field Model), the precursor to nSIGHTS. GTFM has a long history of field use including the Swiss, Swedish, and French nuclear waste programs, as well as at the DOE's Waste Isolation Pilot Plant (WIPP) in New Mexico (Roberts et al., 1999). A description of the governing equations used in both codes can be found in Pickens et al. (1987). nSIGHTS was verified following Sandia National Laboratories Nuclear Waste Management Program Procedure NP19-1, "Software Requirements," Rev. 4 to meet NQA-2 requirements (ASME, 1990). Verification of nSIGHTS was documented through comparison to the analytical solutions for constant-rate pumping tests (Theis, 1935), constant drawdown tests (Lohman, 1972), slug tests (Cooper et al., 1967), and pulse tests (Bredehoeft and Papadopulos, 1980). It is complete with a suite of statistical routines that support the identification and quantification of parameter sensitivity and uncertainty.

nSIGHTS uses a numerical approach to simulate radial/nonradial groundwater flow through a confined, single-phase, single-porosity, one-dimensional (for this analysis) flow domain in response to boundary conditions (i.e., pumping rate changes) applied at the production well. The flow domain is discretized into a system of concentric rings centered on the borehole that uses a multiplicative factor to increase the spacing between rings with increasing distance from the borehole. Each ring is represented by a node, hence the radial symmetry. The formation thickness is defined as the observation well completion interval (Figure 1-5), although there is uncertainty associated with this parameter, discussed later in Section 2.2.4. 


\subsubsection{Conceptual Model}

The interpretive conceptual model is determined by reviewing the log-log diagnostic plots of the drawdown data. Because it is the slope of the log-log plot from which a diagnosis is made, the derivative is also shown to aid in the identification of flow regimes. The log-log plots (along with their derivatives) of the MWAT-TT drawdown and recovery data for the cluster observation wells (ER-6-1 upper completion, ER-6-1 lower completion, ER-6-1\#1) and distal well ER-7-1 are shown in Figure 2-4 through Figure 2-7, respectively. Log-log diagnostics for ER-6-1\#2 (pumping well), ER-3-1, UE-1h, and the USGS-monitored wells (UE-7nS and U3cn5) are not presented, although the Cartesian plots for these wells (with the exception of UE-1h) are presented in Figure 2-8. The response data from ER-6-1\#2 are uncertain as a result of flow loss and transient well development/skin effects through the pumping period; the $\log$-log diagnostics are uninterpretable. The response data from ER-3-1 are uncertain as a result of fault-induced flow effects between the pumping and observation well (see Figure 1-8), and are discussed further in Section 2.2.4. At UE-1h, no response was observed to pumping at ER-6-1\#2, an inferred effect also of fault-induced flow. Data from UE-7nS and U3cn5 are too sparse for a log-log plot but are considered semi-quantitatively in the analysis later.

\subsubsection{ER-6-1 Well Cluster}

The log-log pressure and pressure derivative plots for the wells in the ER-6-1 cluster all show similar behavior as follows:

- First, a period of developing flow that is approximately radial after about the first one-half day of pumping. Examination of the pumping record (Figure 2-3) shows that there are wide fluctuations in rate at ER-6-1\#2 over this exact period, effectively decreasing drawdown; therefore, this interpretation is somewhat uncertain. The shallow "valley" in the derivative from about 0.1 to 0.6 (elapsed time) days has some of the character of a dual-porosity response, but again the variation in the pumping makes this interpretation uncertain.

- Between about one-half day and one day of elapsed time the pressure differential slope gradually increases to approximately $1 / 2$. Again, there are some rate fluctuations that obscure the response somewhat, particularly in the derivative. A slope of $1 / 2$ is unique to linear flow (Figure 2-9).

- The slope begins to change again after about 3.5 days, gradually becoming flatter for the rest of the test. During this transition period the slope is approximately 0.25 , although in some cases the $1 / 4$ slope identified may represent only the transition from linear to radial flow. A $1 / 4$ slope is indicative of bilinear flow, where a secondary component of permeability contributes to a linear flow feature, as idealistically shown in Figure 2-9. Thus, some kind of change in geometry is postulated. This period is more pronounced at ER-6-1\#1 and ER-6-1 lower than at ER-6-1 


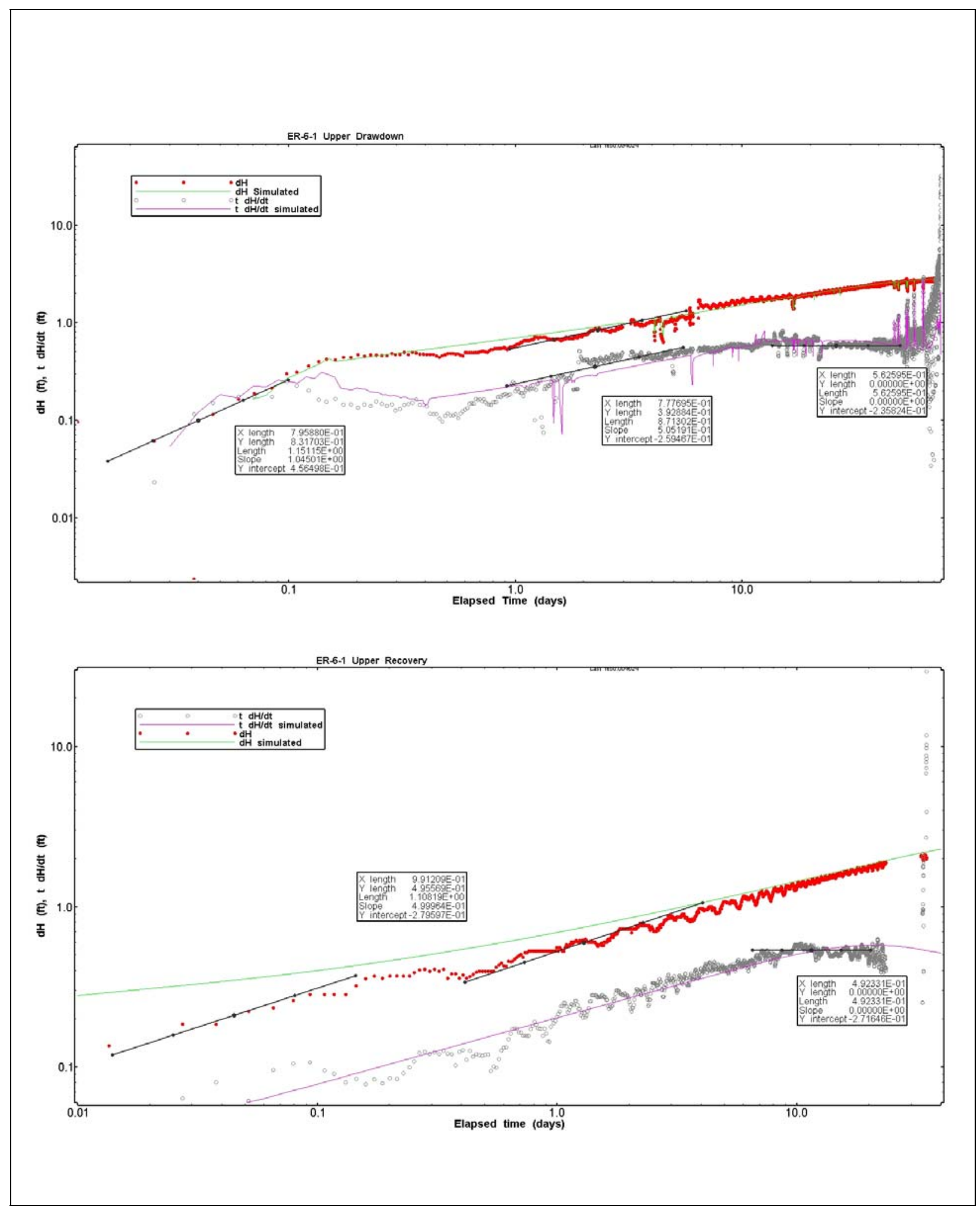

Figure 2-4

Observation Well ER-6-1 Upper Completion Log-Log Diagnostics 


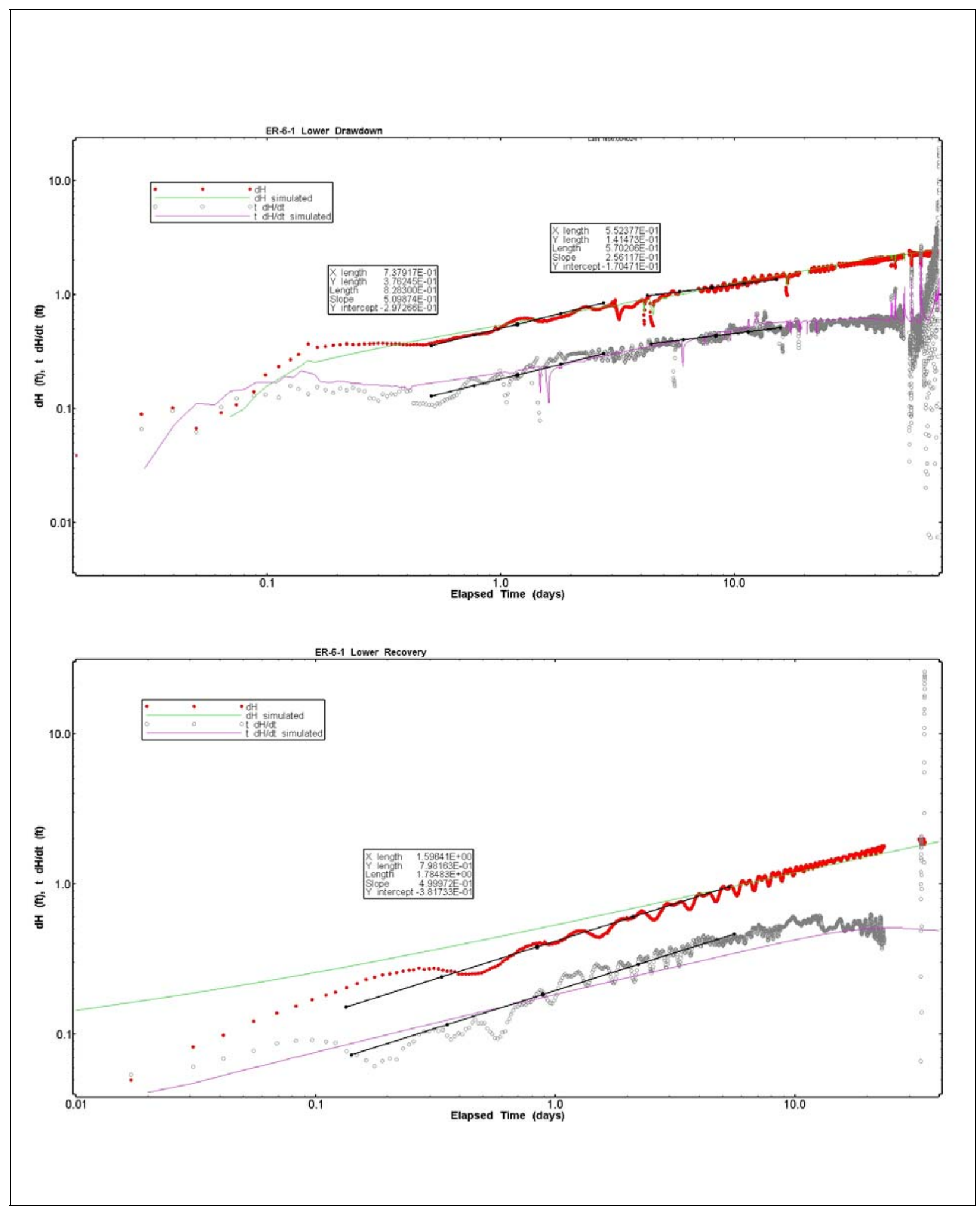

Figure 2-5

Observation Well ER-6-1 Lower Completion Log-Log Diagnostics 


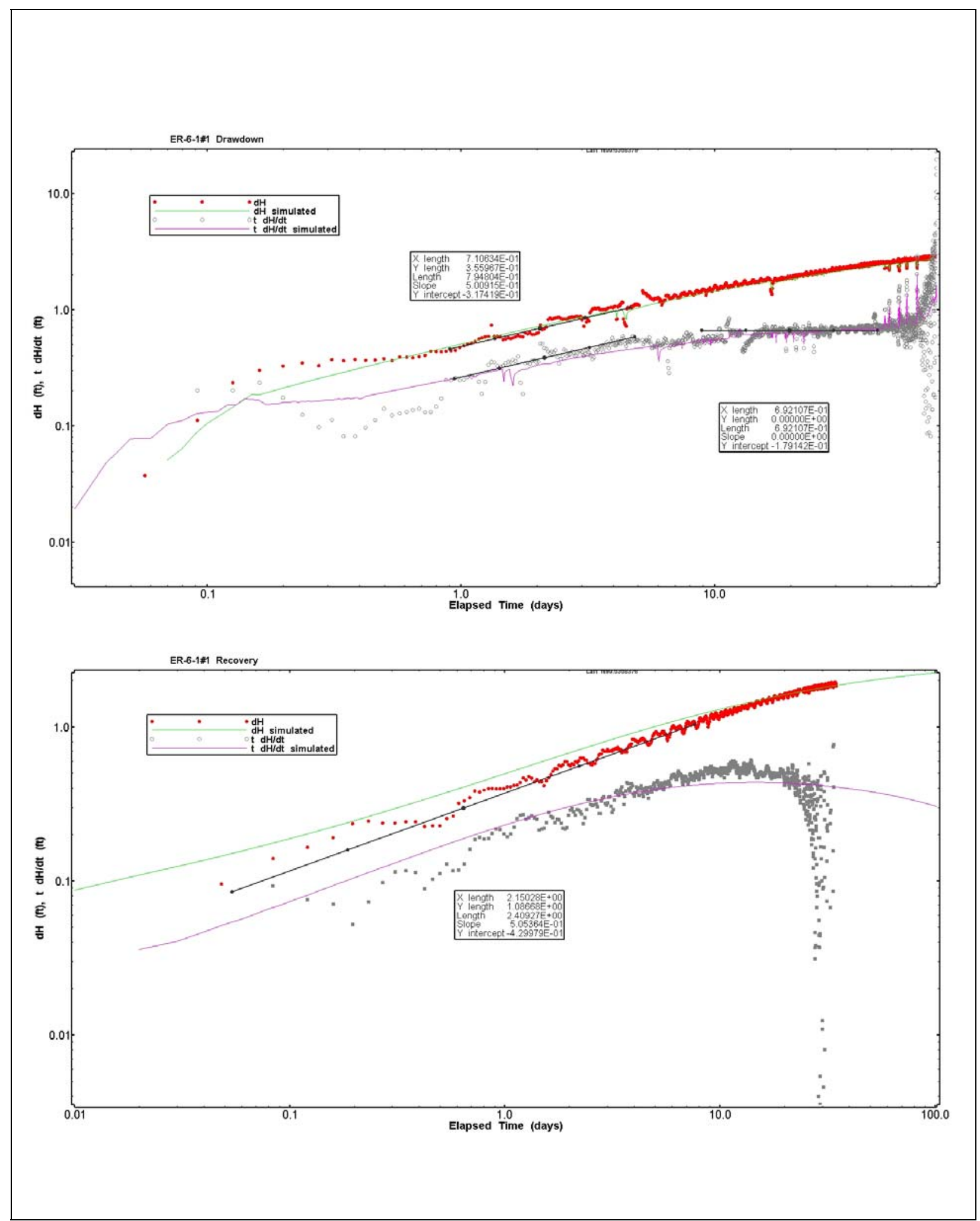

Figure 2-6

Observation Well ER-6-1\#1 Log-Log Diagnostics 


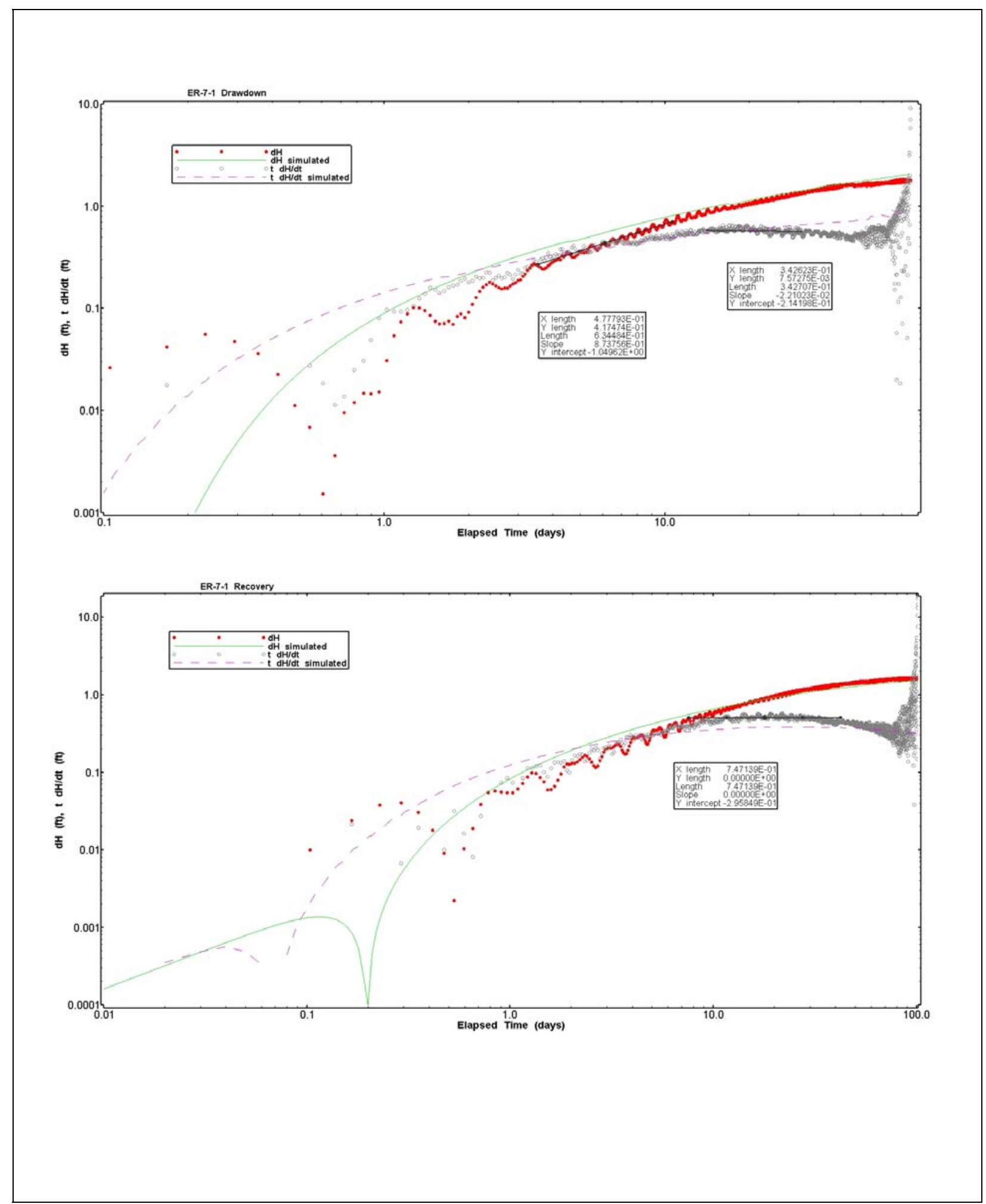

Figure 2-7

Observation Well ER-7-1 Log-Log Diagnostics 


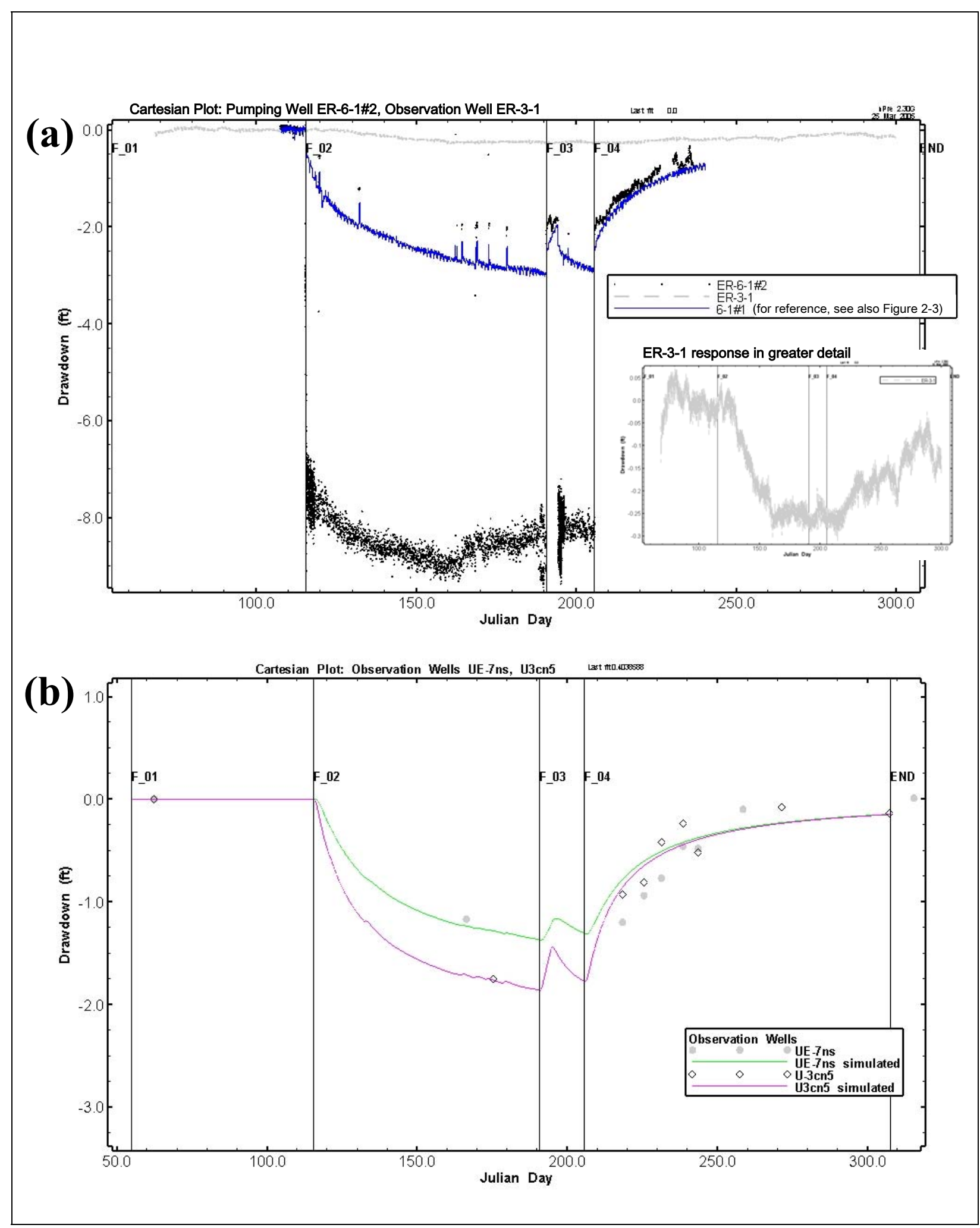

Figure 2-8

(a) Pumping Well ER-6-1\#2 and ER-3-1, and (b) UE-7nS and U3cn5 Cartesian Response Sequences 

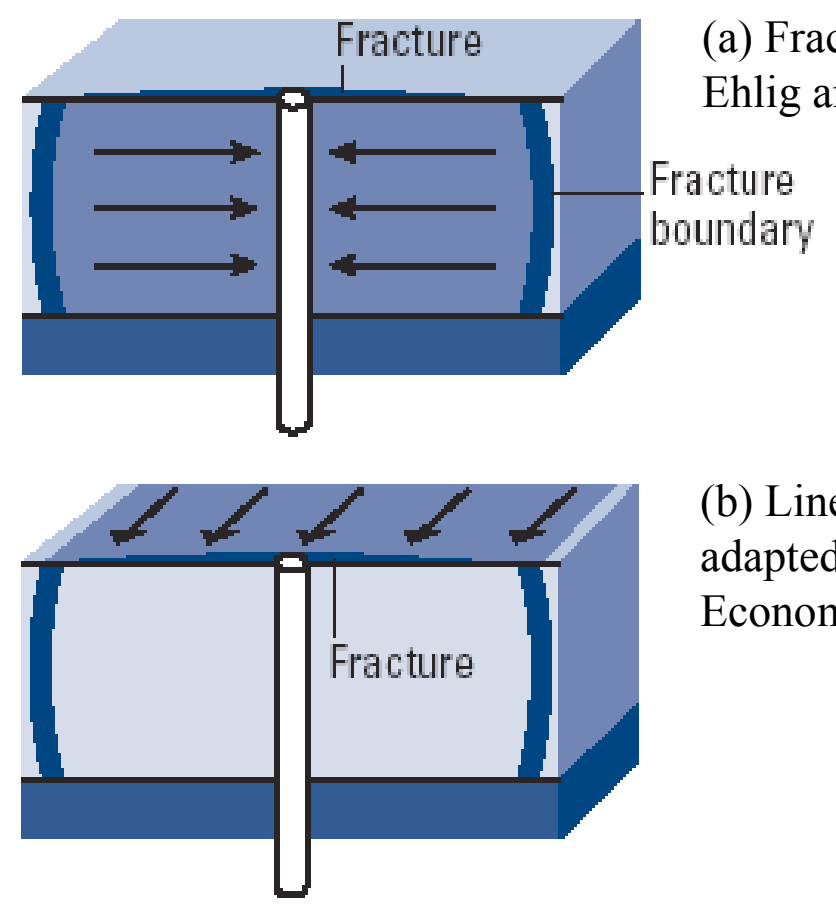

(b) Linear flow to fracture ; adapted from Ehlig and Economides et al. (1994)

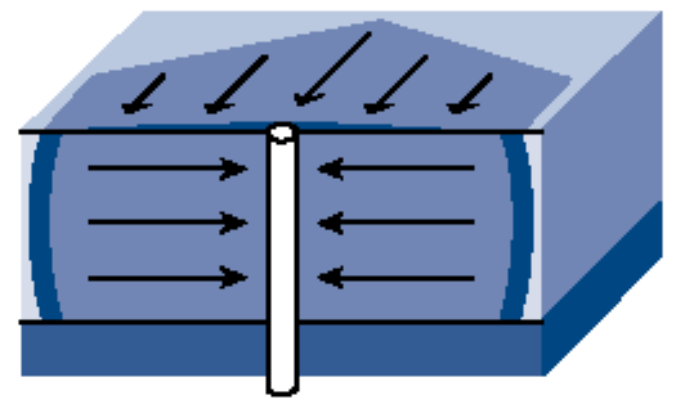

(c) Bilinear flow: the simultaneous occurrence of two linear flow patterns in normal directions; adapted from Ehlig Economides et al. (1994)

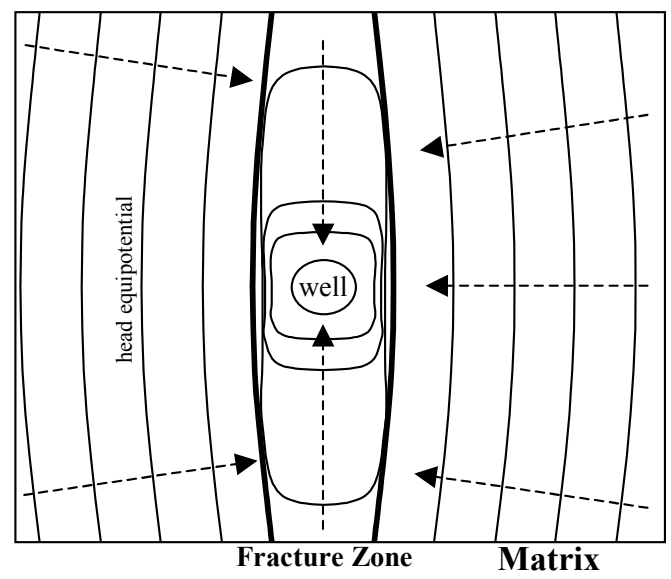

(d) Bilinear flow: contour map of drawdown after a large duration of pumping for the case of the strip transmissivity much larger than that of the matrix; adapted from Butler and Liu (1991)

Figure 2-9

Schematic Representations of Ideal Flow Geometries 
upper. The difference between the drawdown and its derivative is a factor of about 2, which is indicative of discrete fracture flow with infinite conductivity (Horne, 1995).

- During the recovery sequence, all wells show a slope of about $1 / 2$ from about 0.3 until about 10 days, where the slope decreases to $1 / 4$, and finally flattens (suggesting IARF) by the end of the data. Late-time flattening of the slope, particularly evident in the derivative, also results from the asymptotic approach of the water level to static conditions.

The persistent diagnostic plot slope of $1 / 2$ shows that at the cluster the flow geometry is nearly linear, rather than being typical of a radially infinite and homogenous formation. Very early on there may be a dual-porosity response, but the pumping rate fluctuation makes diagnosis difficult. In fact, a 80 -gpm reduction in pumping rate at 0.1 (elapsed time) days corresponds with the start of the derivative "valley" between about 0.1 and 0.6 days, which results from the flattening of the differential during this period. Further, there is no other specific evidence in the drawdown response for dual porosity.

\subsubsection{Distal Wells}

The log-log and/or Cartesian pressure and pressure derivative plots for the distal observation wells show the following characteristics:

- UE-1h, located on the other side of the Yucca and Topgallant Fault systems (Figure 1-8), showed no discernible response. Other wells (e.g., ER-3-1) at similar distances showed response to pumping. The dip-slip displacement offset of the LCA along the Topgallant (and nearby Carpetbag) Fault is interpreted as disconnecting, at least for the duration of the MWAT-TT, UE-1h from the effects of pumping at ER-6-1\#2.

- ER-7-1 showed little phase lag in its response to pumping, with measurable response after about two hours. Beginning at about a quarter of one day and lasting until about one day (elapsed time), there is a sharp change in the rate of drawdown that corresponds to rate fluctuations during about the same period. This implies that ER-7-1 is well connected hydraulically to ER-6-1\#2. After about one day the response develops relatively smoothly, with the nearly horizontal derivative beginning at about 10 days, suggesting IARF.

- Well ER-3-1 showed a marked, on the order of 10 days, lag in response to pumping (Figure 2-8) even though ER-3-1 is over 10,000 ft closer to ER-6-1\#2 than ER-7-1. The response is slight and earth tides obscure the diagnostic somewhat, but the flow geometry appears to be radial. This implies that ER-3-1 is not as well hydraulically connected to ER-6-1\#2. Additionally, drawdown ceases at about JD 160, which indicates that some constant-head feature, possibly a high conductivity fault-induced feature, was encountered. 
ER-7-1 was previously analyzed as a single-well pump test by SNJV (2004b), and a constant-head boundary was identified in the analysis. The response was complicated, and no dual-porosity effects were obvious. Clearly there are no constant heads in Yucca Flat, but a very strong increase in hydraulic properties associated with a fault or fracture zone would give a similar effect. Given that ER-7-1 responded relatively quickly to ER-6-1\#2 pumping, a possible explanation is that the "fast-path" geologic feature (e.g., faults and associated sympathetic fracture zones) that is responsible for the bilinear to linear geometry responses at the ER-6-1 cluster is also responsible for the strong property change detected by the ER-7-1 single-well test. The hydraulic conductivity estimated from the ER-7-1 single-well test is moderate at $1.4 \times 10^{-3}$ meters per second $(\mathrm{m} / \mathrm{s})$ (397 feet per day [ft/d]); thus, it does not appear that ER-7-1 lies directly on a very high permeability feature, but is proximal to such a feature (see ER-7-1 location on Figure 1-8).

Wells UE-7nS and U3cn5 did not have an extensive enough record $(\sim 10$ data each) to allow diagnostic analysis; however, data from an earlier single-well test at UE-7nS was available in SNJV files. Brief reanalysis revealed a 1/4-slope period indicative of bilinear flow. Hydraulic conductivity was estimated at $6 \times 10^{-7} \mathrm{~m} / \mathrm{s}$ $(0.17 \mathrm{ft} / \mathrm{d})$.

\subsubsection{Discussion}

Bilinear and linear flow, as diagnosed by $1 / 4$ and $1 / 2$ slope lines on the diagnostic plots, can arise from two sources: discrete fracture flow or a strip geometry. The bilinear condition is characterized by flow from a (usually) lower hydraulic conductivity part of the formation into a higher hydraulic conductivity (linear) feature. The lower and higher hydraulic conductivity parts of the domain can be the less fractured and more fractured parts of the formation (Horne, 1995), respectively, or lower and higher hydraulic conductivity material juxtaposed from depositional changes (e.g., juxtaposed channel and overbank stream deposits [Butler and Liu, 1991]). Considering a fractured formation, the $1 / 4$ slope is representative of a finite-conductivity fracture, and the $1 / 2$ slope by an infinite-conductivity fracture. A finite-conductivity fracture gives an initial 1/4 slope response, and may (rarely) transition to a linear condition en route to radial flow as the fracture dies out and the entire formation responds (Horne, 1995). Unless fracture heterogeneity is invoked it is not possible to go from the $1 / 2$ to $1 / 4$ slope condition. Jenkins and Prentice (1982) observed linear flow responses at observation wells in fractured rocks lasting for several days, with no apparent approach to radial conditions. Thus, a large-scale geologic feature such as a fault and associated fracture zone could produce the observed response and is consistent with the geologic conceptual model. Additionally, the 1/4 and 1/2 slopes representative of finite- and infinite-conductivity fractures are accompanied by identical slopes on the derivative, separated by factors of 4 and 2, respectively. These features are marked on the cluster well diagnostic plots for wells ER-6-1 upper, ER-6-1 lower, and ER-6-1\#1, also supporting the conceptual model proposed (Figure 2-4 through Figure 2-6). 
An alternative conceptual model that gives similar behavior to that noted at the ER-6-1 cluster is that of an arrangement of semi-infinite strips with the center strip (e.g., a fracture zone) having a much higher hydraulic conductivity. Butler and Liu (1991) show that if the strip has a much higher hydraulic conductivity than the surrounding material (matrix), then bilinear and linear flow are the primary flow regimes with possibly an early time radial response until the edges of the center strip are felt (see Figure 2-9[d]). However, in this case the 1/2 slope line occurs before the $1 / 4$ slope. Initial flow is linear until a gradient between the central strip and the lower hydraulic-conductivity material is established, thus inducing bilinear flow. A final radial flow period may occur within the strip depending on the contrast of strip and matrix properties. The duration of the bilinear and linear flow regimes is a measure of the contrast between the strip and matrix. Butler and Liu also note that at distant observation wells linear flow is not usually observed and it is the appearance of bilinear flow that reveals a large contrast between strip and matrix. A fault and associated fracture zone can easily be conceptualized as a high hydraulic conductivity strip embedded in a lower (less fractured) conductivity matrix. Finally, the timing of the flow regimes in the strip model (nearly radial, linear, bilinear, and back to radial) is more consistent with the data, if bilinear flow occurs.

The fracture and strip aquifer conceptual models discussed above are useful prototypes for examining the basic response to pumping of stylized aquifer configurations; reality is often more complicated. The response at the ER-6-1 cluster has features that are consistent with both the discrete fracture and strip aquifer geometries, and it may be that reality is some hybrid of the two. Regardless of the specific interpretive model, it is clear that large-scale heterogeneity exists that results in sub-radial flow very near the ER-6-1 cluster that also creates preferential pathways for rapid transmission of pressure disturbances over great distances.

\subsubsection{Hydraulic Response Analysis}

As previously discussed the nSIGHTS numerical well-test simulator was used to analyze the test data. nSIGHTS does not use the typical analytic solution approach where a mathematical model constructed from a prototypical geologic geometry is selected and then formation properties determined. nSIGHTS uses a more general formulation known as the flow dimension, where the geometry factor itself can be varied. Integer flow dimensions of 1, 2, and 3 are equivalent to linear, radial, and spherical flow, respectively. Walker and Roberts (2003) show that the flow dimension can be calculated as follows:

$$
\eta=2-2 v
$$

where $v$ is the slope of the pressure derivative and $\eta$ is the flow dimension. Thus, linear flow with a slope of $1 / 2$ has a flow dimension of 1.0 , and bilinear flow with a slope of $1 / 4$ has a flow dimension of 1.5 . For the one-dimensional simulations applied in this analysis, the flow dimension may be thought of as the numerical analogue to the actual heterogeneity that exists within the formation volume tested, and is analogous to the geometric configuration of a heterogeneous 
permeability field that would be parameterized in a two- or three-dimensional numerical model.

In this analysis, hydraulic conductivity, specific storage, and a laterally-variable flow dimension are used as fitting parameters to solve the inverse problem of fitting the measured test data with estimates of formation properties. Each observation well response is partitioned into four sequences (designated F_01, F_02, F_03, and F_04) identified by pumping conditions (Figure 2-3). The sequences, in increasing order, represent (1) static conditions prior to the MWAT-TT, (2) constant-rate pumping (full of small time-scale fluctuations), (3) a second period of constant rate pumping that is initiated by a four-day cessation of pumping, (4) and recovery after termination of pumping. The third sequence was created so that it could be excluded from the log-log diagnostic analysis as it would have imparted an unnecessary and overly complex flow regime into the interpretation. To solve for hydraulic conductivity, specific storage, and flow dimension, response data for the drawdown (F_02) and recovery (F_04) diagnostic plots (differential and derivative) were simultaneously fit in nSIGHTS. The simulation was completed individually for each observation well response; there was no justification for the simultaneous simulation of multiple well responses given the high degree of lateral heterogeneity (presented as the conceptual model). The hydraulic conductivity and storage fitting parameters are effective properties, or property estimates representative of the LCA over a square kilometer $\left(\mathrm{km}^{2}\right)$-scale areal extent in most cases. The laterally varying flow dimension parameters represent changes in flow geometry with distance into the formation. The number of flow dimension parameters permitted per response analysis is dependent on two factors: (1) parameter sensitivity and (2) the (spatial) scale of the test volume. Regarding parameter sensitivity, a lateral flow dimension is included as a fitting parameter if the simulated response is shown to be sensitive to that parameter. Identification of a sensitivity threshold is subjective. Regarding scale, the smaller the distance between the observation and pumping wells, the greater the detail of flow geometry variability that is imparted in the measured response. A larger number of flow dimension parameters may be required to capture the detail if the spatial scale of heterogeneity is small. Distant responses will, in general, present more of an effective response as a larger volume of aquifer is tested. For the response fitting simulations, the best-fit flow dimension parameters should correspond to (bi)linear flow, with values between 1.0 and 2.0, if the conceptual model discussed in Section 2.2.3 is in fact valid.

Beauheim and Roberts (1998) used a similar flow-system conceptualization and modeling approach for the simulation of hydraulic testing conducted in the (fractured) Culebra dolomite at the WIPP site. After developing a conceptual model that included a variable flow geometry (area), as interpreted from the response log-log diagnostics, a laterally variable flow dimension was incorporated into the flow simulator as a set of hydraulic fitting parameters. The optimized flow dimensions were in good agreement with the conceptual model. However, the authors recognized that flow dimension(s) interpreted from a hydraulic test represent a non-unique combination of geometry and diffusivity; the strong correlation between flow dimension and diffusivity, compounded by the actual variability of both properties in the system, present some degree of uncertainty. Therefore, in lieu of a detailed analysis of parameter correlation, the flow 
dimension(s) can be either assumed or predicted with confidence if it corresponds with the derivative of the pressure change with log time and agrees with the interpretive model.

The best-fit simulated drawdowns for the cluster and distal wells (excluding the USGS-monitored wells [UE7nS and U3cn5], ER-3-1, and ER-6-1\#2) are presented in Figure 2-4 through Figure 2-7. Table 2-2 lists the hydraulic conductivity, storage, and flow dimension estimates per well. Uncertainty in the LCA hydraulic conductivity and storage estimates is addressed through the variability between results per observation well, which provides some measure of the lateral anisotropy embedded within the observation well responses.

Table 2-2

Best-fit Parameter Estimates Derived from Individual Observation Well Response Simulation

\begin{tabular}{|c|c|c|c|c|c|c|c|c|c|c|c|}
\hline $\begin{array}{c}\text { Observation } \\
\text { Well }\end{array}$ & $\begin{array}{l}\text { Borehole } \\
\text { Interval } \\
\text { Tested (ft bgs) }\end{array}$ & $\begin{array}{l}\text { Hydraulic } \\
\text { Conductivity } \\
\text { (ft/d) }\end{array}$ & $\begin{array}{l}\text { Specific } \\
\text { Storage } \\
(1 / \mathrm{ft})\end{array}$ & \multicolumn{8}{|c|}{$\begin{array}{l}\text { Radial Distance (ft) from Pumping Well ER-6-1\#2 (above); } \\
\text { Flow Dimension }{ }^{\text {a }} \text { (below) }\end{array}$} \\
\hline \multirow{2}{*}{$\begin{array}{l}\text { ER-6-1 } \\
\text { Upper }\end{array}$} & \multirow{2}{*}{$1,775-3,090$} & \multirow{2}{*}{234} & \multirow{2}{*}{$1.7 \times 10^{-9}$} & 30 & 60 & 100 & 200 & 1,000 & 5,000 & 10,000 & 20,000 \\
\hline & & & & 1.9 & 2.2 & 2.4 & 2.2 & 2.0 & 2.2 & 1.4 & 1.1 \\
\hline \multirow{2}{*}{$\begin{array}{l}\text { ER-6-1 } \\
\text { Lower }\end{array}$} & \multirow{2}{*}{$1,775-3,090$} & \multirow{2}{*}{249} & \multirow{2}{*}{$2.3 \times 10^{-9}$} & 30 & 60 & 100 & 200 & 1,000 & 5,000 & 10,000 & 20,000 \\
\hline & & & & 2.0 & 2.4 & 2.3 & 2.1 & 2.0 & 1.6 & 1.0 & 1.2 \\
\hline \multirow{2}{*}{ ER-6-1\#1 } & \multirow{2}{*}{$1,835-2,085$} & \multirow{2}{*}{157} & \multirow{2}{*}{$5.4 \times 10^{-7}$} & 15 & 30 & 60 & 100 & 500 & 1,000 & 5,000 & 12,000 \\
\hline & & & & 2.7 & 1.3 & 1.0 & 2.7 & 1.0 & 1.0 & 1.0 & 1.6 \\
\hline \multirow{2}{*}{ ER-7-1 } & \multirow{2}{*}{$1,775-3,090$} & \multirow{2}{*}{4} & \multirow{2}{*}{$7.9 \times 10^{-9}$} & \multicolumn{3}{|c|}{500} & \multicolumn{2}{|c|}{2,500} & \multicolumn{3}{|c|}{20,000} \\
\hline & & & & \multicolumn{3}{|c|}{2.4} & \multicolumn{2}{|c|}{1.0} & \multicolumn{3}{|c|}{1.6} \\
\hline ER-6-1\#2 & $1,775-3,090$ & $36^{\mathrm{b}}$ & $N A^{c}$ & \multicolumn{8}{|c|}{ NA } \\
\hline
\end{tabular}

aFlow dimension is constant in space for each constant-distance step

${ }^{b}$ Cooper-Jacob analyses, because of the radial flow assumption, result in hydraulic conductivity estimates that are one order of magnitude less than those derived in the nSIGHTS analysis, which incorporate the (bi)linear flow geometry indicated (as presented in this section)

${ }^{\text {c}}$ Single-well test analysis for well transmissivity does not permit storage estimate

bgs $=$ Below ground surface

$\mathrm{ft}=$ Foot

$\mathrm{ft} / \mathrm{d}=$ Feet per day

NA $=$ Not Applicable

Uncertainty from fitting-parameter correlation is not assessed, although from a qualitative viewpoint the conductivity and storage parameters were stable (within a factor of three) during the optimization (parameter perturbation) analysis.

Additionally, the similarity in parameter estimates from the individual simulation of the ER-6-1 upper and lower responses indicates that a unique set of parameters is derived. Under the assumption that the ER-6-1 upper and lower responses are equivalent to two measurement points within the same flow regime, then similar analysis results provide independent confirmation of uniqueness. Uncertainty in the flow dimension parameters is not determined. There are up to eight flow dimension parameters permitted per well response. A smaller number of flow dimension parameters would not permit the fitting of the curvature observed in the 
derivative, which indicates that the flow geometry is variable with distance from the pumping well. Their lateral sequences, from closest to furthest from the pumping well, approximately follow a radial-to-(bi)linear pattern, consistent with the conceptual model presented. For the optimizations, the flow dimension fitting bounds were set at 1.0 and 3.0, with the initial condition set to radial (2.0); therefore, the parameter sets derived appear to be representative of the actual flow geometry encountered during the MWAT-TT and represent physical properties of the system as opposed to merely fitting parameters.

It is important to observe that for the cluster-site wells, the formation interval tested is an uncertain datum because of the (bi)linear flow geometry evident in the hydraulic responses, which itself is corroborated by the flow dimension fitting parameters. In the case of an idealistically confined radial flow system, the formation interval tested at each observation well would equal the completion interval thickness. In the LCA tested, (bi)linear features indicate that only a fraction of the formation is tested, with a preferential north-south orientation, and also with some degree of vertical heterogeneity (presented in the borehole flow logging analysis in Section 2.3). Comparative analyses of the drawdown data using the Cooper-Jacob (1946) analytical method, which assumes Theis-like conditions, result in hydraulic conductivities that are at least one order of magnitude less than those derived from the numerical analyses, verifying the importance of the incorporation of the flow geometry into the analysis. Lower hydraulic conductivities are appropriate for a "radial" analysis because a larger formation volume is available to provide the same amount of drawdown as observed in the actual sub-radial flow system. Thus, having incorporated the laterally-varying flow geometry into the analysis, the bulk formation hydraulic diffusivity and transmissivity can be estimated with confidence. Although the partitioning of transmissivity into hydraulic conductivity based on interval thickness is uncertain, the equivalent responses measured in the ER-6-1 upper and lower completions indicate that both zones measured the response over the entire $1,315-\mathrm{ft}$ section of LCA completed by the pumping well. Therefore, $1,315 \mathrm{ft}$ is the thickness applied to estimate hydraulic conductivity at ER-6-1 upper and lower. ER-6-1\#1, which is too shallow of a completion to have been stressed by the entire LCA interval at a distance of $167 \mathrm{ft}$ from the pumping well, is assumed to test a thickness equal to its completion interval.

For wells UE-7nS and U3cn5, the best-fit simulated responses are presented in Figure 2-8. Given the paucity of the data, parameter estimates are highly uncertain and are not provided. However, the parameter estimates are within the range of those presented in Table 2-2, indicating that the LCA flow regimes identified across the observation well array probably apply to these two measurement locations as well. Both wells are north of the ER-6-1 well cluster and juxtapose fault systems parallel to that which intersects the cluster (Figure 1-8).

A best-fit response simulation for the ER-3-1 response was not attained. From observation of the full Cartesian response (Figure 2-8) (the log-log diagnostics are uninterpretable), and in conjunction with the conceptual model, fault-controlled boundary conditions appear to strongly influence the response. ER-3-1 is positioned northeast of ER-6-1\#2 across multiple north-south trending faults 
(Figure 1-8), which may act (according to the conceptual model) as either low permeability flow barriers or high permeability features that dissipate the pumping response north-south along the fault. Either could produce both the ( 10-day) lag in the initial response to MWAT-TT pumping and the apparent constant-head boundary encountered at JD 160 (Figure 2-8). Recall that no response was measured to MWAT-TT pumping at UE-1h, positioned west of ER-6-1\#2 across Yucca and Topgallant Faults. In the ER-3-1 analysis, a variable flow dimension was not able to account for these flow features. A definitive set of LCA hydraulic properties was not derived for this observation well. Similarly, a standard analytical method was not applied to the response data because a response period representative of ideal conditions (i.e., IARF) was not identifiable on the log-log diagnostics.

The ER-6-1\#2 (single-well test) response was not analyzed in nSIGHTS. As discussed in Section 2.2.3, significant flow losses are apparent at the onset of pumping, and head recovery that begins during pumping at JD 162 (Figure 2-8) indicates well development through the test (i.e., transient skin effects). Accordingly, both the Cartesian and log-log diagnostics are uninterpretable for estimation of LCA hydraulic properties. A Cooper-Jacob analysis performed for the response period assumed to be representative of IARF (derived from interpretation of the ER-6-1 upper and lower log-log diagnostics) resulted in a low hydraulic conductivity. The graphical method is presented in Figure 2-10. Again, exclusion of the flow geometry from the analysis method biases the conductivity low. This results is not recommended for further use in related analyses.

\subsection{Borehole Flow Logging}

Boreholes ER-6-1 and ER-6-1\#2 were characterized by the DRI using their borehole flow logging tools including a spinner flow meter (SFM) and a thermal flow meter (TFM) tool. Each of these tools and their use are described in detail in Oberlander and Russell (2003) and (2004). This section of the report will briefly describe the logging performed in boreholes ER-6-1 and ER-6-1\#2 and will then provide additional interpretation of the results presented in Oberlander and Russell (2004).

The logging campaigns performed in boreholes ER-6-1 and ER-6-1\#2 are described in Table 2-3. The campaigns for each borehole are organized by a logging campaign ID which identifies the logging run type in chronological order. Logging runs for ER-6-1\#2 have an additional \#2 added to the campaign ID to differentiate from logs run at boreholes ER-6-1 and ER-6-1\#2. The details regarding each set of logs run in boreholes ER-6-1 and ER-6-1\#2 are presented in SNJV (2005a) and in Oberlander and Russell (2004).

The logs that are analyzed in this report include the SFM logs, temperature logs, and TFM logs. The calibration and data reduction associated with each of these specific borehole-logging tools is of critical importance, especially under the complex borehole conditions experienced at the ER-6-1 well cluster. The raw logging data require analysis to develop borehole flow velocities, and then borehole volumetric fluxes. Desert Research Institute performed this step of raw 


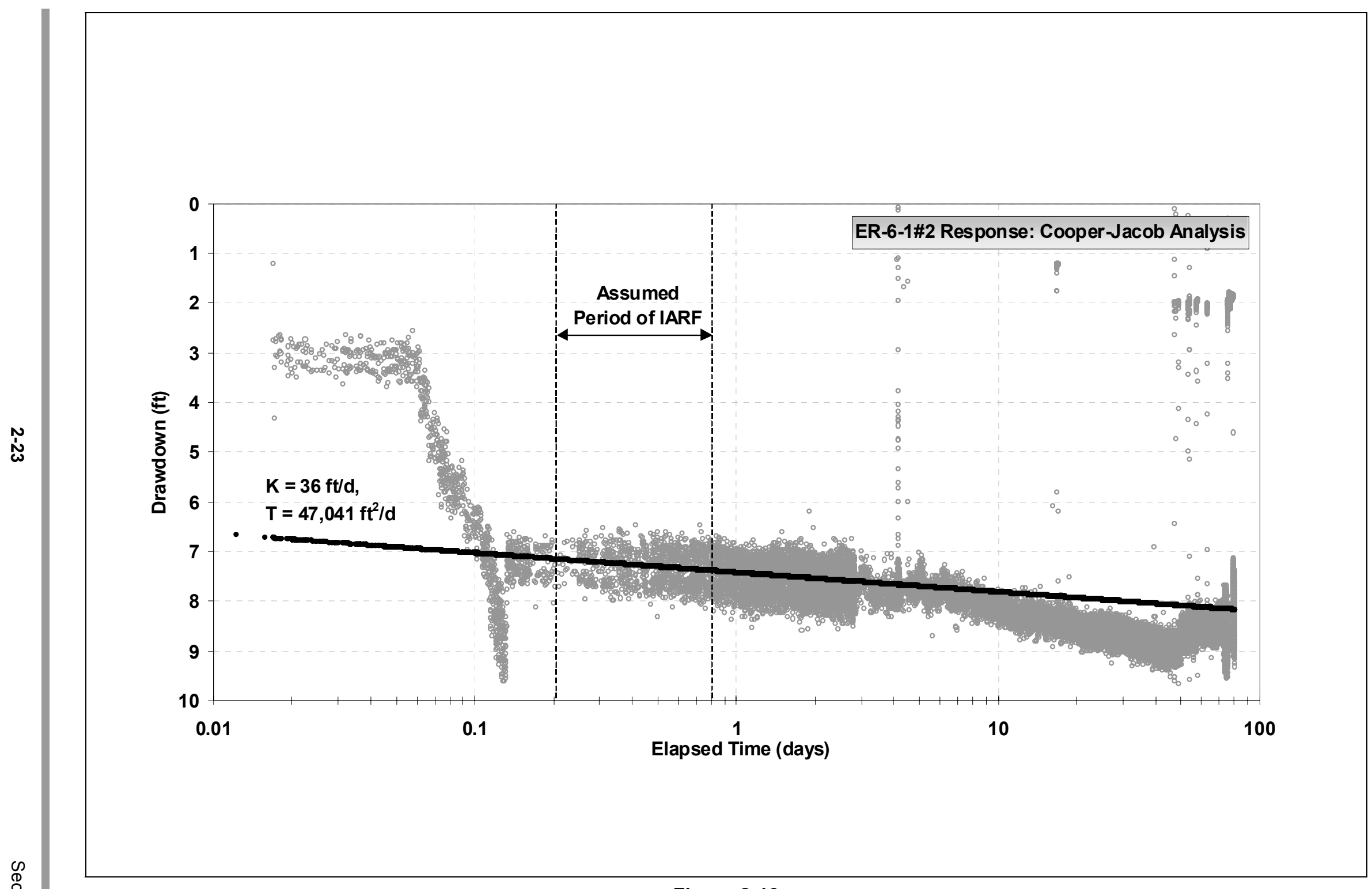

Figure 2-10

ER-6-1\#2 Cooper-Jacob Analysis 
Table 2-3

DRI Logging Campaigns for the ER-6-1 Well Cluster

\begin{tabular}{|c|c|c|c|c|c|c|c|}
\hline Well & $\begin{array}{c}\text { Campaign } \\
\text { ID }\end{array}$ & $\begin{array}{c}\text { Log Run } \\
\text { Type }\end{array}$ & Log Date & $\begin{array}{l}\text { Top } \\
\text { (ft) }\end{array}$ & $\begin{array}{l}\text { Bottom } \\
\text { (ft) }\end{array}$ & $\begin{array}{c}\text { Well } \\
\text { Conditions }\end{array}$ & Comments \\
\hline \multirow{8}{*}{ ER-6-1 } & $\mathrm{T}-1$ & Temperature & 10/16/03 & 1,499 & 2,270 & Ambient & \\
\hline & T-2 & Temperature & $1 / 14 / 04$ & 1,499 & 2,404 & Ambient & \\
\hline & SFM-1 & $\begin{array}{l}\text { Spinner Flow } \\
\text { Meter }\end{array}$ & $1 / 26-27 / 04$ & 1,553 & 2,940 & Pumping & $\begin{array}{c}\text { Pumped at } \\
275,475, \& \\
565 \mathrm{gpm}, 2 \\
\text { static logs }\end{array}$ \\
\hline & EC-1 & ChemTool & 2/10/04 & 1,825 & 2,900 & Interference & $\begin{array}{c}\text { ER-6-1\#2 } \\
\text { pumped }\end{array}$ \\
\hline & TFM-1 & $\begin{array}{l}\text { Thermal } \\
\text { Flow Meter }\end{array}$ & $2 / 10 / 04$ & 1,825 & 2,900 & Interference & $\begin{array}{l}\text { ER-6-1\#2 } \\
\text { pumped }\end{array}$ \\
\hline & EC-2 & ChemTool & $2 / 12-14 / 04$ & 1,550 & 2,942 & Interference & $\begin{array}{l}9 \text { logs during } \\
\text { fast-path } \\
\text { tracer test }\end{array}$ \\
\hline & EC-3 & ChemTool & 3/30/04 & 1,825 & 2,900 & Ambient & \\
\hline & TFM-2 & $\begin{array}{l}\text { Thermal } \\
\text { Flow Meter }\end{array}$ & $3 / 30 / 04$ & 1,825 & 2,900 & Ambient & \\
\hline \multirow{7}{*}{ ER-6-1\#2 } & $\mathrm{T}-1 \# 2$ & Temperature & $11 / 18 / 03$ & 1,500 & 3,080 & Ambient & \\
\hline & EC-1\#2 & ChemTool & $12 / 3 / 03$ & 1,547 & 3,046 & Ambient & \\
\hline & TFM-1\#2 & $\begin{array}{l}\text { Thermal } \\
\text { Flow Meter }\end{array}$ & $12 / 3 / 03$ & 2,000 & 3,031 & Ambient & \\
\hline & EC-2\#2 & ChemTool & $1 / 28 / 04$ & 1,554 & 3,043 & Interference & $\begin{array}{l}\text { ER-6-1 } \\
\text { pumped }\end{array}$ \\
\hline & TFM-2\#2 & $\begin{array}{l}\text { Thermal } \\
\text { Flow Meter }\end{array}$ & $1 / 28 / 04$ & 2,000 & 3,031 & Interference & $\begin{array}{l}\text { ER-6-1 } \\
\text { pumped }\end{array}$ \\
\hline & SFM-1\#2 & $\begin{array}{c}\text { Spinner Flow } \\
\text { Meter }\end{array}$ & $2 / 7-9 / 04$ & 1,850 & 3,025 & Pumping & $\begin{array}{c}\text { Pumped at } \\
275,475, \& \\
545 \mathrm{gpm}, 6 \\
\text { static logs }\end{array}$ \\
\hline & EC-3\#2 & ChemTool & $2 / 9 / 04$ & - & - & Pumping & \\
\hline
\end{tabular}

$\mathrm{ft}=$ Foot

gmp $=$ Gallon per minute

data reduction for all logs presented in this report. A complete discussion of the data reduction process used by DRI is documented in Oberlander and Russell (2004) and for the most part will not be reproduced here. The reader interested in the methods used to calibrate and/or normalize logging results presented herein is referred to Oberlander and Russell (2003) and (2004).

The analysis provided in this section of the report attempts to add to the interpretations provided by Oberlander and Russell (2004) while exploiting the strengths of the multiple types and conditions over which the logging was performed. Because the SPF, TFM, and temperature logs were run over a large variation in borehole conditions, the integrated analysis of the logs provides constraints to the interpretation of variability of hydraulic properties along the borehole open interval. Specifically, the SFM provides a good estimate of where 
formation flow originates in a long open-borehole section which, under the proper conditions, provides a means of allocating interval transmissivity within the borehole. The ambient TFM logs provide a means of understanding the natural interval head variations which generally exist in a long open borehole interval. Finally, the TFM logging campaign run when a nearby well is being pumped can provide evidence of connections between the boreholes. In a fractured system, inter-borehole transmissivity is controlled by connected fractures, or fracture systems which may not be the most transmissive zones at each individual borehole. The connected transmissivity may be quite different from the entire borehole interval transmissivity as determined from aquifer tests or from the SFM results.

The remainder of the section will be organized in the following subsections: a discussion of the methods used to estimate borehole interval transmissivity using flow logging data, an analysis of the temperature and SPF logs for boreholes ER-6-1 and ER-6-1\#2, an analysis of the TFM logs for boreholes ER-6-1 and ER-6-1\#2, and a section which provides a synthesis of the flow log analyses and its implications for the hydrogeologic conceptualization associated with the ER-6-1 well cluster.

\subsubsection{Transmissivity as Calculated from Fluid Logging Flow Rates}

The primary result of all of the fluid logging analyses is borehole flow rate. In each analysis, these borehole flow rates have been made attributable to intervals, or in the case of electrical conductivity logging, to discrete inflow points. Interval transmissivities $\left(T_{\mathrm{i}}\right)$ can be estimated from the individual interval flow rates $\left(q_{\mathrm{i}}\right)$ as determined through the various fluid logging events and the head difference driving the flow rate. In the case of internal borehole flow rates measured during static or ambient fluid logging events, the driving force is the head difference between a flowing interval head $\left(h_{\mathrm{i}}\right)$ relative to the average borehole head $\left(h_{\mathrm{b}}\right)$, termed $\left(D_{\mathrm{si}}\right)$. In the case of constant-rate fluid logging events, the driving force is the head difference between the flowing interval head $\left(h_{\mathrm{i}}\right)$ and the head in the borehole as a result of pumping $\left(h_{\mathrm{b}}\right)$, termed $\left(D_{\mathrm{Ri}}\right)$. The observed drawdown in the borehole as a result of a constant-rate withdrawal event is equal to the head in the borehole prior to pumping minus the head in the borehole measured during pumping and is termed $D_{\mathrm{RW}}$ and may or may not be equal to $D_{\mathrm{Ri}}$. That is to say that the drawdown measured in the borehole $\left(D_{\mathrm{RW}}\right)$ may not be equal to the drawdown felt by an individual flowing feature $\left(D_{\mathrm{Ri}}\right)$. To calculate transmissivities from flow rates derived from fluid logs, it is generally assumed that, for each analyzed interval, $D_{\mathrm{si}}$ is approximately equal to $D_{\mathrm{RW}}$ which means that heads in the individual flowing features are very nearly equal relative to the magnitude of $D_{\mathrm{Ri}}$. Under the assumption listed above, the interval transmissivities are calculated using elementary analytical solutions to the diffusion equation.

In the methodology and equations used to calculate transmissivity, each individual inflow zone is assumed to behave independently of the other, and responds to the borehole condition which is either imposed or natural. It is generally assumed that there is zero hydraulic connection between zones and that the zones are considered 
horizontal, and the interbeds are considered to have zero hydraulic diffusivity. Explicitly stated, the assumptions are that:

1. Flow is horizontal.

2. The medium is infinite, isotropic, and homogeneous.

3. The well is fully penetrating.

\section{Steady Flow Solution}

The steady-state solution to the diffusion equation is termed Dupuit's or Theim's formula, and, at a radius equal to the well radius $\left(r=r_{w}\right)$, is written:

$$
D_{W}=\frac{Q_{W}}{2 \pi T} \ln \left(\frac{R}{r_{W}}\right)
$$

where $D_{w}$ is the steady-state drawdown in the well, $Q_{w}$ is the steady-state flow rate, $T$ is the system transmissivity, and $R$ is the location of the outer constant head boundary condition where the head is always constant. Although $R$ is unknown, the solution of the equation is relatively insensitive to the evaluation of the natural $\log$.

Because this is a steady-state equation, it is independent of both time and medium storage parameter, and therefore such variables need not be estimated. This equation is considered applicable for static flow events where head changes and borehole flow rates are assumed to result from steady-state conditions.

\section{Transient Solution}

During some logging events the head in the borehole may be transient (changes as a function of time). The primary solution for transient drawdown in a well is the Theis solution. The Theis solution requires evaluation of the exponential integral function and is therefore not easily applied. Cooper and Jacob (1946) found that if the argument of the exponential integral met certain criteria, then a simplified logarithmic approximation could replace the exponential integral in the transient formula. The Cooper-Jacob approximation for a constant-rate withdrawal test would be written as

$$
D_{R W}(t)=\frac{q_{R i}}{2 \pi T_{i}} \ln \left(\frac{2.25 T_{i}}{S_{i} r_{W}^{2}}\right)
$$

where $D_{R W}(t)$ is the drawdown in the well at time $t, q_{R i}$ is the flow rate of layer $i$ in response to $D_{R W}, T_{i}$ is the transmissivity of layer $i$, and $S_{i}$ is the storage coefficient for layer $i$. The approximation is valid as long as the following condition holds:

$$
\frac{4 T_{i} t}{S_{i} r_{w}^{2}} \geq 100
$$


This condition is met in less than a minute for interval transmissivities reported by Oberlander and Russell (2004). Assuming that $D_{\mathrm{RW}}>>D_{\mathrm{si}}$ for all intervals analyzed, Equation 2-3 is appropriate for estimating transmissivity for SFM results from constant-rate pumping events.

By rearranging Equation 2-3 to solve for $T_{\mathrm{i}}$ outside of the logarithm, one can then iteratively solve for $T_{\mathrm{i}}$. This technique is used to estimate interval transmissivity. As stated, this implicitly assumes that the natural head variation between the intervals is small relative to $D_{\mathrm{RW}}$. A derivative of this method was used by Oberlander and Russell (2004) in their interpretation of the SFM logs for the ER-6-1 well cluster.

\section{Normalized Transmissivity Calculation}

An alternative method of estimating individual inflow (layer) transmissivity is available. This method assumes the analyst has an estimate of the borehole interval transmissivity for the interval being analyzed with the fluid logs. This method is generally referred to as the normalized transmissivity calculation method and is the method applied for use in interpreting SFM results.

Based upon knowledge of the total logged section transmissivity $(T)$, one can estimate the transmissivity $\left(T_{\mathrm{j}}\right)$ for each borehole interval. This method, as well as the one presented above, takes advantage of the fact that flow becomes horizontal at the well-bore radius $\left(r_{\mathrm{w}}\right)$ in an ideally layered aquifer even when the individual layers have relatively high contrasts in conductance (Javendel and Witherspoon, 1969). When this condition is met, the flow from an individual inflow point or layer is proportional to that layer's transmissivity by a proportionality constant (Molz et al., 1989). The relationship for a layer's transmissivity can be expressed

$$
q_{i}=\alpha T_{i}
$$

where $\alpha$ is the proportionality constant and $q_{i}$ is the flow rate from the layer $i$.

Molz et al. (1989) report that Equation 2-5 is applicable at dimensionless times (Equation 2-4) greater than 100. The proportionality constant $\alpha$ is equal to

$$
\alpha=Q_{W} / T
$$

With the total production rate known, and an estimate of $q_{i}$ for each layer from fluid logging, one can calculate a normalized transmissivity equal to

$$
\frac{T_{i}}{T}=\frac{q_{i}}{Q_{W}}
$$

where $Q_{w}$ is the total production rate for the logged interval and where $(1.0 \geq T / T$ $>0$ ). The vertical transmissivity distribution can be presented as a normalized distribution. In this case, no assumptions are made about $S, S_{\mathrm{i}}, t$, or $r_{w}$. If one has a good estimate of $T$, then the individual transmissivities $\left(T_{i}\right)$ can be calculated as dimensional quantities. If $T$ can be estimated from a steady-state response, again estimates of $S, S$, and $t$ are not required. Systematic or multiplicative errors will be canceled out using a normalized transmissivity interpretation method. 
Estimates of these types of errors have been reported to be as much as factors of 0.5 and 2 for spinner flowmeters (Rehfeldt et al., 1989).

\subsubsection{Spinner Flow Meter Results}

Spinner flow meter logs were run in boreholes ER-6-1 and ER-6-1\#2 in January and February of 2004, respectively. A description of the logging runs including the pumping rate and the logging line speed and direction can be found for each borehole in Oberlander and Russell (2004) and SNJV (2005a). This section provides a normalized transmissivity interpretation of the SFM results presented in Oberlander and Russell (2004) for both boreholes ER-6-1 and ER-6-1\#2. This section also presents the interpretation of temperature logs measured under pumping conditions in boreholes ER-6-1 and ER-6-1\#2 and ambient conditions in ER-6-1\#2.

The SFM determines flow velocity within the borehole based upon the relative movement of the SFM impeller. The SFM impeller is calibrated for certain borehole conditions, generally flow rate and diameter, which govern borehole fluid velocity. Oberlander and Russell (2003) and (2004) provide a complete and concise description of the process. This report will not provide details regarding SFM calibration. In addition to flow log calibration, the flow log impeller rotations must be converted to a borehole velocity and from velocity to a borehole flow rate. Oberlander and Russell (2004) refer to this data reduction step as the abstraction of the flow logging information. For a description of the flow meter calibration process and the log abstraction process, the interested reader is referred to Oberlander and Russell (2004).

\subsubsection{Borehole ER-6-1}

Borehole ER-6-1 was logged in January 2004 with the SFM over the interval from 1,553 to $2,940 \mathrm{ft}$ bgs. The borehole was logged at several pumping rates varying from 275 to $565 \mathrm{gpm}$. Oberlander and Russell (2004) post processed all of the logs measured at a common flow rate to develop a single composite log which abstracts the basic flow variations within the interval and smooths out some of the observed variations in borehole flow rates. The SFM logs measured at a common flow rate are averaged over a six-centimeter interval developing a composite log for the given flow rate. Figure 3 of Oberlander and Russell (2004) provides the composite SFM logs for borehole ER-6-1 flow rates of 275, 475, and $425 \mathrm{gpm}$. They observed that, while the logs had significant variability, the spatial correlation of the composite logs was very strong. In an effort to develop a representative, normalized borehole flow log for ER-6-1, Oberlander and Russell (2004) averaged the normalized composite logs for flow rates of 275, 475, and 425 gpm (denoted normalized Q on Figure 2-11 in this document). The normalized borehole flow log is linearized to smooth the variations (Oberlander and Russell, 2004). 


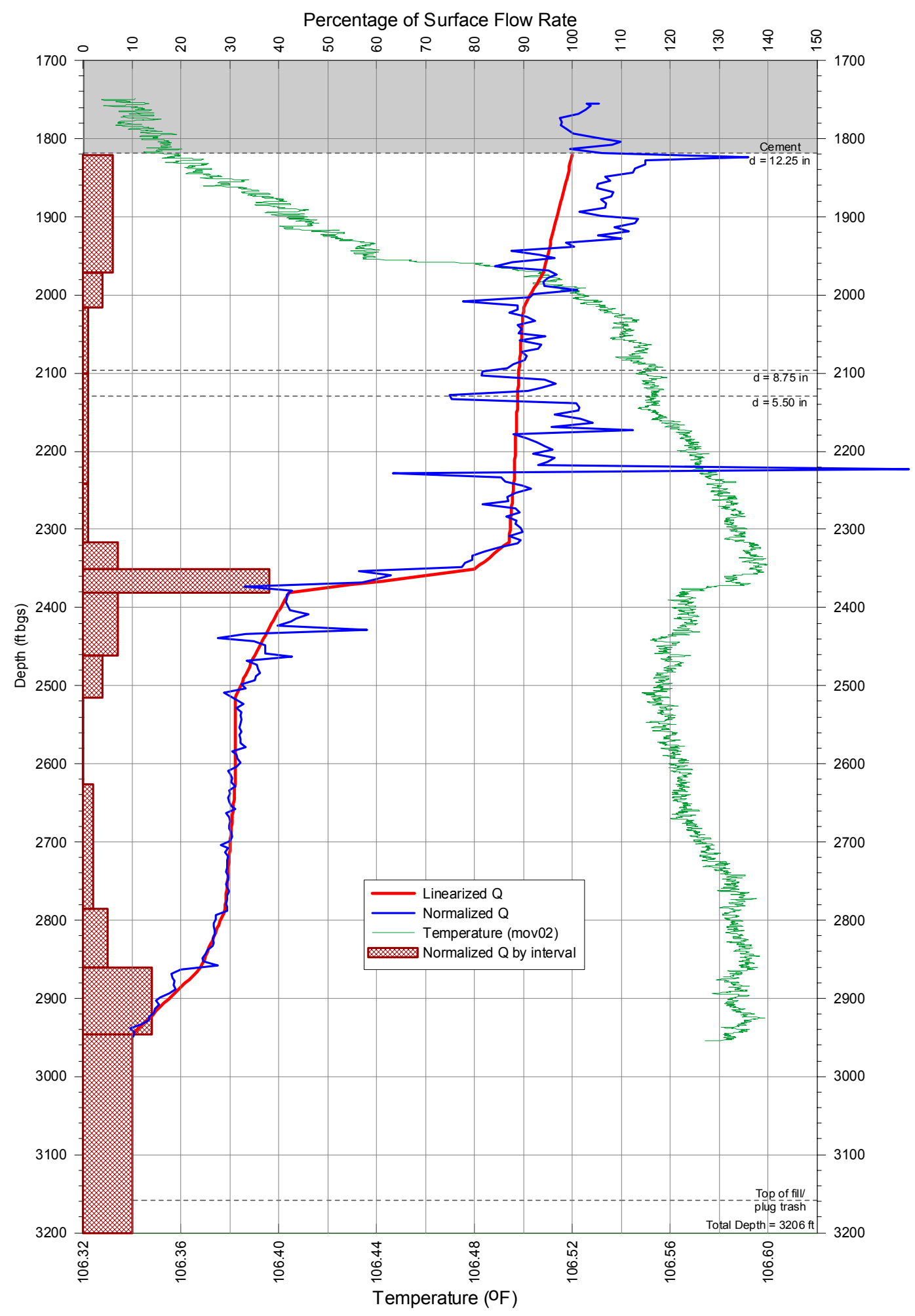

Figure 2-11

Normalized Spinner Flow Meter Log for ER-6-1 (SFM-1) 
Figure 2-11 plots the composite normalized flow log for ER-6-1 along with calculated interval flow rates (expressed as a percent of the total) and a representative temperature log from the SFM tool (log MOV 02). From Figure 2-11, one can see that 10 percent of the borehole flow is originating at a depth below 2,946 ft bgs. Table 2-4 presents the normalized flow percentages for the ER-6-1 SFM-1 logging campaign. From a review of Figure 2-11, one can see that the dominant flow feature in the logged interval occurs between 2,351 and $2,381 \mathrm{ft}$ bgs with the second most productive horizon between 2,861 and $2,946 \mathrm{ft}$ bgs. Twenty-four percent of the borehole flow originates below a depth of $2,861 \mathrm{ft}$ bgs, which implies that approximately one-quarter of the borehole transmissivity lies below this depth.

Table 2-4

ER-6-1 SFM-1 Normalized Flow and Transmissivity (SFM-1)

\begin{tabular}{|c|c|c|c|c|c|}
\hline $\begin{array}{l}\text { Interval Top } \\
\text { (ft bgs) }\end{array}$ & $\begin{array}{l}\text { Interval Bottom } \\
\text { (ft bgs) }\end{array}$ & $\begin{array}{c}\text { Normalized Flow } \\
\text { Rate }\end{array}$ & $\begin{array}{l}\text { Interval Thickness } \\
\text { (ft) }\end{array}$ & $\begin{array}{c}\text { Normalized } \\
\text { Transmissivity } \\
\left(\mathrm{ft}^{2} / \mathrm{d}\right)\end{array}$ & $\begin{array}{c}\text { Hydraulic } \\
\text { Conductivity } \\
\text { (ft/d) }\end{array}$ \\
\hline 1,821 & 1,971 & $6 \%$ & 150 & 20,059 & 134 \\
\hline 1,971 & 2,016 & $4 \%$ & 45 & 13,373 & 297 \\
\hline 2,016 & 2,101 & $1 \%$ & 85 & 3,343 & 39 \\
\hline 2,101 & 2,241 & $1 \%$ & 140 & 3,343 & 24 \\
\hline 2,241 & 2,316 & $1 \%$ & 75 & 3,343 & 45 \\
\hline 2,316 & 2,351 & $7 \%$ & 35 & 23,402 & 669 \\
\hline 2,351 & 2,381 & $38 \%$ & 30 & 127,040 & 4,235 \\
\hline 2,381 & 2,461 & $7 \%$ & 80 & 23,402 & 293 \\
\hline 2,461 & 2,516 & $4 \%$ & 55 & 13,373 & 243 \\
\hline 2,516 & 2,626 & $0 \%$ & 110 & 0 & 0 \\
\hline 2,626 & 2,786 & $2 \%$ & 160 & 6,686 & 42 \\
\hline 2,786 & 2,861 & $5 \%$ & 75 & 16,716 & 223 \\
\hline 2,861 & 2,946 & $14 \%$ & 85 & 46,804 & 551 \\
\hline 2,946 & $3,206^{a}$ & $10 \%$ & 260 & 33,432 & 129 \\
\hline \multicolumn{2}{|c|}{ SUM } & $100 \%$ & 1,385 & 334,316 & \\
\hline
\end{tabular}

a Bottom of lower carbonate aquifer is at $3,090 \mathrm{ft}$ bgs bgs $=$ Below ground surface $\mathrm{ft}=$ Foot $\mathrm{ft} / \mathrm{d}=$ Feet per day

$\mathrm{ft}^{2} / \mathrm{d}=$ Square feet per day

Figure 2-11 includes a temperature profile from SFM log MOV 02 measured during pumping at a rate of $275 \mathrm{gpm}$. One can see an inflow of cooler water from the bottom of the logged interval to a depth of approximately $2,380 \mathrm{ft}$ bgs where the high inflow zone occurs. At this depth an inflow of relatively warmer water enters the borehole and steadily cools off as it accumulates additional formation water and travels up the borehole. This interval correlates to an interval where the DRI ChemTool encountered an abrupt change in temperature, electrical conductivity, and $\mathrm{pH}$. At a depth of approximately $1,970 \mathrm{ft}$ bgs the temperature $\log$ encounters significantly cooler formation fluid. 
With the composite interval normalized flow rates and a logged interval total transmissivity, the individual interval transmissivities can be estimated. This assumes that the observed borehole drawdown is approximately constant along the entire borehole interval. The downhole pressure corrections made by Oberlander and Russell (2004) resulted in only an approximate 4 to 7 percent variation in estimated drawdown, well within the uncertainty of the calculation. In deeper boreholes, these corrections can become significant (Oberlander, personal comm.). Borehole ER-6-1 transmissivity was estimated from interference testing (see Section 2.2.4). For the total interval completed by wells ER-6-1 and ER-6-1\#2, a mean hydraulic conductivity of $241 \mathrm{ft} / \mathrm{d}$ was estimated. Over the 1,315 -ft interval, the transmissivity is 334,316 square feet per day $\left(\mathrm{ft}^{2} / \mathrm{d}\right)$. Using total interval transmissivity, the normalized interval flow rates, and Equation 2-7, interval transmissivities are estimated and summarized in Table 2-4. Based upon the interval length, average interval hydraulic conductivity was also calculated. The high flow interval from 2,351 to 2,381 ft bgs has an average hydraulic conductivity of over $4,000 \mathrm{ft} / \mathrm{d}$.

It should be noted that the cumulative interval transmissivity $\left(11,657 \mathrm{ft}^{2} / \mathrm{d}\right)$ calculated from the interval hydraulic conductivities from Oberlander and Russell (2004) is significantly smaller than the value determined through analysis of the interference test in this report. Nominal drawdowns reported for the three flow rates imposed during SFM logging varied from $6.9 \mathrm{ft}$ to $14.5 \mathrm{ft}$ for flow rates of 279 and $476 \mathrm{gpm}$, respectively. Using a steady-state drawdown solution (Equation 2-2; assuming a 5.5-inch [in.] well diameter and a constant-head outer radius at 1,000 meters $[\mathrm{m}]$ ) provides an interval transmissivity of approximately 10,000 to $12,000 \mathrm{ft}^{2} / \mathrm{d}$. However, the drawdowns applied in the calculations are not corrected for head losses, shown to be significant at both ER-6-1 and ER-6-1\#2. From analysis of step-drawdown testing at ER-6-1 prior to flow logging, (nonlinear) head losses at pumping rates of 274 and 425 gpm are about 2.9 and $6.8 \mathrm{ft}$, respectively, or 47 and 57 percent of measured drawdown (SNJV, 2005a). Further, the (bi)linear flow geometry implemented in this analysis implies higher transmissivity fracture zone features rather than radial flow through a lower transmissivity, homogenous porous medium. These concepts and the difference between well transmissivities derived in this analysis and in Oberlander and Russell (2004) are discussed further in the presentation of ER-6-1\#2 flow logging results. Regardless of the total well transmissivity uncertainty, the normalized flow calculation provides a good indicator of relative transmissivity within the borehole.

\subsubsection{Borehole ER-6-1\#2}

Borehole ER-6-1\#2 was logged in February 2004 with the SFM over the interval from 1,850 to $3,025 \mathrm{ft}$ bgs. Because a liner is located from 1,724 to $1,949 \mathrm{ft}$ bgs (Figure 1-5), no inflow data was obtained for the open borehole interval from the bottom of the casing at $1,775 \mathrm{ft}$ to the bottom of the liner at 1,949 $\mathrm{ft}$ bgs. The borehole was logged at several pumping rates varying from 275 to $545 \mathrm{gpm}$. As in the case for borehole ER-6-1, the ER-6-1\#2 composite SFM log for borehole flow rates of 275, 425, and 545 gpm (Figure 12 of Oberlander and Russell 2004) was examined. 
Prior to discussing the normalized composite SFM log, it provides additional insight to review an ambient temperature log measured in borehole ER-6-1\#2 on November 18, 2003 (Log Campaign T-1\#2, Table 2-3). Figure 2-12 plots the temperature $\log \mathrm{T}-1 \# 2$. An initial inspection of this log shows an apparent inflow of cooler water occurring between a depth of approximately 3,000 and $2,870 \mathrm{ft}$ bgs. The temperature log remains reasonably steady from a depth of $2,800 \mathrm{ft}$ bgs to $2,300 \mathrm{ft}$ bgs with a small decrease at $2,370 \mathrm{ft}$ bgs. Above $2,300 \mathrm{ft}$ bgs the temperature decreases strongly to the bottom of the uncemented liner at a depth of $1,949 \mathrm{ft}$ bgs.

Figure 2-13 plots the composite normalized flow log for ER-6-1\#2 along with calculated interval flow rates (expressed as a percent of the total) and a representative temperature log from the SFM tool (log MOV 23; $275 \mathrm{gpm})$. From Figure 2-13 one can see that borehole inflow starts approximately at a depth of $2,950 \mathrm{ft}$ bgs. Table $2-5$ presents the normalized flow percentages for the ER-6-1\#2 SFM-1\#2 logging campaign. Figure 2-13 indicates that the dominant flow feature in the logged interval occurs between 2,151 and 2,226 ft bgs (36 percent) with the second most productive horizon between 2,851 and 2,951 ft bgs ( 25 percent). Approximately 36 percent of the borehole flow is originating at a depth below 2,816 ft bgs in an interval comprising 12 percent of the open hole interval. In fact, 61 percent of the interval flow originates from 19 percent of the open interval length.

Figure 2-13 includes a temperature profile from SFM-1\#2, log MOV 23 measured during pumping at a rate of $275 \mathrm{gpm}$. Borehole fluid temperature decreases from the bottom of the interval upward until a depth of approximately $2,380 \mathrm{ft} b g \mathrm{~s}$ where an apparent inflow of warmer formation water occurs with a peak at approximately a depth of $2,315 \mathrm{ft}$ bgs. The temperature from this depth steadily cools off as it accumulates additional formation water and travels up the borehole with little inflection through the high flow interval between 2,151 and 2,226 ft bgs.

In summary, the temperature profiles under pumping conditions are almost identical for ER-6-1 and ER-6-1\#2. The lower extent of the higher temperature fluid correlates to the zone with the highest rate-of-inflow in ER-6-1. However, there is no correlation of temperature with the highest rate-of-inflow zone in ER-6-1\#2 (i.e., the temperature anomaly is $154 \mathrm{ft}$ below the highest inflow zone); rather, it correlates with a smaller inflow zone around $2,380 \mathrm{ft}$ bgs.

With the composite interval normalized flow rates and a logged interval total transmissivity, the individual interval transmissivities can be estimated. This assumes that the observed borehole drawdown is approximately constant along the entire borehole interval. Borehole ER-6-1\#2 transmissivity was estimated from drawdown at ER-6-1 upper and lower; the ER-6-1\#2 response was uninterpretable (Section 2.2.4). Recall that both wells penetrated the entire thickness of the LCA and that identical responses in ER-6-1 upper and lower indicate measurement of the same flow system induced by ER-6-1\#2 pumping. Using total interval transmissivity, the normalized interval flow rates, and Equation 2-7, interval transmissivities are estimated and summarized in Table 2-5. Based upon the interval length, average interval hydraulic conductivity was also calculated. The 


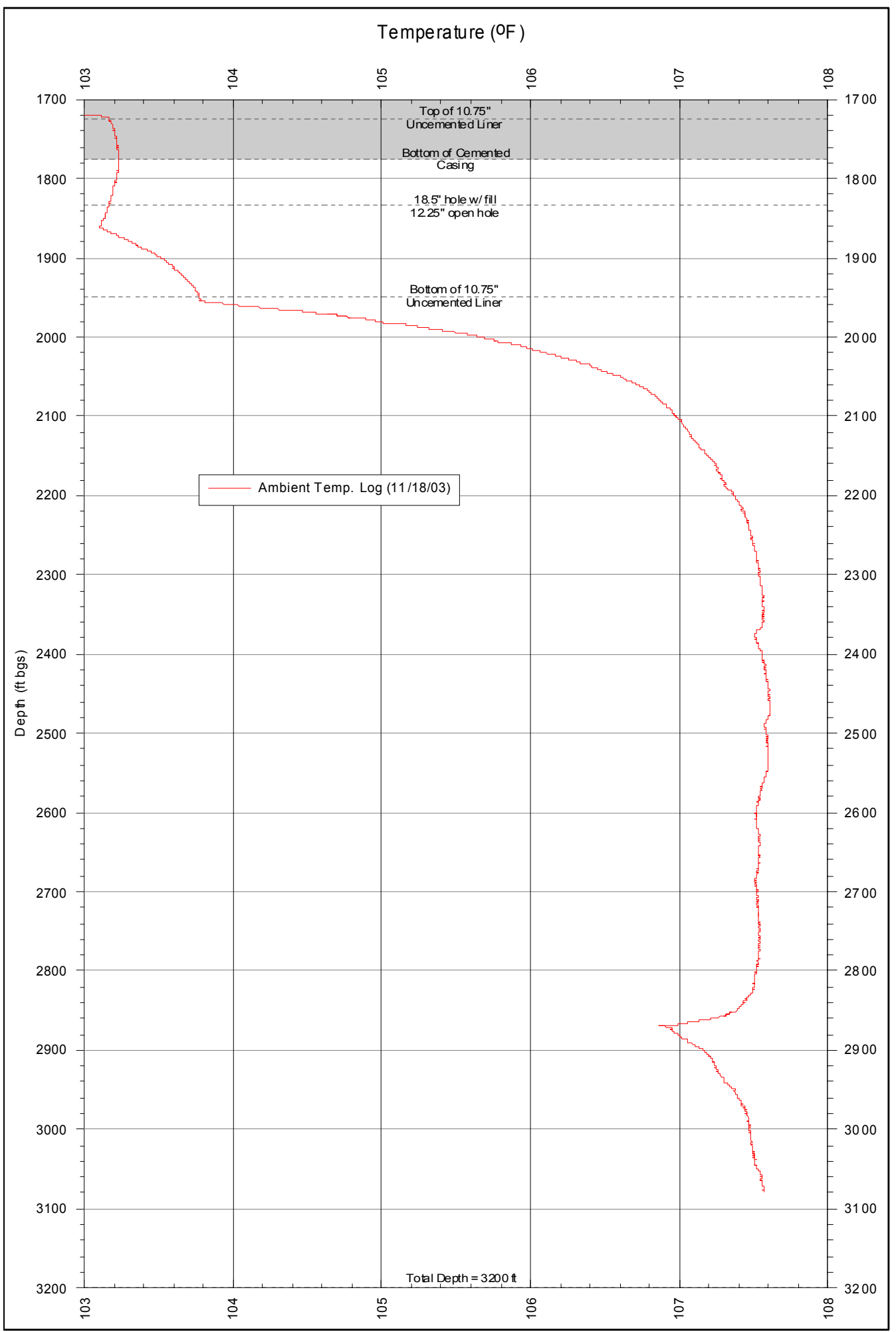

Figure 2-12

Ambient Temperature Log for ER-6-1\#2 (T-1\#2) 


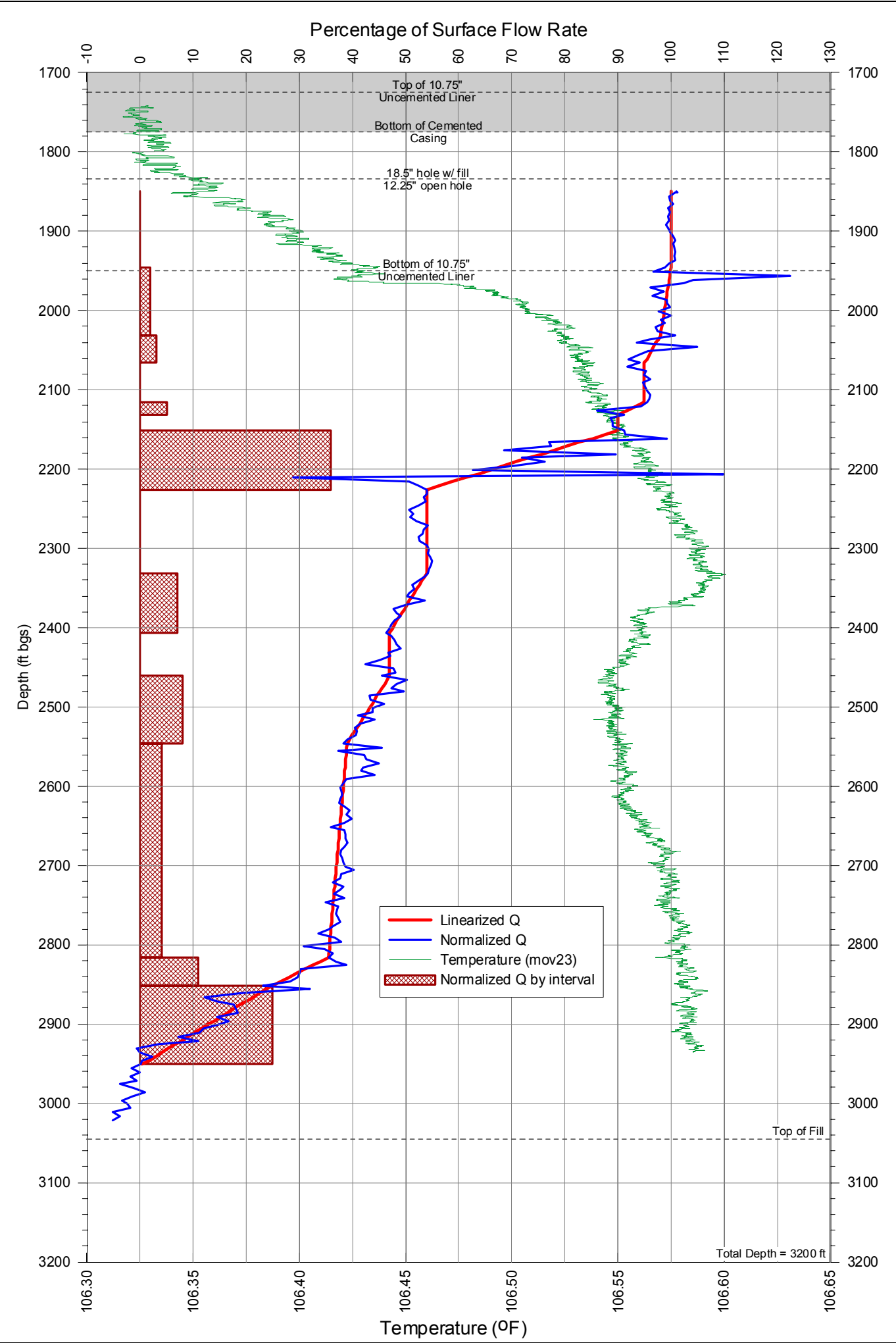

Figure 2-13

Normalized Spinner Flow Meter Log for ER-6-1\#2 (SFM-1\#2) 
Table 2-5

ER-6-1\#2 Normalized Flow and Transmissivity (SFM-1\#2)

\begin{tabular}{|c|c|c|c|c|c|}
\hline $\begin{array}{c}\text { Interval Top } \\
\text { (ft bgs) }\end{array}$ & $\begin{array}{l}\text { Interval } \\
\text { Bottom } \\
\text { (ft bgs) }\end{array}$ & $\begin{array}{c}\text { Normalized } \\
\text { Flow Rate }\end{array}$ & $\begin{array}{c}\text { Interval } \\
\text { Thickness } \\
\text { (ft) }\end{array}$ & $\begin{array}{c}\text { Normalized } \\
\text { Transmissivity } \\
\left(\mathrm{ft}^{2} / \mathrm{d}\right)\end{array}$ & $\begin{array}{c}\text { Hydraulic } \\
\text { Conductivity } \\
\text { (ft/d) }\end{array}$ \\
\hline 1,850 & 1,946 & $0 \%$ & 96 & 0 & 0 \\
\hline 1,946 & 2,031 & $2 \%$ & 85 & 6,686 & 79 \\
\hline 2,031 & 2,066 & $3 \%$ & 35 & 10,029 & 287 \\
\hline 2,066 & 2,116 & $0 \%$ & 50 & 0 & 0 \\
\hline 2,116 & 2,131 & $5 \%$ & 15 & 16,716 & 1,114 \\
\hline 2,131 & 2,151 & $0 \%$ & 20 & 0 & 0 \\
\hline 2,151 & 2,226 & $36 \%$ & 75 & 120,351 & 1,605 \\
\hline 2,226 & 2,331 & $0 \%$ & 105 & 0 & 0 \\
\hline 2,331 & 2,406 & $7 \%$ & 75 & 23,402 & 312 \\
\hline 2,406 & 2,461 & $0 \%$ & 55 & 0 & 0 \\
\hline 2,461 & 2,546 & $8 \%$ & 85 & 26,745 & 315 \\
\hline 2,546 & 2,816 & $4 \%$ & 270 & 11,701 & 43 \\
\hline 2,816 & 2,851 & $11 \%$ & 35 & 35,103 & 1,003 \\
\hline 2,851 & 2,951 & $25 \%$ & 100 & 83,579 & 836 \\
\hline \multicolumn{2}{|c|}{ Sum } & $100 \%$ & 1,101 & 334,316 & \\
\hline
\end{tabular}

bgs $=$ Below ground surface $\mathrm{ft}=$ Foot $\mathrm{ft} / \mathrm{d}=$ Feet per day

$\mathrm{ft}^{2} / \mathrm{d}=$ Square feet per day

high flow interval from 2,151 to $2,226 \mathrm{ft}$ bgs has an average hydraulic conductivity of $1,605 \mathrm{ft} / \mathrm{d}$.

As reported in Section 2.3.2.1, the interval transmissivities reported by Oberlander and Russell (2004) are significantly smaller than the values determined by interference-test analysis. Two factors contribute to this difference. First, the ER-6-1 and ER-6-1\#2 measured drawdowns applied in the Oberlander and Russell (2004) analysis do not appear to have been corrected for nonlinear head loss. From analysis of step-drawdown testing at ER-6-1\#2 prior to flow logging, head loss at pumping rates of 276 and 545 gpm are approximately 35 and 50 percent of measured drawdown, respectively (SNJV, 2005a), and are probably greater. For example, production of ER-6-1 at 570 gpm resulted in less than $2 \mathrm{ft}$ of drawdown at ER-6-1\#2, whereas production of ER-6-1\#2 at $545 \mathrm{gpm}$ resulted in about $9 \mathrm{ft}$ of drawdown. Without correction, application of the measured drawdown biases well transmissivity low. Second, the assumption of radial flow in both the Oberlander and Russell (2004) and Cooper-Jacob (Figure 2-10) analyses also bias well transmissivity low. (Bi)linear flow feature(s) imply that a fraction of the formation surrounding the well contributes to production; therefore, for a given drawdown, transmissivity of the (bi)linear features must be higher than that of a porous, radial flow system that would provide the same measured drawdown under the same production rate. The difference in well transmissivities derived in this analysis and that of Oberlander and Russell (2004) is the conceptual model 
and its translation in the analytical/numerical models. However, even with the uncertainty of the total interval transmissivity the normalized flow calculation provides a good indicator of relative transmissivity within the borehole.

\subsubsection{Thermal Flow Meter Results}

The TFM was used to characterize boreholes ER-6-1 and ER-6-1\#2 under ambient conditions in the logged borehole. Desert Research Institute provided the analyzed TFM logs to the UGTA SNJV staff. The TFM determines borehole flow rates by detecting the decay of heated pulses created by the tool. The tool is much more sensitive to low flow rates than the SFM and is therefore better suited to ambient borehole flow rates than a SFM tool. The error in the tool ranged at the ER-6-1 cluster from approximately +/-0.01 to +/-0.1 gpm with a peak error of $+/-0.36 \mathrm{gpm}$ for a measured flow rate of $1.9 \mathrm{gpm}$. The following section will present the TFM results for boreholes ER-6-1 and ER-6-1\#2.

\subsubsection{Borehole ER-6-1}

The TFM was run in borehole ER-6-1 on March 30, 2004, over the interval from 1,825 to 2,900 ft bgs (Campaign TFM-2). The TFM was also run in ER-6-1 when borehole ER-6-1\#2 was pumped. This log was run on February 2, 2004, over an interval from 1,825 to $2,900 \mathrm{ft}$ bgs (Campaign TFM-1).

Figure 2-14 plots the TFM measured borehole flow rates for logging campaigns TFM-1 (ER-6-1\#2 not pumping) and TFM-2 (ER-6-1\#2 pumping). Under ambient conditions, flow within borehole ER-6-1 is downward at rates up to $-0.55 \mathrm{gpm}$ at a depth of 2,140 ft bgs. Figure 2-14 also plots the borehole flow rates measured when well ER-6-1\#2 is being pumped at $475 \mathrm{gpm}$. Again, the same general trend in borehole flow rate exists with magnitudes increasing to a maximum down borehole flow rate of $-1.35 \mathrm{gpm}$ at a depth of 2,300 $\mathrm{ft}$ bgs.

Figure 2-15 plots the successive difference between interval flow rates measured by the TFM and presented in Figure 2-14. The plot characterizes borehole inflows and outflows during both ambient and pumping conditions. Under ambient conditions (TFM-2), formation water flows into the borehole at depths above $2,170 \mathrm{ft}$ bgs and water flows back out of the borehole below that depth with the strongest outflow between 2,350 and 2,540 ft bgs. From a review of this figure, the borehole can be divided into two zones based upon the average formation head in the zone relative to the composite borehole head. In Zone 1 (above a depth of $2,170 \mathrm{ft} \mathrm{bgs})$, the formation head $\left(\mathrm{h}_{1}\right)$ is greater than the borehole head $\left(\mathrm{h}_{\mathrm{b}}\right)$ and flow is directed into the borehole. In Zone 2 (below a depth of 2,170 ft bgs), the formation head $\left(h_{2}\right)$ is less than the borehole head $\left(h_{b}\right)$ and flow is directed out of the borehole. When the TFM is run in ER-6-1 when borehole ER-6-1\#2 is pumping (TFM-1), again we see downward flow (Figure 2-15). However, in this case flow enters the borehole over an interval that extends to a further depth than in the ambient case. In TFM-1 the Zone $1\left(h_{1}\right.$ greater than $\left.h_{b}\right)$ extends to a depth of approximately $2,350 \mathrm{ft}$ bgs. 


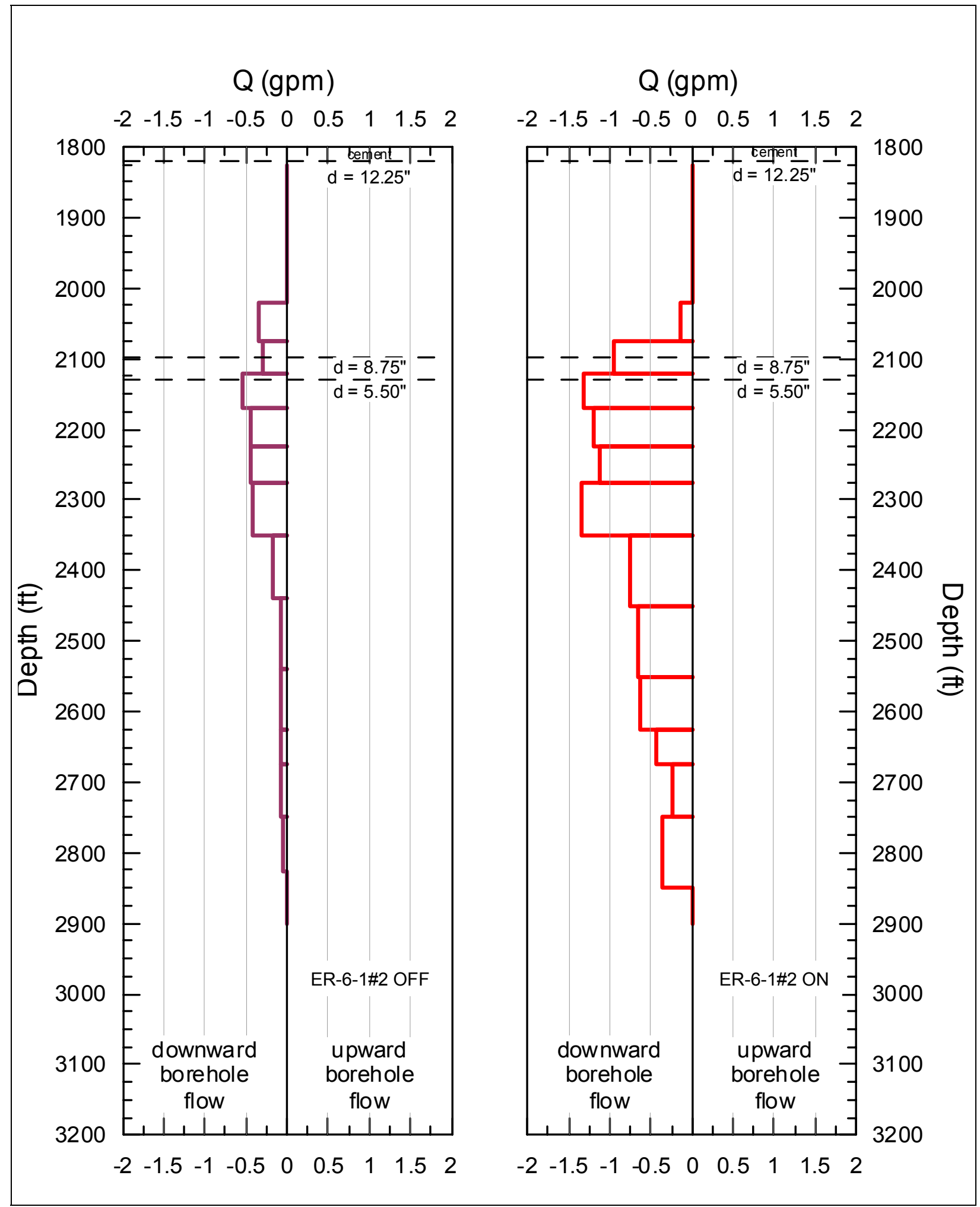

Figure 2-14

TFM Borehole Flow Rates for ER-6-1 (TFM-2 \& TFM-1) 


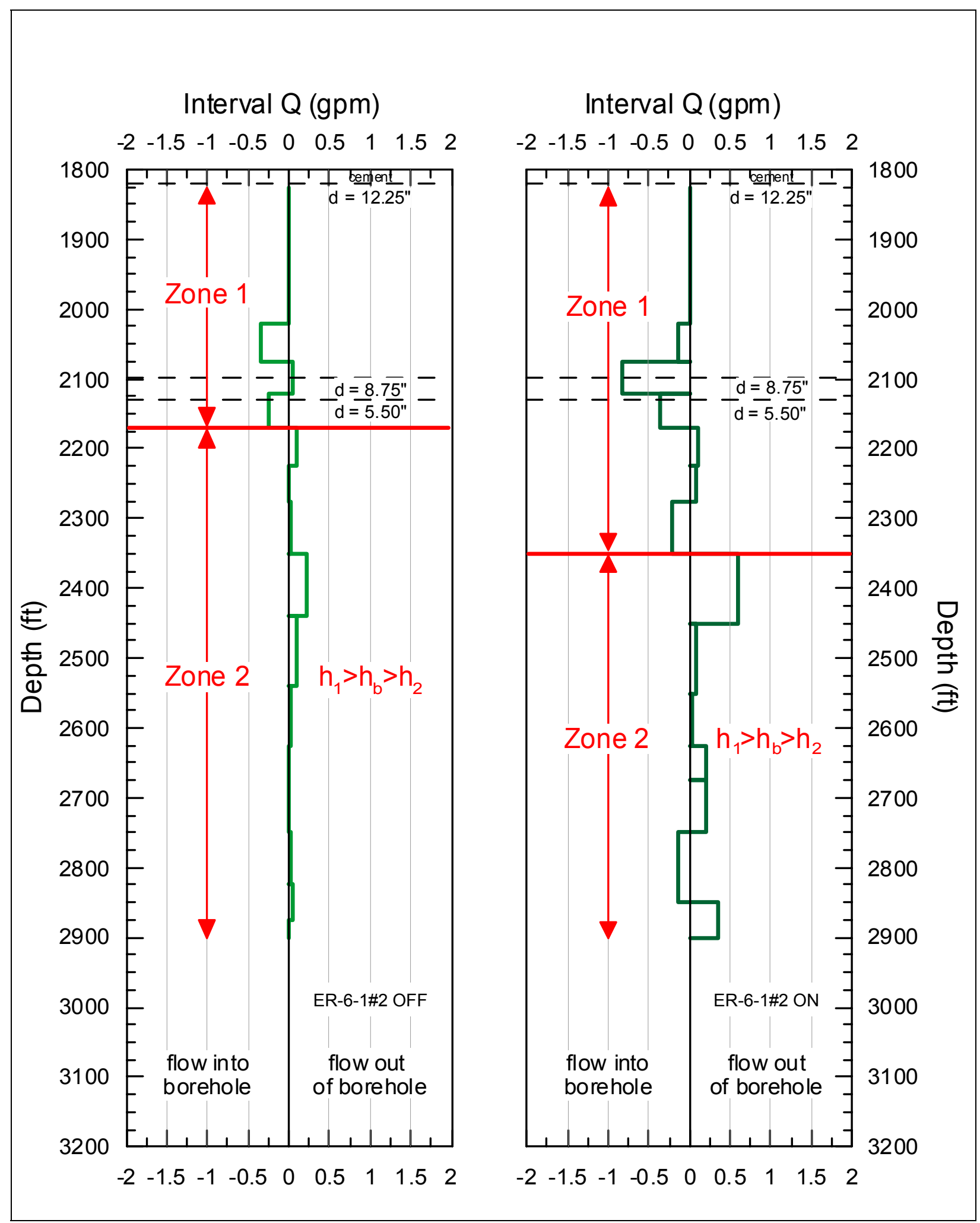

Figure 2-15

TFM Interval Flow Rates for ER-6-1 (TFM-2 \& TFM-1) 
From the SFM results for this borehole it appears that a major transmissive feature exists between 2,351 and 2,381 ft bgs. This coincides with the interval where most flow exits the borehole under both ambient and ER-6-1\#2 pumping conditions. From these logs we can also conclude that when ER-6-1\#2 is pumped, it lowers the head in borehole ER-6-1 zones sufficiently to create both a stronger downward flow cell in the borehole and to lower the zone of borehole inflow to a depth of 2,350 ft bgs. It appears that ER-6-1 is better connected to ER-6-1\#2 in the lower zone (Zone 2), located between 2,350 and the bottom of the borehole under conditions of pumping in ER-6-1\#2.

\subsubsection{Borehole ER-6-1\#2}

The TFM was run in borehole ER-6-1\#2 on December 3, 2003 over the interval from 2,000 to 3,031 ft bgs (Campaign TFM-1\#2). The TFM was also run in ER-6-1\#2 when borehole ER-6-1 was pumped. This log was run on January 28, 2004, over an interval from 2,000 to 3,031 ft bgs (Campaign TFM-2\#2).

Figure 2-16 plots the TFM measured borehole flow rates for logging campaigns TFM-1\#2 and TFM-2\#2. Under ambient conditions, flow within borehole ER-6-1\#2 is almost non-measurable (less than 0.09 gpm, +/-0.03 gpm). Flow appears to enter the borehole around a depth of $3,031 \mathrm{ft}$ bgs and exit above a depth of 2,900 ft bgs. Figure 2-16 also plots the borehole flow rates measured when well ER-6-1 is being pumped at 560 gpm. Under these borehole conditions, flow up the borehole increases significantly with strong borehole inflow occurring above a depth of 2,900 ft bgs and slowly exiting the borehole from an approximate depth of 2,725 up to a depth of $2,000 \mathrm{ft}$ bgs. The maximum upward flow rate measured is $1.94 \mathrm{gpm}$ centered at a depth of $2,755 \mathrm{ft}$ bgs.

Figure 2-17 plots the difference between borehole flow rates (i.e., interval flow rates) measured by the TFM and presented in Figure 2-16. This plot characterizes borehole inflows and outflows during both ambient and pumping conditions. Under ambient conditions (TFM-1\#2), formation water flows into the borehole at depths below 2,900 ft bgs and water flows back out of the borehole between a depth of 2,900 and 2,800 ft bgs. Again, interval flows are very low. Under ambient conditions, borehole interflow is negligible, which is indicative that formation heads are near equilibrium with the borehole head.

Conditions change significantly when ER-6-1 is pumped while logging ER-6-1\#2. Figure 2-17 also shows the interval flow rates for logging campaign TFM-2\#2. When ER-6-1 is pumping, flow into the borehole occurs in the interval from 2,725 to 3,040 ft bgs. Flow rates into the borehole exceed $1 \mathrm{gpm}$ in the interval from approximately 2,800 to $2,900 \mathrm{ft}$ bgs. This zone coincides with an ambient temperature kick of lower temperature water flowing up the borehole (see Figure 2-12). This zone also coincides with a relatively high transmissive zone (2,816 to 2,951 ft bgs) as determined from the SFM logs run in ER-6-1\#2 (see Table 2-5). 


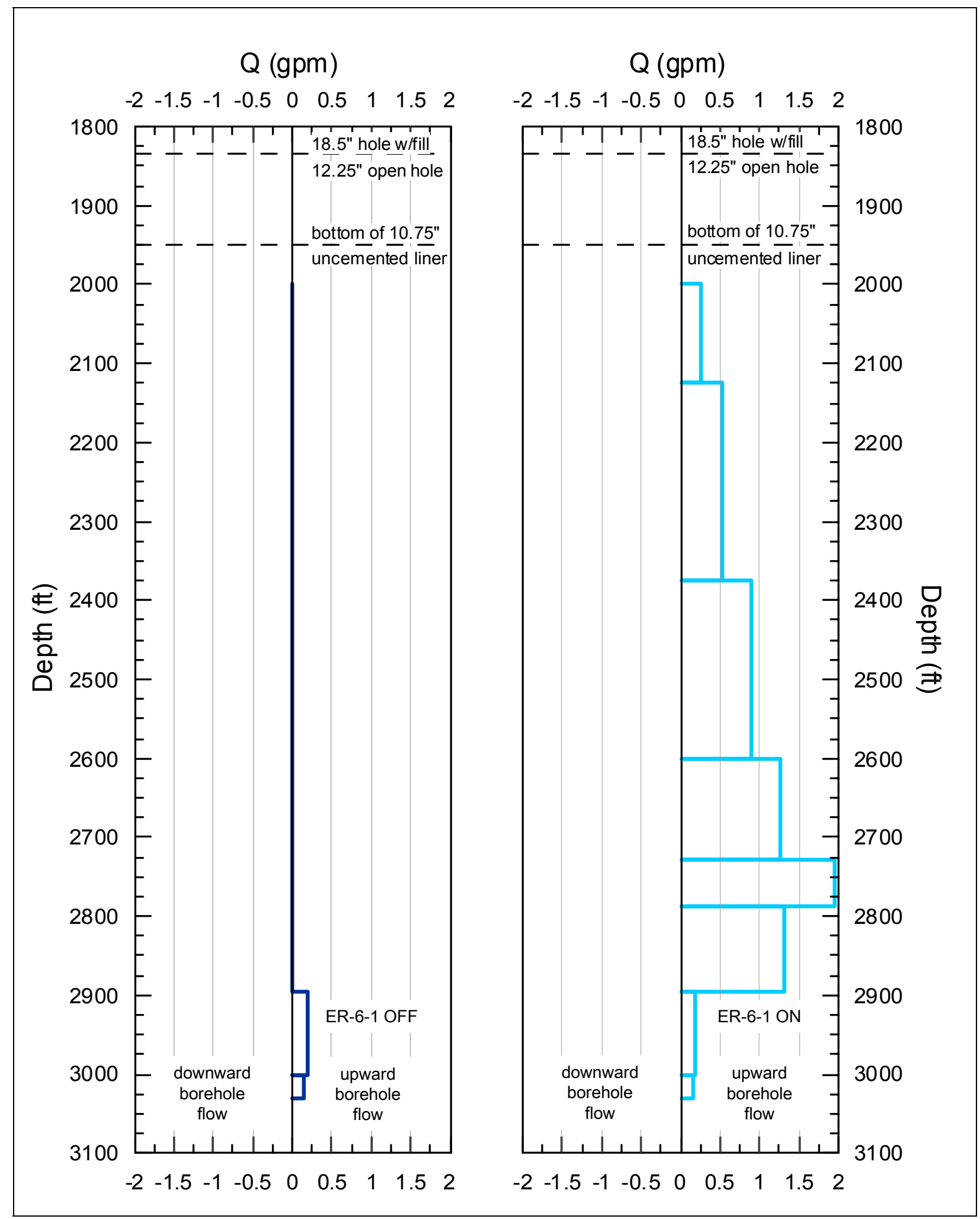

Figure 2-16

TFM Borehole Flow Rates for ER-6-1\#2 (TFM-1\#2 \& TFM-2\#2) 


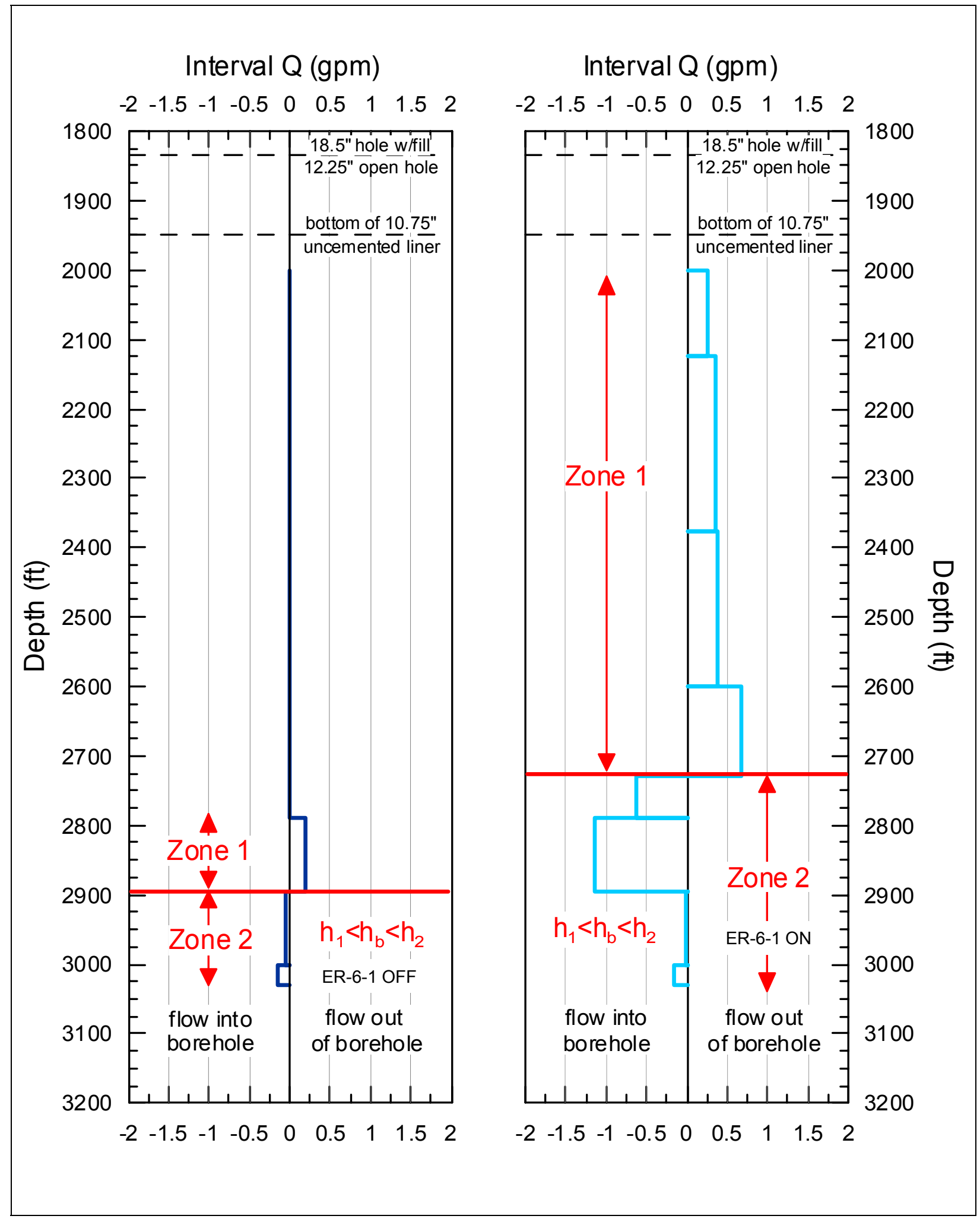

Figure 2-17

TFM Interval Flow Rates for ER-6-1\#2 (TFM-1\#2 \& TFM-2\#2) 
Above a depth of $2,725 \mathrm{ft}$ bgs, the borehole fluid exits the borehole over a zone extending up to a depth of 2,000 ft bgs. The largest borehole flow rate change centers around a depth of 2,725 ft bgs. From a review of Figure 2-17, the borehole can be divided into two zones based upon the average formation head in that zone relative to the composite borehole head. In Zone 1 (above a depth of 2,725 ft bgs), the formation head $\left(h_{1}\right)$ is less than the borehole head $\left(h_{b}\right)$ and flow is directed out of the borehole. In Zone 2 (below a depth of $2,725 \mathrm{ft} \mathrm{bgs}$ ), the formation head $\left(\mathrm{h}_{2}\right)$ is greater than $h_{b}$ and flow is directed into the borehole.

From the SFM results for this borehole we found that a major transmissive feature exists between 2,151 and 2,226 ft bgs ( 36 percent normalized transmissivity) and 2,816 and 2,951 $\mathrm{ft}$ bgs ( 36 percent normalized transmissivity). From these logs we can conclude that when ER-6-1 is pumped, it lowers the head in ER-6-1\#2 borehole zones sufficiently to create a stronger upward flow cell in the ER-6-1\#2 borehole. It appears that ER-6-1\#2 is better connected to ER-6-1 in the upper zone (Zone 1) located between depths 2,000 and 2,725 ft bgs under conditions of pumping in ER-6-1.

\subsubsection{Integration of Fluid Logging Results}

In this section, the fluid logging results will be compared and integrated to develop a consistent understanding of borehole conditions and the relationships between boreholes ER-6-1 and ER-6-1\#2. Comparison of SFM logs and normalized transmissivities in Figure 2-18 indicates similar transmissivity and temperature profiles for boreholes ER-6-1 and ER-6-1\#2. Conclusions from an analysis of the two SFM composite logs in Figure 2-18 yield the following observations:

- The borehole logs characterize boreholes that are dominated by discrete flow zones which are related to fractures and brecciated zones within the LCA and also the underlying Eureka Quartzite.

- In both boreholes there is significant transmissivity in the lower portion of the borehole with a dominant transmissive interval in the upper-borehole sections. In ER-6-1 the most transmissive interval resides between 2,351 and 2,381 ft bgs. In borehole ER-6-1\#2 the most transmissive interval resides between 2,151 and 2,226 ft bgs, which is an apparent 200-foot climb in section between boreholes.

- There is a distinct temperature increase during pumping conditions at a depth of 2,380 ft bgs in both boreholes (Laketown Dolomite) and a distinct temperature decrease at a depth of approximately $1,960 \mathrm{ft}$ bgs in both boreholes.

Figure 2-19 and Figure 2-20 plot the ambient borehole TFM interval flow rates when the opposing borehole is being pumped, the normalized interval transmissivities as determined from the SFM logging, and documented washouts, fracture zones, and breccia zones. From a review of these two figures, several observations can be made. 


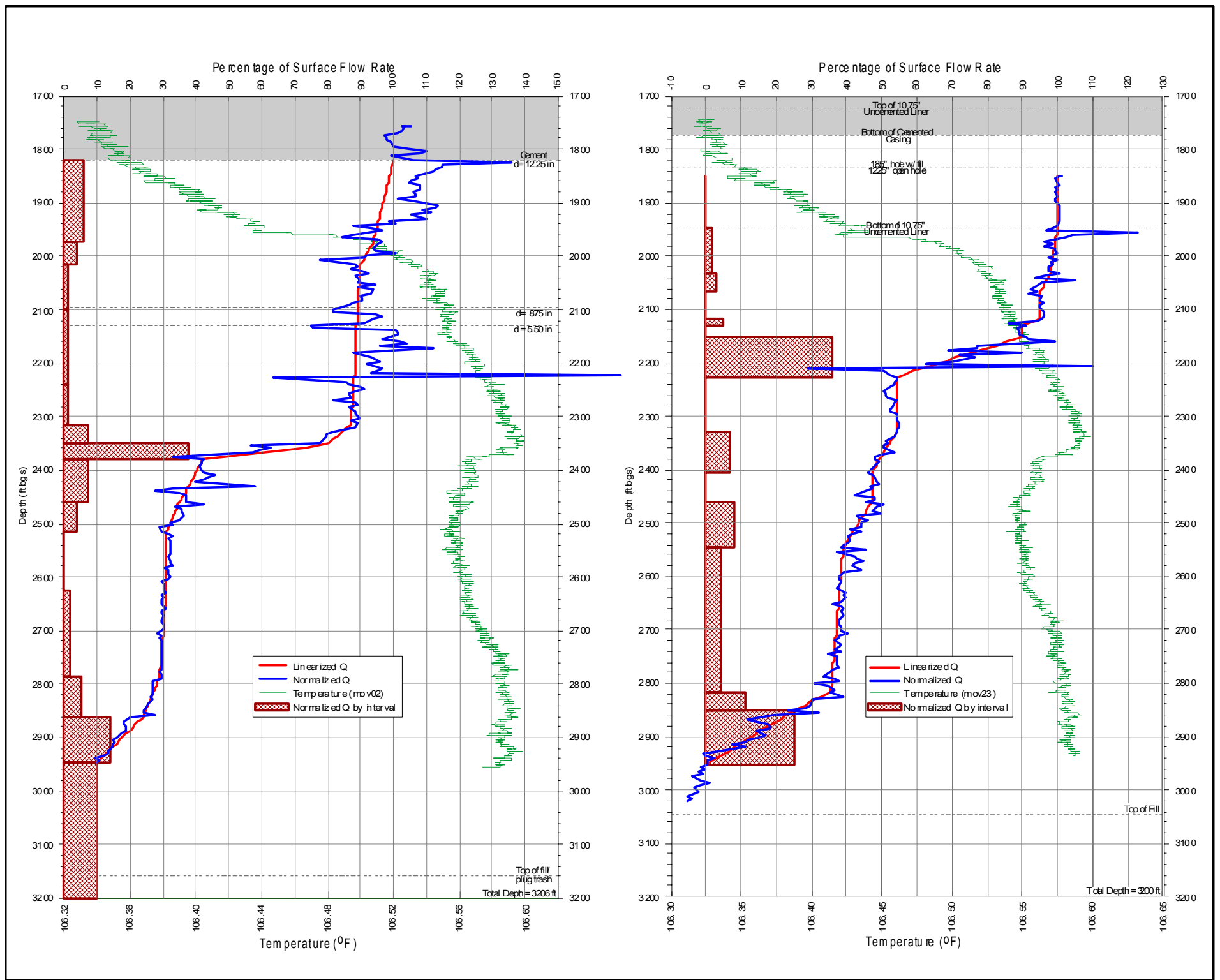

Figure 2-18

Composite SFM Logs for Boreholes ER-6-1 and ER-6-1\#2 


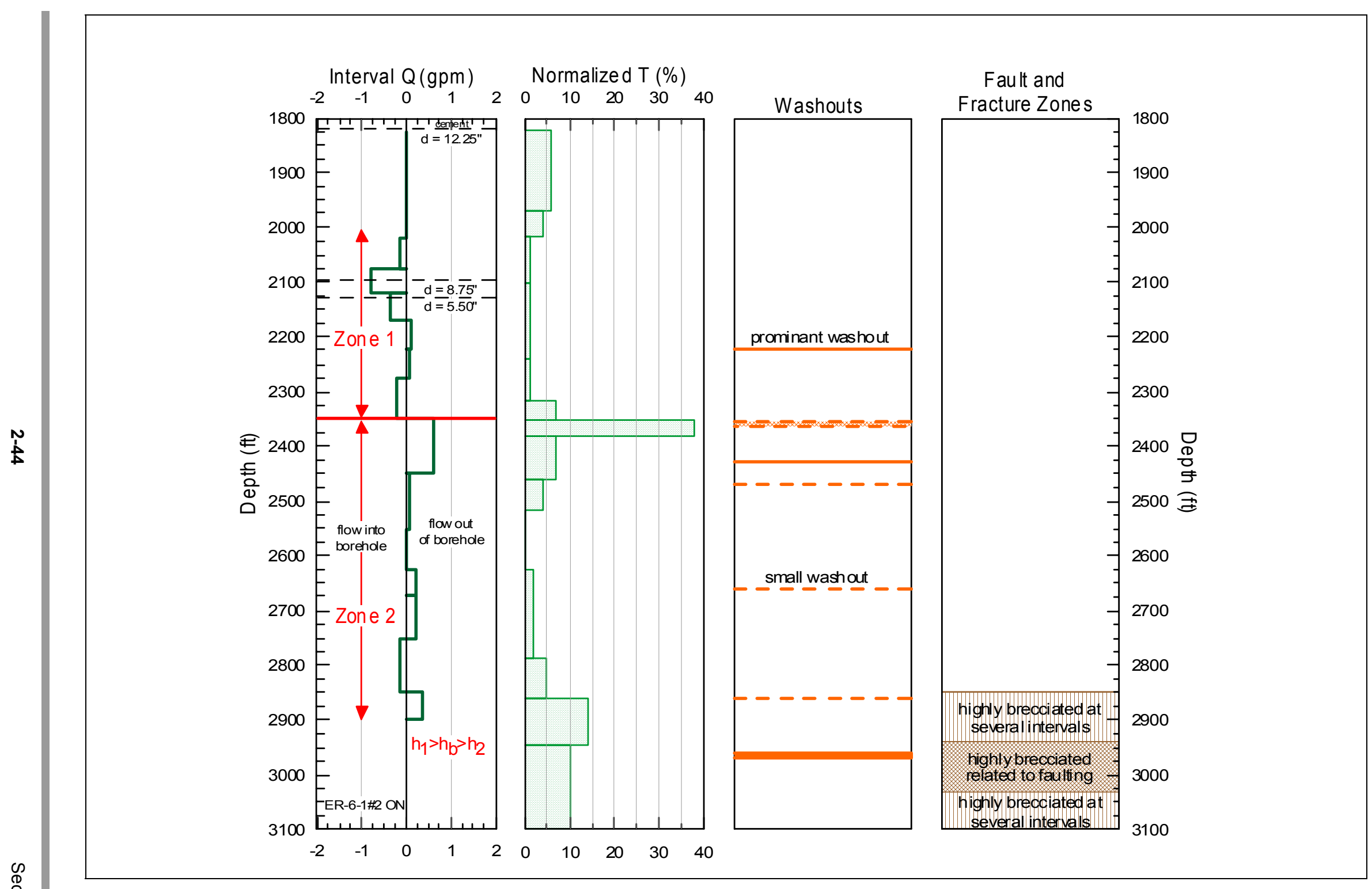

Figure 2-19

Composite Log for ER-6-1 


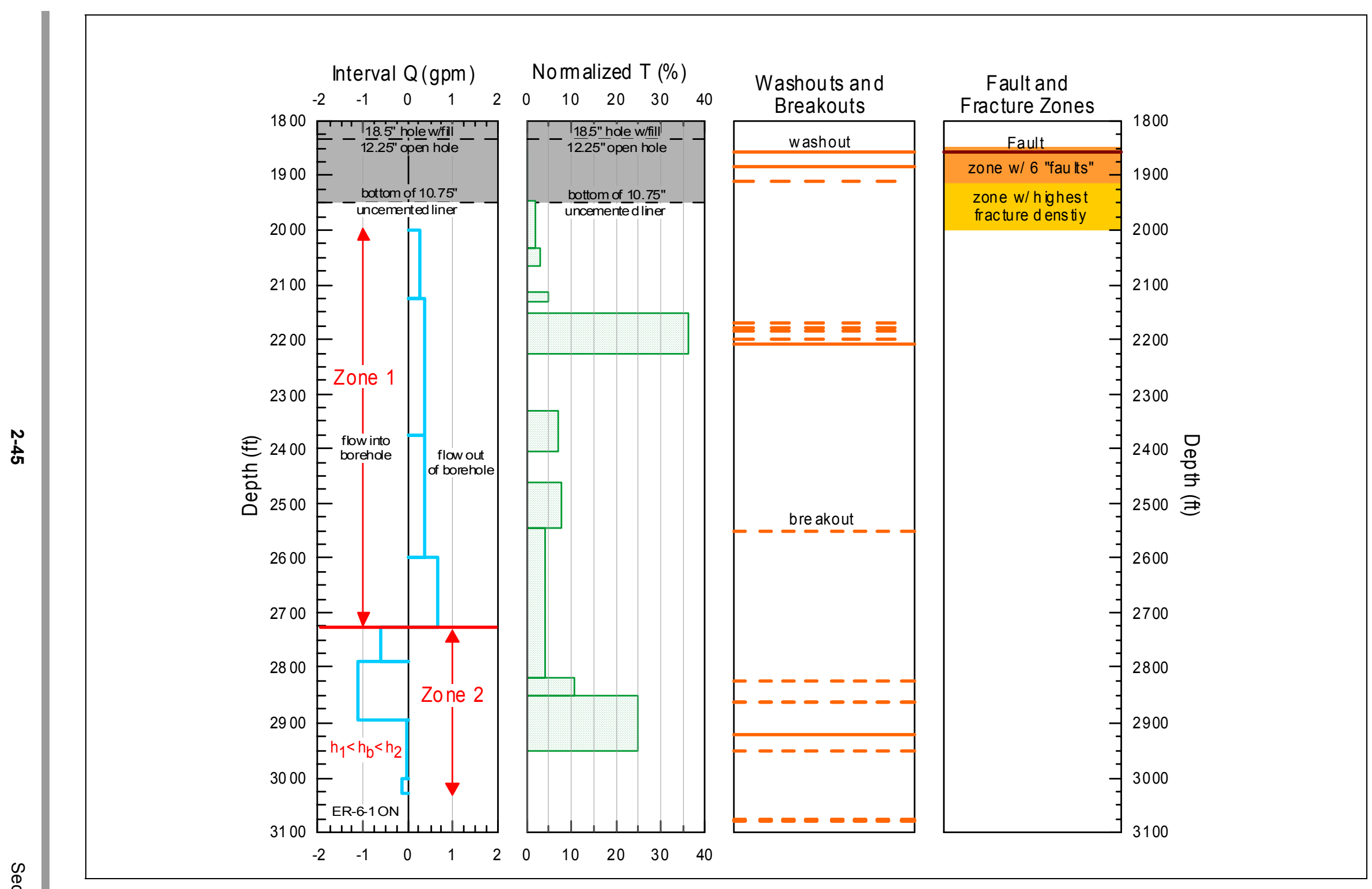

Figure 2-20

Composite Log for ER-6-1\#2 
- Heads are naturally variable within the LCA. The borehole has provided a pathway connecting the intervals inducing ambient flow within the boreholes. This flow would be expected to decrease over time as higher head, transmissive features recharge lower head transmissive intervals. The observed static head in each of the ER-6-1 cluster boreholes is an integrated environmental head which is a composite head of the completed intervals.

- The borehole geologic logs and fracture mapping and the ChemTool logs provide significant insight into the high flow (transmissivity) intervals. In both ER-6-1 and ER-6-1\#2 the highest transmissive features correlate well to observed washouts and brecciated zones.

- In fractured systems, borehole interval transmissivity cannot be correlated to connected transmissivity, even within a the scale of the ER-6-1 well cluster.

- In ER-6-1 under conditions of ER-6-1\#2 pumping, heads are highest in the interval from 2,025 to approximately $2,350 \mathrm{ft}$ bgs and lowest in the interval from 2,350 to 2,900 ft bgs. In ER-6-1\#2 under conditions of ER-6-1 pumping, heads are highest at the bottom of the borehole from 2,725 to $3,025 \mathrm{ft}$ bgs and lowest in the interval from 2,000 to $2,725 \mathrm{ft}$ bgs. Therefore, under interference pumping conditions, the relative higher and lower head zones are reversed. This suggests an angled transmissive connection between the two boreholes that is lower in ER-6-1 than in ER-6-1\#2.

Several conclusions and observations can be made that may be salient to the tracer test interpretation. These include:

- The transmissive features in boreholes ER-6-1 and ER-6-1\#2 are discrete intervals comprised of fractured and brecciated carbonates. One can infer that the connections between the two boreholes will also be discrete intervals.

- The TFM logs analyzed for conditions when the opposing well is pumped provide evidence for defining the borehole connections. Specifically, the TFM results indicate that the ER-6-1 interval from 2,350 ft bgs to the borehole total depth is preferentially connected to the ER-6-1\#2 interval from 2,000 to 2,725 ft bgs. That is, the connections identified suggest that approximately 40 percent of ER-6-1\#2 transmissivity below a depth of $2,700 \mathrm{ft}$ is poorly connected to the bulk of the transmissive features in borehole ER-6-1. 


\subsection{Summary of Hydraulic Test Interpretation and Results}

\subsection{Interpretive Model and Formation Hydraulic Properties}

The interpretive model is based upon diagnosis of the ER-6-1 cluster and distal observation well log-log diagnostic plots. The conceptualization and interpretation, presented in detail in Section 2.2.3 and Section 2.2.4, respectively, indicate a fracture- or high permeability strip-dominated flow regime. The directional variation in observation well responses indicates that CAU-scale, north-south trending faults impact flow through the LCA. Depending on the orientation of the observation well relative to the pumping well, the measured responses show that faults act as both (east-west) flow barriers, by juxtaposing permeable and non-permeable formations or otherwise breaking the feature connection, and (north-south) high-permeability conduits. The Yucca Flat LCA head gradient (Figure 2-1 and Figure 2-2) appears to confirm this.

Two hydraulic-testing data sets permitted the estimation of LCA hydraulic properties, the 90-day constant-rate pump test (MWAT-TT), and (cross-)borehole flow logging at ER-6-1 and ER-6-1\#2. For the former, observation-well responses to pumping at ER-6-1\#2 were individually analyzed to determine directional estimates of LCA hydraulic conductivity and storage. The resultant properties are inherently effective and represent the approximate 1,300 -ft completion interval through the LCA. Borehole interval flow rates measured under pumping conditions, in addition to supplementary borehole measurements (e.g., temperature profiles), were analyzed to determine borehole interval conductivities. These data permit the identification of discrete fault- or fracture-dominated flow features, coherent with the inferred interpretative flow model local to the well site.

Table 3-1 lists the composite set of LCA hydraulic properties derived from the ER-6-1 MWAT-TT and borehole flow logging analyses. At the Yucca Flat CAU-scale, MWAT-TT results show that regional faults hydraulically constrict, or in some cases isolate, the LCA into north-south trending blocks (in Section 1.3 it was noted that the well site is located on a minor structural block bounded by two north-south trending faults [Figure 1-9]). This is evidenced by the lack of a response at UE-1h, west of the ER-6-1 well site across the Yucca and Topgallant Fault systems (Figure 1-8), and from the unusual response at ER-3-1, northeast of the site across at least three major faults. The ER-3-1 response showed both a 10-day lag to pumping at ER-6-1\#2 and the response of a constant-head (or high-permeability) feature, both of which are probably fault-related. Just over six miles north of the well site (the second furthest observation well), ER-7-1 showed 
Table 3-1

Summary Table for Derived LCA Hydraulic Properties

\begin{tabular}{|c|c|c|c|c|c|}
\hline Observation Well & $\begin{array}{l}\text { Borehole Interval } \\
\text { Tested (ft bgs) }\end{array}$ & $\begin{array}{l}\text { Hydraulic Test } \\
\text { Method }\end{array}$ & Analysis Method & $\begin{array}{c}\text { Hydraulic } \\
\text { Conductivity } \\
(\mathrm{ft} / \mathrm{d})\end{array}$ & $\begin{array}{c}\text { Specific Storage } \\
(1 / \mathrm{ft})\end{array}$ \\
\hline ER-6-1 Upper & $1,775-3,090$ & \multirow{5}{*}{$\begin{array}{l}\text { Constant-rate } \\
\text { pumping test }\end{array}$} & \multirow{4}{*}{$\begin{array}{l}\text { nSIGHTS (see } \\
\text { Section 2.2.4) }\end{array}$} & 234 & $1.7 \times 10^{-9}$ \\
\hline ER-6-1 Lower & $1,775-3,090$ & & & 249 & $2.3 \times 10^{-9}$ \\
\hline ER-6-1\#1 & $1,835-2,085$ & & & 157 & $5.4 \times 10^{-7}$ \\
\hline ER-7-1 & $1,775-3,090$ & & & 4 & $7.9 \times 10^{-9}$ \\
\hline ER-6-1\#2 & $1,775-3,090$ & & $\begin{array}{c}\text { Cooper-Jacob } \\
(1946)\end{array}$ & 36 & $N A^{b}$ \\
\hline ER-6-1 & $1,821-1,971$ & \multirow{14}{*}{$\begin{array}{l}\text { Borehole flow } \\
\text { logging }\end{array}$} & \multirow{14}{*}{$\begin{array}{c}\text { Molz et al. (1989) } \\
\text { (see } \\
\text { Section 2.3.1) }\end{array}$} & 134 & \multirow{14}{*}{ NA } \\
\hline ER-6-1 & $1,971-2,016$ & & & 297 & \\
\hline ER-6-1 & $2,016-2,101$ & & & 39 & \\
\hline ER-6-1 & $2,101-2,241$ & & & 24 & \\
\hline ER-6-1 & $2,241-2,316$ & & & 45 & \\
\hline ER-6-1 & $2,316-2,351$ & & & 669 & \\
\hline ER-6-1 & $2,351-2,381$ & & & 4,235 & \\
\hline ER-6-1 & $2,381-2,461$ & & & 293 & \\
\hline ER-6-1 & $2,461-2,516$ & & & 243 & \\
\hline ER-6-1 & $2,516-2,626$ & & & 0 & \\
\hline ER-6-1 & $2,626-2,786$ & & & 42 & \\
\hline ER-6-1 & $2,786-2,861$ & & & 223 & \\
\hline ER-6-1 & $2,861-2,946$ & & & 551 & \\
\hline ER-6-1 & $2,946-3,206$ & & & 129 & \\
\hline ER-6-1\#2 & $1,850-1,946$ & \multirow{14}{*}{$\begin{array}{l}\text { Borehole flow } \\
\text { logging }\end{array}$} & \multirow{14}{*}{$\begin{array}{c}\text { Molz et al. (1989) } \\
\text { (see } \\
\text { Section 2.3.1) }\end{array}$} & 0 & \multirow{14}{*}{ NA } \\
\hline ER-6-1\#2 & $1,946-2,031$ & & & 79 & \\
\hline ER-6-1\#2 & $2,031-2,066$ & & & 287 & \\
\hline ER-6-1\#2 & $2,066-2,116$ & & & 0 & \\
\hline ER-6-1\#2 & $2,116-2,131$ & & & 1,114 & \\
\hline ER-6-1\#2 & $2,131-2,151$ & & & 0 & \\
\hline ER-6-1\#2 & $2,151-2,226$ & & & 1,605 & \\
\hline ER-6-1\#2 & $2,226-2,331$ & & & 0 & \\
\hline ER-6-1\#2 & $2,331-2,406$ & & & 312 & \\
\hline ER-6-1\#2 & $2,406-2,461$ & & & 0 & \\
\hline ER-6-1\#2 & $2,461-2,546$ & & & 315 & \\
\hline ER-6-1\#2 & $2,546-2,816$ & & & 43 & \\
\hline ER-6-1\#2 & $2,816-2,851$ & & & 1,003 & \\
\hline ER-6-1\#2 & $2,851-2,951$ & & & 836 & \\
\hline
\end{tabular}

aFlow dimension is constant for each constant-distance step

bSingle-well test analysis for well transmissivity (Figure 2-10) does not permit storage estimate

bgs $=$ Below ground surface

$\mathrm{ft}=$ Foot

$\mathrm{ft} / \mathrm{d}=$ Feet per day

$\mathrm{NA}=$ Not Applicable 
a nearly immediate response to pumping with a lag on the order of hours, and so too at the start of the recovery period. ER-7-1 is probably situated along the same fault system as the ER-6-1 cluster (Figure 1-8), strongly suggesting that the fault system acts as a high-permeability conduit through which a pressure response readily propagates.

As the UE-1h, ER-3-1, and ER-7-1 responses appear controlled by fault-related flow features, the cluster well responses measured at ER-6-1 upper, ER-6-1 lower, and ER-6-1\#1 appear more controlled by the local flow geometry within the fault block. In general, analysis of the response log-log diagnostics indicates a primary (linear) fracture-flow dominated system, which at later times is fed by the secondary block permeability (bilinear) once head in the main conduit(s) drops beneath some threshold. After about 10 days, the volume of influence is sufficiently large that the flow system becomes effectively radial.

Differences in estimated transmissivity at the ER-6-1 cluster and distal wells may arise because of scale effects found in fractured rock. Rovey and Cherkauer (1995) believed that they observed scale effects in testing of a carbonate rock in the Midwest, with increasing magnitude of hydraulic conductivity with increasing test scale. Beauheim (1988) noted scale effects in a fractured dolomite in southeastern New Mexico, but the effects of scale did not always results in increased hydraulic conductivity at increased test scale. The National Research Council (NRC) (1996) points out that the issue with fractured rock is how to use properties estimated at the test scale in a numerical model of often quite larger scale.

The ER-7-1 single-well and MWAT-TT analyses may evidence a scale effect. Of the two estimates of hydraulic conductivity obtained from analyzing ER-7-1 responses, which would be appropriate for the CAU model? In principle, the MWAT-TT analysis is more applicable because its scale is similar to that of the CAU. The NRC (1996) suggests that the conceptual model is key in dealing with the issue of scale by identifying the most important features in the hydrologic system. The single-well test at ER-7-1 yielded a higher hydraulic conductivity than the MWAT-TT, although the single-well test also detected a strong permeability change nearby that can be interpreted (in light of current understanding) as the effect of the north-south fault and fracture system found near the ER-6-1 cluster. In this case the conceptual model would suggest that properties associated with enhanced permeability and connectivity along the north-south fault structures is the appropriate scale. Finally, it would be inappropriate to assign the hydraulic conductivity from the MWAT-TT analysis to the ER-6-1 cluster without first incorporating the (bi)linear flow response conceptual model.

\subsection{Comparison to Previous Analyses for the LCA}

Historical hydraulic testing of the LCA in the NTS region has provided both conceptual models and hydraulic property estimates similar to those derived in this investigation. For example, Rojstaczer (1987) analyzed the effects of groundwater pumpage in Ash Meadows, where groundwater flow is known to be 
fault-influenced, and suggests a LCA conceptual flow model dominated by large-scale groundwater flow through fractures or conduits. Garber and Thordarson (1962) provided a similar conceptual flow model from pumping the LCA at Test Well C where they, in fact, were not able to pump at a rate sufficiently high to produce a drawdown response greatly distinct from barometric and earth-tide effects.

Table 3-2 lists the results of hydraulic test analysis for selected wells in the Yucca Flat and NTS area. Hydraulic conductivities reported are within the 0.1- to $100-\mathrm{ft} / \mathrm{d}$ order-of-magnitude range and correspond with those presented in this analysis over similar completion intervals. A direct comparison of hydraulic conductivity estimates is difficult because of both the spatially variable characteristics of fractures in general and the fault-controlled flow regime at Yucca Flat. For example, the single-well and MWAT-TT estimates of the LCA hydraulic conductivity at ER-7-1 are $397 \mathrm{ft} / \mathrm{d}$ and $4 \mathrm{ft} / \mathrm{d}$, respectively. Each test sampled a different portion of the LCA, the single-well test stressing a volume centered at the well, and the MWAT-TT (in relation to the ER-7-1 location) stressing the LCA along a north-south trending fault from ER-6-1\#2, and then the fault blocks normal to the fault (Figure 1-8). The variable nature of fault- and fracture-induced flow regimes, compounded with the variable formation volumes stressed via different hydraulic testing methods, provides a good measure of the uncertainty related to scale encountered in the LCA hydraulic conductivity.

Table 3-2

Summary Table for Selected Historical NTS and Yucca Flat LCA Hydraulic Testing Results

\begin{tabular}{|c|c|c|c|c|c|}
\hline $\begin{array}{l}\text { Pumping } \\
\text { Well }\end{array}$ & $\begin{array}{c}\text { Observation } \\
\text { Well }\end{array}$ & $\begin{array}{c}\text { Borehole } \\
\text { Interval Tested } \\
\text { (ft bgs) }\end{array}$ & $\begin{array}{c}\text { Hydraulic } \\
\text { Conductivity (ft/d) }\end{array}$ & $\begin{array}{c}\text { Specific Storage } \\
(1 / \mathrm{ft})\end{array}$ & Source \\
\hline ER-7-1 & NA & $2,182-2,370$ & 397 & NR & SNJV (2004a) \\
\hline ER-6-1 & NA & $1,819-2,130$ & $9.3-11.0$ & & Rehfeldt et al. (2004) \\
\hline ER-6-1\#2 & ER-6-1 & $1,939-3,200$ & $36.0\left(1.0 \times 10^{-3}\right)^{a}$ & $1.0 \times 10^{-7}\left(1.0 \times 10^{-4}\right)^{a}$ & SNJV (2004b) \\
\hline ER-6-1\#2 & ER-6-1\#1 & $1,939-3,200$ & $22.2\left(1.0 \times 10^{-3}\right)^{a}$ & $1.0 \times 10^{-7}\left(5.0 \times 10^{-4}\right)^{a}$ & SNJV (2004b) \\
\hline TW-10 & NA & $1,020-1,301$ & 9.5 & NR & \multirow{6}{*}{$\begin{array}{c}\text { Winograd and } \\
\text { Thordarson (1975) }\end{array}$} \\
\hline Army 1 & NA & $785-1,168$ & 13.6 & NR & \\
\hline TW-4 & NA & $737-1,490$ & 2.0 & NR & \\
\hline TW-2 & NA & $2,550-3,422$ & 0.2 & NR & \\
\hline TW-3 & NA & $1,103-1,853$ & 0.7 & NR & \\
\hline U $3 \mathrm{cn} 5$ & NA & $2,821-3,026$ & 1.6 & NR & \\
\hline
\end{tabular}

aDual-porosity analytical model applied; value out of and in parentheses correspond to fracture and matrix, respectively

bgs $=$ Below ground surface

$\mathrm{ft}=$ Foot

$\mathrm{ft} / \mathrm{d}=$ Feet per day

NA $=$ Not Applicable

$\mathrm{NR}=$ Not Reported 
For the Death Valley regional groundwater flow system (encompassing an area of about 43,500 $\mathrm{km}^{2}$ in southeastern California and southern Nevada), Belcher et al. (2001) provide a comprehensive summary of hydraulic test analyses for the LCA and Upper Carbonate Aquifer HSUs. Derived from 33 single-well and 5 multiple-well aquifer tests, horizontal hydraulic conductivities ranged from $3 \times 10^{-5}$ (reported as $\left.1 \times 10^{-5}\right)$ to $2,690 \mathrm{ft} / \mathrm{d}(820$ meters per day $[\mathrm{m} / \mathrm{d}])$. Of these tests, those performed in extensively faulted or karstic units were identified with a geometric mean conductivity of $10 \mathrm{ft} / \mathrm{d}(3 \mathrm{~m} / \mathrm{d})$, about one order of magnitude greater than the geometric mean $(0.3 \mathrm{ft} / \mathrm{d}[0.1 \mathrm{~m} / \mathrm{d}])$ of those tests performed in unfaulted to simply-faulted limestone and dolomite. Similar to the conceptual model presented in this analysis, Belcher et al. (2001) concluded that extensive faulting significantly increases hydraulic conductivity in the LCA.

Estimates of specific storage in the LCA are sparse. Storage estimates have been provided from outside of the NTS by the analysis of earth tides measured in continuously monitored wells. Galloway and Rostajczer (1989) estimated a specific storage from earth-tide analysis of $1.1 \times 10^{-11} \mathrm{ft}^{-1}\left(3.5 \times 10^{-11} \mathrm{~m}^{-1}\right)$ for well UE-25p1 (thought to lie in a fault zone) near Yucca Mountain. Kilroy (1992) analyzed LCA responses to earth tides throughout southern Nevada and estimated LCA specific storage. A total of 12 analyses were performed, with values ranging from $4.57 \times 10^{-8} \mathrm{ft}^{-1}\left(1.50 \times 10^{-7} \mathrm{~m}^{-1}\right)$ to $1.06 \times 10^{-7} \mathrm{ft}^{-1}\left(3.47 \times 10^{-7} \mathrm{~m}^{-1}\right)$. One site, Devils Hole, was located in a fracture zone and gave the lowest value. In a modeling analysis Bredehoeft (1997) used a LCA specific storage of $9 \times 10^{-10} \mathrm{ft}^{-1}$ $\left(3 \times 10^{-9} \mathrm{~m}^{-1}\right)$. Bredehoeft (1997) also analyzed the effects of fault properties on the earth-tide signal and found that fault permeabilities much larger than that assumed for the formation proper did not produce plausible responses. In general, the above reported values correspond well with and bound those storage estimates derived in this analysis. However, the magnitude of storativity is a function of the observation well's connectivity to the fracture zone and is, therefore, spatially variable. There is likely a strong cross-correlation in the LCA between the degree of fracturing, hydraulic conductivity, and storage. 


\subsection{References}

ASME, see American Society of Mechanical Engineers.

American Society of Mechanical Engineers. 1990. Quality Assurance Requirements of Computer Software for Nuclear Facility Applications, ASME NQA-2a-1990 addenda, Part 2.7. New York, NY.

Beauheim, R. 1988. "Scale Effects in Well Testing in Fractured Media," In Proceedings of the Fourth Canadian/American Conference on Hydrogeology Fluid Flow, Heat Transfer, and Mass Transport in Fractured Rocks, Banff, Alberta, Canada. 21-24 June.

Beauheim, R.L., and R.M. Roberts. 1998. Flow-Dimension Analysis of Hydraulic Tests to Characterize Water-Conducting Features, SAND98-1927C. Sandia National Laboratories, Albuquerque, NM, and Livermore, CA.

Belcher, W.R., P.E. Elliot, and A.L. Geldon. 2001. Hydraulic-Property Estimates for Use with a Transient Ground-Water Flow Model of the Death Valley Regional Ground-Water Flow System, Nevada and California, USGS WRIR-01-4210. Carson City, NV.

Bredehoeft, J.D. 1997. "Fault Permeability Near Yucca Mountain.” In Water Resources Research, 33(11), 2459-2463.

Bredehoeft, J.D., and S.S. Papadopulos. 1980. "A Method for Determining the Hydraulic Properties of Tight Formations." In Water Resources Research, 16(1), 233-238.

Byers, F.M., Jr., W.J. Carr, P.P. Orkild, W.D. Quinlivan, and K.A. Sargent. 1976. Volcanic Suites and Related Cauldrons of Timber Mountain-Oasis Valley Caldera Complex, Southern Nevada: USGS Professional Paper 919. Denver, CO: U.S. Geological Survey.

Butler, J.J., and W.Z. Liu. 1991. "Pumping Tests in Non-Uniform Aquifers - The Linear Strip Case.” In Journal of Hydrology, Vol. 128, 69-99. Amsterdam: Elsevier, BV.

Cooper, H.H., Jr. and C.E. Jacob. 1946. "A Generalized Graphical Method for Evaluating Formation Constants and Summarizing Well-Field History." In Transaction American Geophysical Union, Vol. 27:526-534. Washington, DC. 
Cooper, H.H., Jr., J.D. Bredehoeft, and S.S. Papadopulos. 1967. "Response of a Finite-Diameter Well to an Instantaneous Charge of Water." In Water Resources Research, 3(1), 263-269.

Desert Research Institute. 1993. ER-6-1 Hydrologic Testing and Geochemical Sampling Results - Data Report. Las Vegas, NV.

Drellack, S.L., Jr., L.B. Prothro, R.L. McCall, and P.H. Thompson. 1992. Preliminary Geology and Drill Hole Data Report for Groundwater Characterization Well ER-6-1, Nevada Test Site, Nye County, Nevada. Las Vegas, NV: Raytheon Services Nevada.

Ehlig-Economides C.A., P. Hegeman, and S. Vik. 1994. "Guidelines Simplify Well Test Interpretation.” In Oil and Gas Journal. 18 July.

Galloway, D., and S. Rojstacer. 1988. "Analysis of the Frequency Response of Water Levels in Wells to Earth Tides and Atmospheric Loading." In Proceedings Fourth Canadian/American Conference on Hydrogeology. Banff, Alberta, Canada.

Garber, M.S., and W. Thordarson. 1962. Ground Water Test Well C, Nevada Test Site, Nye County, Nevada, USGS Report TEI-818.

Gonzales, J.L., S.L. Drellack, and M.J. Townsend. 1998. Descriptive Narrative for the Hydrogeologic Model at the Yucca Flat Corrective Action Unit: An Interim Report. Las Vegas, NV: Bechtel Nevada.

Gonzales, J.L., and S.L. Drellack. 1999. Addendum to the Descriptive Narrative for the Hydrogeologic Model of the Yucca Flat Corrective Action Unit: Northern Extension. Las Vegas, NV: Bechtel Nevada

Grasso, D.N. 2004. Geologic Surface Effects of Underground Nuclear Testing, Yucca Flat, Nevada Test Site, Nevada. U.S. Geological Survey Open-File Report 00-0176.

Horne, R.N. 1995. Modern Well Test Analysis. Palo Alto, CA: Petroway, Inc.

IT Corporation. 1996. Wells ER-6-1 and ER-6-2 Core Fracture Analyses and Geophysical Log Comparisons, ITLV/10972-171. Las Vegas, NV.

IT Corporation. 1997. Completion Report for Wells ER-6-1 and ER-6-1 Satellite Hole \#1, Rev. 0, January. Las Vegas, NV.

IT Corporation. 2002. Yucca Flat Hydrogeologic Investigation Wells Drilling and Completion Criteria, Rev. 0, February. Las Vegas, NV.

IT Corporation. 2003. Yucca Flat ER-6-1 \#2 Well Data Report, Preliminary, Rev. 0, March. Las Vegas, NV. 
Javandel, I., and P.A. Witherspoon. 1969. "A Method of Analyzing Transient Fluid Flow in Multilayered Aquifers." In Water Resources Research, Vol. 5(4):856-869. Washington, DC: American Geophysical Union.

Jenkins, D.N., and Prentice, J.K. 1982. "Theory for Aquifer Test Analysis in Fractured Rocks Under Linear (Nonradial) Flow Conditions." In Groundwater, Vol. 20(1): 12-21.

Kilroy, K.C. 1992. Aquifer Storage Characteristics of Paleozoic Carbonate Rocks in Southeastern Nevada Estimated from Harmonic Analysis of Water-Level Fluctuations. University of Nevada at Reno, Ph. D. dissertation.

Laczniak, R.J., J.C. Cole, D.A. Sawyer, and D.A. Trudeau. 1996. Summary of Hydrogeologic Controls on Ground-Water Flow at the Nevada Test Site, Nye County, Nevada. U.S. Geological Survey Water-Resources Investigations Report 96-4109.

Lohman, S. W. 1972. Ground-Water Hydraulics, U.S. Geological Survey, professional paper 708 .

Molz, F.J., R.H. Morin, A.E. Hess, J.G. Melville, and O. Guven. 1989. "The Impeller Meter for Measuring Aquifer Permeability Variations: Evaluation and Comparison with Other Tests." In Water Resources Research, Vol. 25(7):1677-1683. Washington, DC: American Geophysical Union.

NRC, see National Research Council.

National Research Council. 1996. Rock Fractures and Fluid Flow:

Contemporary Understanding and Applications, National Academy Press, Washington, DC.

Oberlander, P.L., Desert Research Institute. 2005. Personal communication with V. Kelley (INTERA, Inc.) regarding flow logging data for Wells ER-6-1(\#2), 15 March. Las Vegas, NV.

Oberlander, P.L., and C. Russell. 2003. Final Report: Depth-Specific Hydraulic Testing of Yucca Flat Environmental Restoration Wells FY 2003.

Las Vegas, NV. Division of Hydrologic Sciences, Desert Research Institute, University and Community College System of Nevada.

Oberlander, P.L., and C. Russell. 2004. Letter Report: Horizontal Hydraulic Conductivity Profile with Depth at Wells ER-6-1 and ER-6-1\#2.

Las Vegas, NV. Division of Hydrologic Sciences, Desert Research Institute, University and Community College System of Nevada.

Pickens, J.F., G.E. Grisak, J.D. Avis, D.W Belanger, and M. Thury. 1987. "Analysis and Interpretation of Borehole Hydraulic Tests in Deep Boreholes: Principles, Model Development, and Applications." In Water Resource Research, Vol. 23(7), 1341-1375. Washington, DC: American Geophysical Union. 
Rehfeldt, K.R., P. Hufschmied, L.W. Gelhar, and M.E. Schaefer. 1989. The Borehole Flowmeter Technique for Measuring Hydraulic Conductivity Variability. Prepared for the Electrical Power Research Institute (EPRI), Palo Alto, California.

Rehfeldt, K., W. Drici, B. Lester, D. Sloop, J. Watrus, T. Beard, M. Sully, W. Fryer, and C. Benedict. 2004. Hydrologic Data for the Groundwater Flow and Contaminant Transport Model of Corrective Action Units 101 and 102: Central and Western Pahute Mesa, Nye County, Nevada, Rev. 0, Shaw/13052-204. Las Vegas, NV: Shaw Environmental, Inc.

Roberts, R.M., R.L. Beauheim, and P.S. Domski. 1999. Hydraulic Testing of Salado Formation Evaporites at the Waste Isolation Pilot Plant Site: Final Report. Sandia Report SAND98-2537 July. Albuquerque, NM.

Rojstaczer, S. 1987. "The Local Effects of Groundwater Pumpage within a Fault-Influenced Groundwater Basin, Ash Meadows, Nye County, Nevada, U.S.A.” In Journal of Hydrology, Vol. 91, 319-337. Amsterdam: Elsevier, BV.

Rovey, C.W., and D.S. Cherkauer. 1995. "Scale Dependency of Hydraulic Conductivity Measurements." In Groundwater, Vol. 33(5): 769-780.

Stoller-Navarro Joint Venture. 2003. Yucca Flat Well ER-6-1 \#2 Data Report for Development and Hydraulic Testing, Preliminary, Rev. 0, October. S-N/99205-XX. Las Vegas, NV.

Stoller-Navarro Joint Venture. 2004a. Underground Test Area Project, ER-6-1 Multi-Well Aquifer Test - Tracer Test Plan, Rev. 0, April. Las Vegas, NV.

Stoller-Navarro Joint Venture. 2004b. Analysis of Well ER-7-1 Testing, Yucca Flat FY 2003 Testing Program, Nevada Test Site, Nevada, S-N/99205--021 Rev. 0, July. Las Vegas, NV.

Stoller-Navarro Joint Venture. 2005a. Written communication prepared for NNSA/NSO, Subject: "ER-6-1 Well Cluster Multiple-Well Aquifer Test Tracer Test Data Report," January. Las Vegas, NV.

Stoller-Navarro Joint Venture. 2005b. Underground Test Area Fracture Analysis Report for Yucca Flat Wells ER-2-1, ER-6-1\#2, ER-7-1, and ER-12-2, Nevada Test Site, Nevada, Rev. 0, March. Las Vegas, NV.

Theis, C.V. 1935. "The Relation Between the Lowering of the Piezometric Surface and the Rate and Duration of Discharge of a Well Using Groundwater Storage.” In Trans Amer. Geophys. Union, 2 pp. 519-524.

Walker D.D., and R.M. Roberts. 2003. "Flow Dimension Corresponding to Hydrogeologic Conditions." In Water Resources Research, 39(12), pp. 1349-1356. 
Winograd, I.J. and W. Thordarson. 1975. Hydrogeologic and Hydrochemical Framework, South-Central Great Basin, Nevada-California, with Special Reference to the Nevada Test Site, U.S. Geological Survey Professional Paper 712-C, p. 126. 


\section{Distribution}

$\underline{\text { Copies }}$

Bill Wilborn

$1 \mathrm{HC} / \mathrm{CD}$

U.S. Department of Energy

National Nuclear Security Administration

Nevada Site Office

Environmental Restoration Division

P.O. Box $98518, \mathrm{M} / \mathrm{S} 505$

Las Vegas, NV 89193-8518

Charles Russell

Desert Research Institute

$1 \mathrm{HC} / \mathrm{CD}$

755 E. Flamingo Road

Las Vegas, NV 89132-0040

Sig Drellack

$1 \mathrm{HC} / \mathrm{CD}$

Bechtel Nevada

P.O. Box 98521 MS/NLV 82

Las Vegas, NV 89193

Paul Reimus

Los Alamos National Laboratory

P.O. Box 1663, M/S J534

Los Alamos, NM 87545

Robert P. Graves

U.S. Geological Survey

160 N. Stephanie St.

Henderson, NV 89074

Reed Maxwell

$1 \mathrm{HC} / \mathrm{CD}$

Lawrence Livermore National Laboratory

7000 East Avenue

Livermore, CA 94551

John McCord

$1 \mathrm{HC} / \mathrm{CD}$

Stoller-Navarro Joint Venture

7710 W. Cheyenne, Bldg. 3

Las Vegas, NV 89129

Greg Ruskauff

$1 \mathrm{HC} / \mathrm{CD}$

Stoller-Navarro Joint Venture

7710 W. Cheyenne, Bldg. 3

Las Vegas, NV 89129

Jeffrey Wurtz

$1 \mathrm{HC} / \mathrm{CD}$

Stoller-Navarro Joint Venture

7710 W. Cheyenne, Bldg. 3

$1 \mathrm{HC} / \mathrm{CD}$

Las Vegas, NV 89129 


\section{$\underline{\text { Copies }}$}

Eric Bhark

Stoller-Navarro Joint Venture

7710 W. Cheyenne, Bldg. 3

Las Vegas, NV 89129

Bill Fryer

Stoller-Navarro Joint Venture

7710 W. Cheyenne, Bldg. 3

Las Vegas, NV 89129

Central Files

Stoller-Navarro Joint Venture

7710 W. Cheyenne Avenue, Bldg. 3

Las Vegas, NV 89129
$1 \mathrm{HC} / \mathrm{CD}$

$1 \mathrm{HC} / \mathrm{CD}$

$1 \mathrm{HC} / \mathrm{CD}$ 